International Scientific-Technical and Production Journal

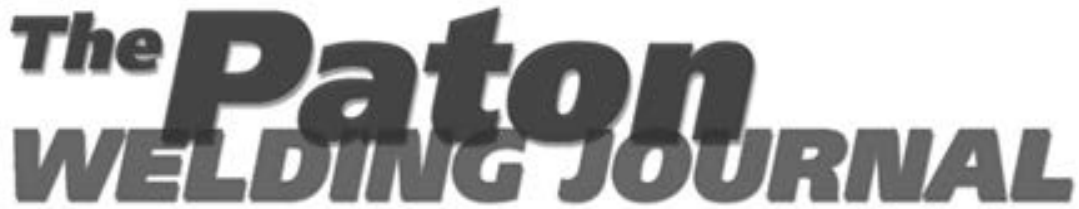

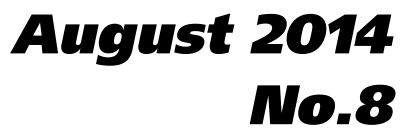

Published since 2000

English translation of the monthly «Avtomaticheskaya Svarka» (Automatic Welding) journal published in Russian since 1948

\section{Editor-in-Chief B.E.Paton EDITORIAL BOARD}

Yu.S. Borisov,

B.V. Khitrovskaya (exec. secretary)

V.F. Khorunov, V.V. Knysh, I.V. Krivtsun,

S.I. Kuchuk-Yatsenko (vice-chief editor)

Yu.N. Lankin, V.N. Lipodaev (vice-chief editor), L.M. Lobanov, A.A. Mazur,

O.K. Nazarenko, I.K. Pokhodnya,

V.D. Poznyakov, I.A. Ryabtsev, K.A. Yushchenko,

A.T. Zelnichenko (exec. director)

(Editorial Board Includes PWI Scientists)

\section{INTERNATIONAL EDITORIAL COUNCIL \\ N.P. Alyoshin}

N.E. Bauman MSTU, Moscow, Russia V.G. Fartushny

Welding Society of Ukraine, Kiev, Ukraine Guan Qiao

Beijing Aeronautical Institute, China V.I. Lysak

Volgograd State Technical University, Russia B.E. Paton

PWI, Kiev, Ukraine

Ya. Pilarczyk

Weiding Institute, Gliwice, Poland U. Reisgen

Welding and Joining Institute, Aachen, Germany O.I. Steklov

Welding Society, Moscow, Russia

G.A. Turichin

St.-Petersburg State Polytechn. Univ., Russia M. Zinigrad

College of Judea \& Samaria, Ariel, Israel A.S. Zubchenko

OKB «Gidropress», Podolsk, Russia

Founders E.O. Paton Electric Welding Institute

International Association «Welding» Publisher

International Association «Welding»

Translators min, O.S. Kurochko

I.N. Kutianova

Editor

N.A. Dmitrieva

Electron galley

D.I. Sereda, T.Yu. Snegiryova

Address

E.O. Paton Electric Welding Institute, International Association «Welding"

11, Bozhenko Str., 03680, Kyiv, Ukraine

Tel.: (38044) 2006016,2008277

Fax: (38044) 2008277,20081

www.patonpublishinghouse.com

State Registration Certificate

KV 4790 of 09.01 .2001

ISSN 0957-798X

Subscriptions

$\$ 348,12$ issues per year,

air postage and packaging included.

Back issues available.

All rights reserved.

This publication and each of the articles contained herein are protected by copyright.

Permission to reproduce material contained in this

journal must be obtained in writing from the Publisher.

\section{CONTENTS}

55th Anniversary of Welding Production Chair of

Admiral Makarov National Shipbuilding University

Kvasnitsky V.V., Kvasnitsky V.F., Markashova L.I. and

Matvienko M.V. Effect of stress-strain state on

structure and properties of joints in diffusion welding of

dissimilar metals

Kvasnitsky V.F., Kvasnitsky V.V., Cherenda N.N., Koval

N.N. and Levchenko I.L. Regularities of creation of modified interlayers in using of highly-concentrated

energy flows

Kolesar I.A. and Ermolaev G.V. Stress-strain state at force and temperature loading of assembles from dissimilar steels with soft interlayer

Ermolaev G.V., Martynenko V.A. and Marunich I.V.

Effect of weld convexity sizes on stress state of butt

joint during tension

Lebedev V.A., Dragan S.V., Goloborodko Zh.G.,

Simutenkov I.V. and Yaros Yu.A. Technological

characteristics of automatic submerged arc surfacing

with high-frequency oscillations of electrode end

Dubovoj A.N., Karpechenko A.A. and Bobrov M.N.

Increase of service properties of electric-arc and

plasma coatings by use of electric-pulse effect on

double-phase high-temperature flow

Vereshchago E.N. and Kostyuchenko V.I. Instability of

mode in circuit with capacity and electric arc supplied

by direct current source

\section{INDUSTRIAL}

Paton B.E., Savitsky M.M., Savitsky A.M. and Mazur

A.A. Effectiveness of natural gas transportation by sea

at application of high pressure welded cylinders

Peremitko V.V. Wear-resistant arc surfacing over the

layer of alloying charge

\section{NEWS}

International Conference «Welding Consumables» 


\section{5th Anniversary of Welding Production Chair of Admiral Makarov National Shipbuilding University}

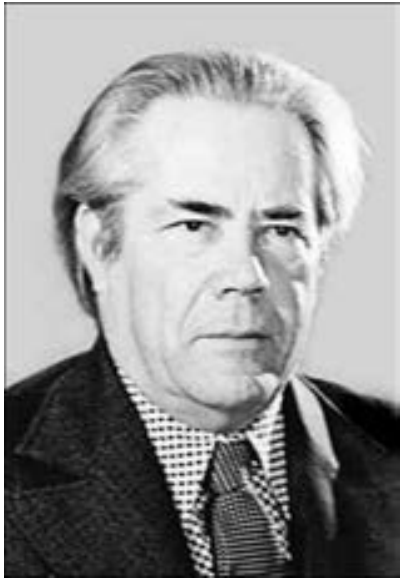

A.I. Safonov

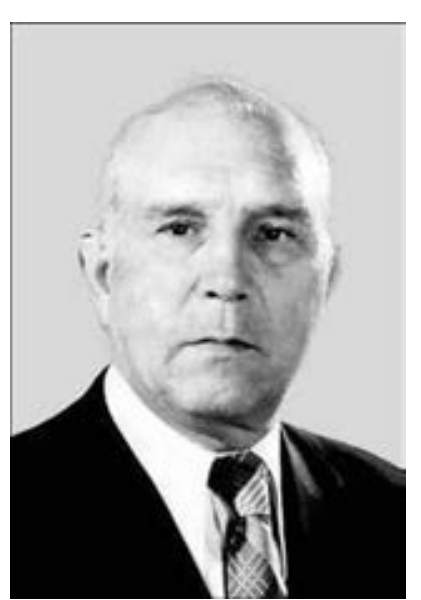

I.I. Dzhevaga
Welding Production Chair was organized in 1959. The first Chair Head was A.I. Safonov, Ass. Prof.; beginning from 1975 the Chair Head was I.I. Dzhevaga, Ass. Prof., and since 1980 the Chair has been headed by Prof. V.F. Kvasnitsky.

Chair development can be divided into several stages:

- organization and optimization of educational process (1959-1964);

- scientific formation of research team staff (1965-1974);

- comprehensive development, realization of chair staff potential and its recognition by scientific community (1975-1990);

- improvement of activity under the conditions of Ukraine's independence, broad international cooperation and European integration in the educational system, training young scientists (starting from 1991 and up to now).

The Chair's first years were particularly difficult: absence of lecturer's staff, laboratories, training-support personnel, equipment and in-

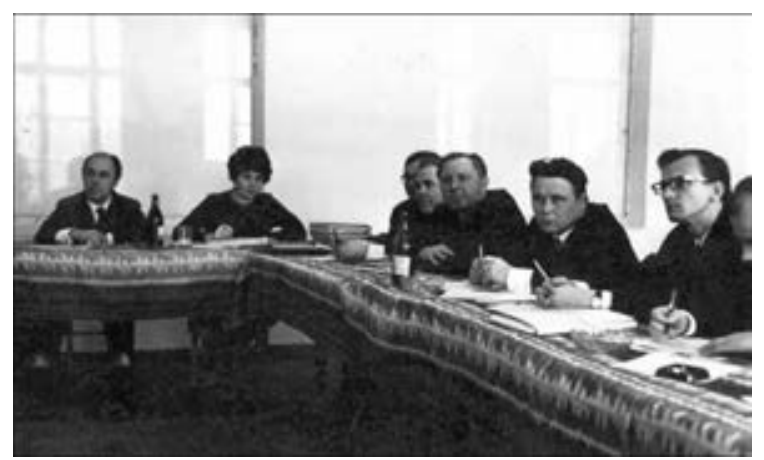

Meeting of State Examination Commission (1983). First on the left - Prof. B.A. Movchan struments. All that created great difficulties in organizing the training process and scientific work. Owing to the activity of A.I. Safonov, I.I. Dzhevaga and M.L. Fukelman, Ass. Profs, close cooperation with production was organized from the very start of the Chair establishment, which allowed, together with local enterprises, to successfully develop and introduce new technologies. This was also promoted by objective conditions in the south of Ukraine, in particular, in Nikolaev. In October, 1953, Yuzhny Turbine Plant (YuTP) was put into operation, in 1961 «Mashproekt» for development of gas turbine engines was set up, «Okean», 61 Communard and Chernomorsky shipbuilding plants were increasing their capacities. Shipbuilding applied traditional structural materials and introduction of highly efficient welding processes was urgent. In gas turbine construction, new structural materials were applied, giving rise to a multitude of urgent and complex problems, which where solved with participation of the Chair' lecturers. Each student, starting from the third year, had his scientific theme, which he pursued together with his professor and plant engineers. Furtheron thee themes became the topics of thesis of Candidates of Science of the Chair graduates. Student scientific work was at the base of their training that is now declared in the Bologna system.

By the end of 1974 the Chair formed the scientific team, which ensured a high level of both educational process and research. By this time V.F. Kvasnitsky (1967), G.V. Ermolaev, A.I. Dremlyuga, Yu.M. Lebedev (1970) and A.I. Sa- 
fonov (1973) defended their theses of Candidate of Science. The Chair maintained contacts with higher educational establishments and scientific organizations of former USSR: N.E. Bauman MSTU, PWI, Institute of Problems of Materials Sciences (IPMS), etc. Close contact with Institute of Welding of Slovenia (Ljubljana) was established. Ass. Prof. I.I. Dzhevaga, Great Patriotic War veteran, was preparing his thesis of Doctor of Science. He helped all the young lecturers to prepare their theses of Candidate of Science, and continued working at Chernomorsky Shipbuilding Plant.

In 1974/1975 academic year four groups (100 pers) of students of day department, two groups (50 pers) of evening department in Nikolaev and two groups (50 pers) of evening department in Kherson were studying in the welding speciality. The Chair had one of the largest scopes of contract work at the Institute every year. During this period about 100 post-graduates and candidates were preparing their theses.

Starting from 1975 up to 1980 the Chair was headed by I.I. Dzhevaga - the country's leading specialist on welding, surfacing, brazing of copper and its alloys to steels, whose health prevented him from completing his Doctor's thesis.

During the next years the Chair efforts enabled expanding and consolidating its facilities and by 1985 increasing the engineering and laboratory areas from 350 up to $1000 \mathrm{~m}^{2}$. This was promoted by the fact that all the scientific activity of the Chair was conducted on the most important topics of government programs.

Several scientific directions of the Chair research were formed from the moment of its organization and started from students' work. Quality control direction started developing from introduction of ultrasonic testing of welds of ship hull structures. Furtheron this direction was expanded through development of procedures and instrumentation for testing of diffusion-welded and brazed joints, in particular those of dissimilar materials. Here we should note the great contribution of V.P. Savchenko, Ass. Prof., who organized the Laboratory of Ultrasonic Testing that predetermined appearance of new specialization in student training - nondestructive method of welded joint quality control.

The scientific direction of the accuracy of manufacture of welded hull structures, in which G.V. Ermolaev worked and defended the Candidate's thesis, was oriented to shipbuilding.

Direction of welding and related processes in gas turbine construction began in 1960 from the work on diffusion welding of high-temperature alloys with the assistance of Prof. N.F. Kazakov, the author and passionate advocate of vacuum

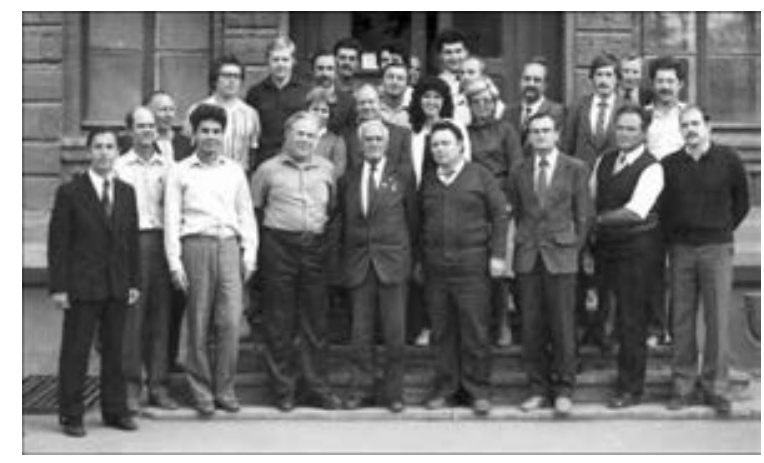

30 years of the Chair team (1984). From left to right: Yu.I. Rusanov, Yu.M. Lebedev, B.V. Bugaenko, A.I. Safonov, Rector of N.E. Bauman MSTU, Prof. G.A. Nikolaev (behind - A.I. Dremlyuga), V.F. Kvasnitsky, G.V. Ermolaev, V.P. Savchenko, V.I. Lukin

diffusion welding process, later on Lenin prize winner, who supervised preparation and defense of more than one hundred candidate's and doctor's theses with broad industrial introduction.

Ship gas turbine construction was progressing vigorously. Several grades of new high-temperature metallic and nonmetallic materials were introduced at the plants every year. Joining these materials both in similar and in dissimilar combinations has always been problematic, and required development of new technologies of welding and related processes. The issues of controlling the quality of welding and brazing, as well as inherent stresses at joining dissimilar materials and particularly in case of component operation under thermal cycling conditions, remained unsolved. Successful solution of the above problems united the efforts of specialists of all the directions. Gradually, this work reached the all-union, and then the international level, and went beyond the limits of shipbuilding.

In 1979 the Scientific-Technical Council of SPA «Energia» headed by Prof. M.V. Melnikov, Deputy Director of the organization, Lenin Prize winner, Hero of Socialist Labour, having listened to the report of V.F. Kvasnitsky, Ass. Prof., on the Chair activities, takes a decision to fund the Chair work on research and manufacture of unique superhigh-vacuum process equipment, as well as manufacture of industrial MHD devices. Intensive work began on development of unique superhigh-vacuum system for welding, brazing, electron beam and ion-plasma spraying, later on included into the State Register of research facilities which are the national assets of Ukraine. Organization of standard product manufacture, in addition to development of equipment, required solving highly complicated problems of residual stresses and strains in components from dissimilar materials, including thin-walled structural elements, as well as controlling the joint quality. In 1981 we developed and put into operation the unique superhigh-vacuum unit VVU- 


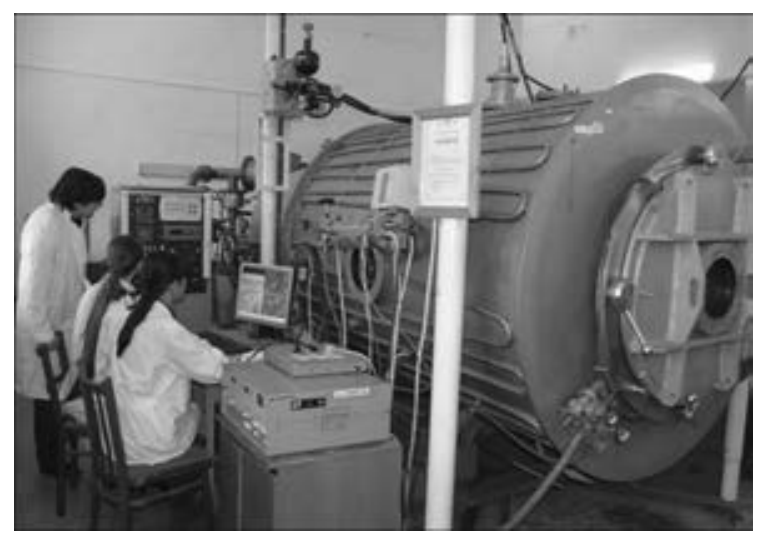

Superhigh-vacuum unit VVU-1D. Young scientists doing research (2012)

1D for diffusion welding, brazing and ion-plasma spraying (working chamber volume of about $4 \mathrm{~m}^{3}$, vacuum of not lower than $10-5 \mathrm{~Pa}$ ), fitted with a manipulator, controlled from outside. In 1983 the superhigh-vacuum unit for electron beam spraying was developed and produced. All the issues of fundamental design of the equipment were solved jointly by V.F. Kvasnitsky and G.V. Ermolaev, Ass. Profs, and the functions of Chief Builder were fulfilled by L.M. Petrenko, with whose active participation the first vacuum process unit UD-SV-DT (for welding turbine parts) was also developed and introduced at YuTP «Zarya» already at the start of 1960s. Work on welding and brazing materials and components of gas turbines, and MHD devices was included into the plan of fundamental R\&D and state programs fulfilled under the Act of USSR government.

In 1985 with active support of Profs M.N. Aleksandrov, Rector, I.V. Gorynin, Director of CRI SM «Prometey», and V.A. Ignatov, Deputy on research, the Branch Laboratory of the Ministry of Shipbuilding on pressure welding and brazing of materials in vacuum (with transfer of staff and labour limits from «Prometey») was set up. V.F. Kvasnitsky was appointed the Scientific Leader and L.M. Petrenko - the Laboratory Head.

At the end of 1970s, the Chair began to actively develop the scientific direction of automation of welding production in shipbuilding,

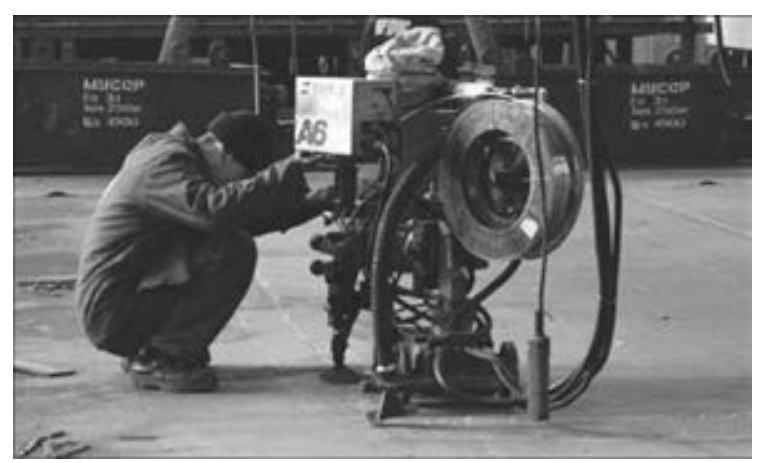

Student during the first practical technological training at «Okean» plant in particular as regards structures from light aluminium alloys. In 1985 Branch Laboratory of automation and mechanization of assembly-welding processes in shipbuilding was established. Dr. A.I. Dremlyuga, Ass. Prof., became the scientific leader of the direction and laboratory, who, unfortunately, passed away in the prime of his creative activity.

S.V. Dragan (1981), V.N. Khristenko (1984), A.Ya. Kaplun (1985) defended the theses of Candidates of Science. The team developed the fundamentals of welding butt and tee joints with simultaneous compensation of welding deformations by rolling of the joints with rollers. «Styk» and «Tavr» automatic machines were developed and manufactured together with Nikolaev Affiliate of CRI SBT for roll welding. Technology of roll welding was introduced in shipbuilding enterprises «Yantar», «More», «Baltia», etc.

The Chair was staffed by its own graduates who had shown an aptitude for scientific work. Thesis work was performed in the Chair laboratories, that was promoted by the substantial facilities and professionalism of the lecturers.

Starting from 1974 the Chair has been developing the scientific direction of brazing structural nonmetallic materials to metals. Contracts were made with DB «Salyut» (Moscow), Nuclear Energy Institution of AS BSSR (Minsk). Fruitful cooperation with IPMS (Kiev) was started. Profs V.I. Trefilov and Yu.V. Najdich made a great contribution to cooperation with Welding Production Chair. In 1975 the Chair, for the first time in Nikolaev, conducted the All-Union Scientific-Technical Conference «Melt Adhesion and Material Brazing», in which more than 350 scientists took part. The proceedings and abstracts were published by Conference results, and a decision was taken about issuing «Metal Adhesion and Material Brazing» Journal. Active co-operation with RI «Grafit» (Moscow), DB «Vint» (Moscow), «Energia» on introduction of investigation results in the field of joining nonmetallic materials to metals began at the same time. Technologies of joining graphite-based structural materials, ceramic materials to titanium alloys, electrical copper and stainless steels were developed. Fundamentally new technology of manufacturing of electrical brushes for electrical machines was developed. In 1979 V.M. Emelianov, Junior Staff Member of the Chair, together with IPMS staff, received AS Ukr.SSR Prize for junior scientists for a package of work on graphite brazing to metals.

The work on welding and related technologies in shipbuilding was conducted the most intensively. Candidate's theses were defended by B.V. Bugaenko (1975), V.P. Savchenko (1976), V.M. Emelianov (1980), and on high-temperature ma- 
terial brazing - by N.V. Altukhov (1985), S.G. Kulik (1986), S.M. Samokhin (1987).

Welding of quenching steels was pursued by Yu.M. Lebedev and L.P. Kravchenko. In 1976 L.P. Kravchenko defended his Candidate's thesis. Ingenious laboratory systems for investigation of structural and phase transformations in metals were created. Diagrams of thermokinetic decomposition of austenite for steels of different structural classes were plotted by investigation results.

All the work at the Chair was performed in close cooperation with «Zarya», «Mashproekt» (now Company «Zarya-Mashproekt»), Nikolaev Affiliate of CRI SBT, «Energia», PWI, IPMS, «Prometey», PA «Almaz», etc. The staff of the above-mentioned enterprises and organizations made a tremendous contribution to development of vacuum technologies and equipment. Cooperation results were highly appreciated by the government by awarding the Prize of the USSR Council of Ministers in the field of science and technology (1991). The creative team included scientists from PWI, «Prometey», «Energia», in particluar three Chair graduates (V.F. Kvasnitsky, V.M. Emelianov and V.P. Nikolaenko).

In the 1980s training of scientific personnel of the highest qualification became more intense. Ass. Profs V.F. Kvasnitsky, A.I. Dremlyuga, Yu.M. Lebedev, G.V. Ermolaev and V.N. Khristenko were doing their Doctor's theses research. In 1988 Doctor's thesis was defended by V.F. Kvasnitsky, and in 1995 - by Yu.M. Lebedev. All the developments were broadly introduced into industry.

The educational process was optimized alongside the scientific activity. With moving into the main academic building, new training laboratories were setup, and new research equipment was purchased. The modern ideas of the Bologna process were realized in 1985-1986. Scientific laboratories were widely used in the educational process, each graduate student pursued research, which were included as a separate section in the diploma project. Scope of commercial contracts increased several times, each staff member was able to increase his professional and scientific level. The staff of the Chair and laboratory was more than 50 persons. Each diploma project, in addition to research section, also had not less than three engineering calculations, including those made using the computer. Students of the Chair mastered the worker's profession of welder. In keeping with demands of the time, the following specializations were added at the Chair, starting from $2013 / 2014$ academic year, to speciality «Welding»: welding and related technologies in shipbuilding, power equipment construction; modern pulse and vacuum technologies in welding, surface engineering and medicine; underwater welding and related technologies. All

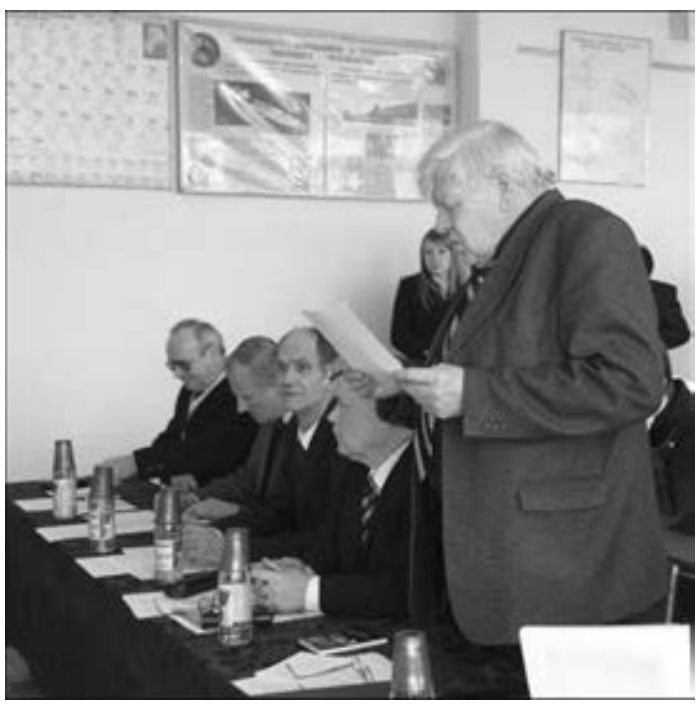

Members of State Examination Commission (2008). From left to right: S.V. Dragan, G.V. Ermolaev, Yu.M. Lebedev, V.F. Kvasnitsky, Prof. G.M. Grigorenko (Commission Chairman)

the disciplines were supported by training and methodical manuals developed at the Chair. Central publishing houses published training manuals on «Fundamentals of technological design of assembly-welding shops», «Special processes of welding and brazing in shipbuilding»; monographs on «Diffusion welding of high-temperature alloys», «Welding and brazing of high-temperature alloys in shipbuilding», «Theory, technology and equipment of diffusion welding»; handbooks «Diffusion welding of materials», «Diffusion bonding of materials», «Handbook on gas cutting, welding and brazing».

The Chair met Ukraine's independence with high results in scientific and educational activities. Despite breaking up of contacts with Russian scientific organizations, enterprises and higher educational establishments, as well as decline of industrial production, the Chair not only preserved its potential, but also continued to develop. In 1992 A.M. Kostin, Junior Rresearch Member, and in 1993 - Eng. V.A. Politov defended their Candidate's theses. Talented young

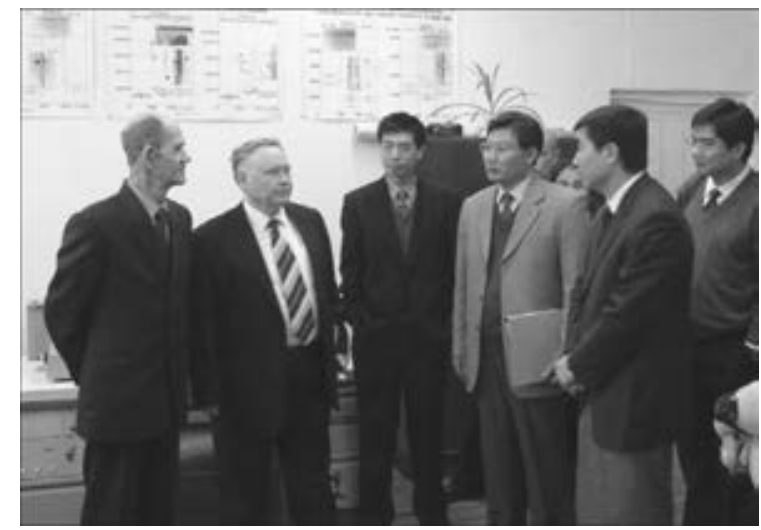

Delegation of Beijing Institute of Aeronautic Materials at the Welding Production Chair (2008) 


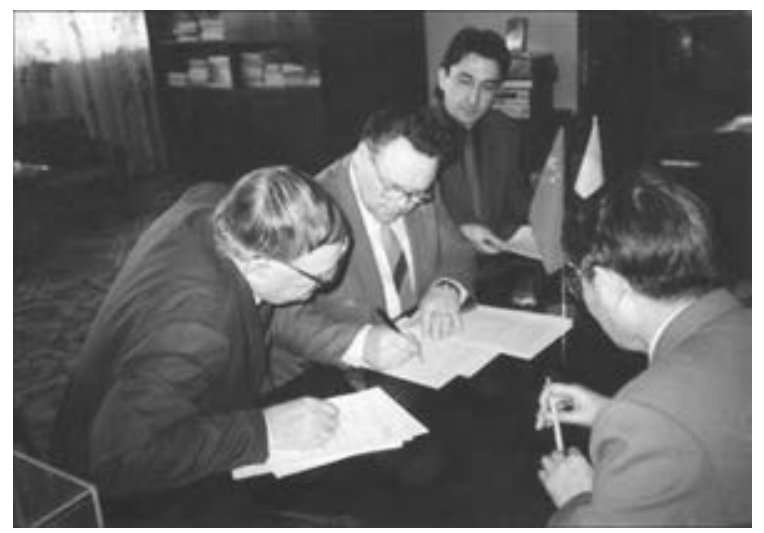

Signing of contract between Admiral Makarov NSU and Institute of Shipbuilding of China (1993)

people came to work at the Chair, who readily mastered computer technologies and systems of technological process control.

Scientific direction on new generation power sources and machines for thermal cutting is formed. For this purpose, Dr. E.N. Vereshchago, having experience of development of new samples of thransistorized power sources with improved welding-technological properties, technico-economic characteristics and electromagnetic compatibility for welding, related processes and technologies, including power sources with quasiresonance switching principles for plasma cutting of metal and alloys of PLASMA 110iHF series, was invited from Electrical Engineering Department. The latter power source was awarded a diploma at All-Ukrainian Competition and Exhibition «Best Local Goods of 2008».

In 2006-2008 specialists of AMITI Ltd. together with the Chair, designed welding rectifiers of VDU25-401, VDU25-506 and VDU26-630 series for submerged-arc welding and surfacing (Certificate of Compliance UA1.012.0165143-

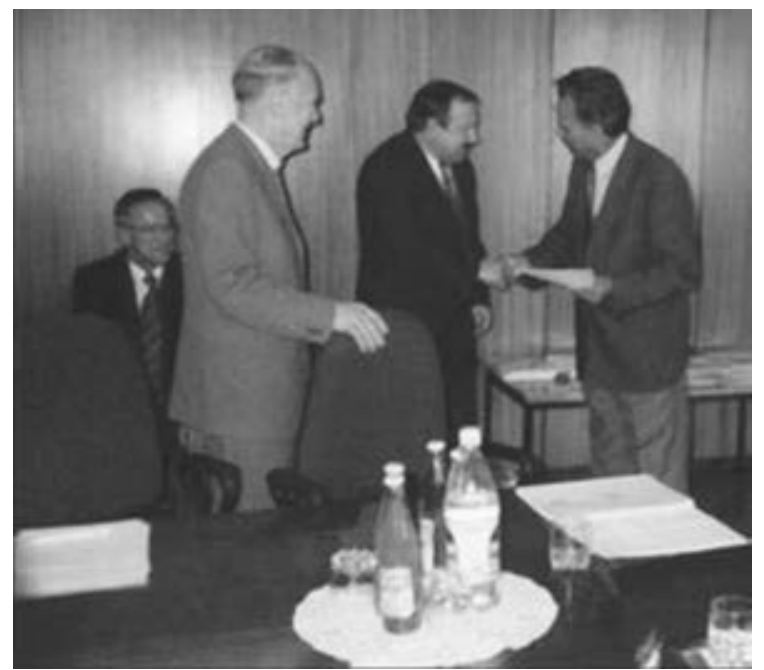

Presentation of Certificate of «European Welding Produc tion Engineer» for graduates of Shipbuilding Training Center of Welding Equipment to N.P. Romanchuk, Director of «Okean» plant, by Prof. B.E. Paton, President of NASU, and Mr. Tutlis, Chairman of SLV-1 Commission (1998)
06), protected by Patent of Ukraine 30840 for utility model. Patent authors S.V. Dragan, Yu.A. Yaros, A.F. Gal were awarded the diploma of winner of All-Ukrainian Competition «Invention-2008» in the nomination of «Best Invention2008》.

In 1994 by the decision of Cabinet of Ministers of Ukraine, the Institute was transformed into the National Shipbuilding University and received the status of higher educational establishment of the IV level. The speciality of Welding Production Chair was also certified to this level.

Within the framework of international cooperation, the Chair established active scientific contacts with higher educational institutions of China that promoted improvement of the facilities. In 1993 a computer classroom was set up at the Chair under an international contract.

In 1997 a research system for scanning electron microscopy and local X-ray microprobe spectral analysis was purchased and the respective laboratory was set up, which performs physico-chemical investigations, including those with application of high-temperature metallography. All the lecturers of the Chair have academic degrees and titles. Training of new generation of scientists was going on. In 1997 V.V. Kvasnitsky and in 2008 V.A. Martynenko defended their theses of Candidate of Science.

At the end of 1980s the Chair initiated new research direction on investigation of stress-strain state in diffusion welding and brazing of dissimilar materials, which successfully advanced in 2000s with introduction of new computer equipment and with active support and assistance of Prof. V.I. Makhnenko (PWI). In this field Candidate's theses were defended by A.V. Labartkava in 2004, M.V. Matvienko in 2013, and V.V. Kvasnitsky defended Doctor's thesis in 2010. Starting from 1995, the Chair has conducted fruitful cooperation with Training-Research Center of Welding Equipment of SLV-1 of Meklenburg-Vorpommern County. Owing to active support of Prof. B.E. Paton, President of the NAS of Ukraine, and assistance of Prof. V.M. Emelianov, People's Deputy of Ukraine, the work of the University and SLV-1 on training and certification of Welding Production Engineers in keeping with European norms was included into Interstate German-Ukrainian Program «Transform». In 1996 the University was appointed the Chief Organization on training welding production staff of all levels for shipbuilding by a joint order $96 / 87$ of the Ministry of Education and Ministry of Mechanical Engineering of Ukraine. In 1997 the University and shipbuilding enterprises of Ukraine organized Shipbuilding Training Center of Welding Equipment, working in cooperation with SLV-1. 


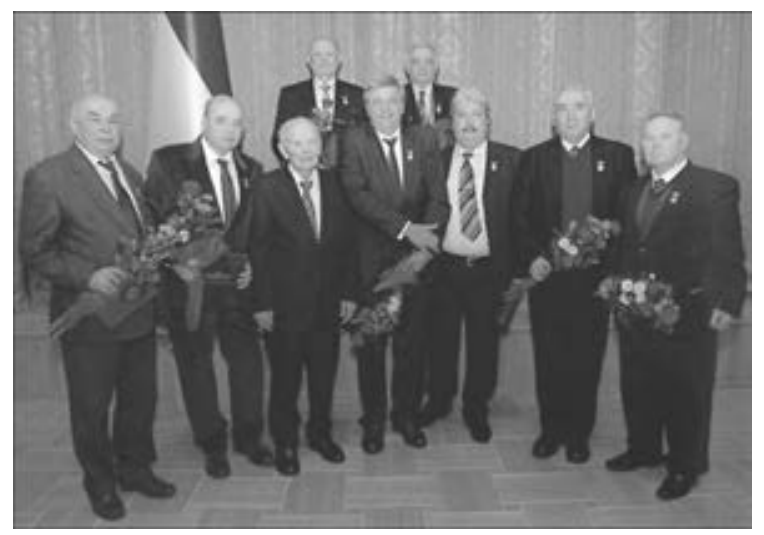

Winners of State Prize of Ukraine in the field of science and technology (2012). From left to right: K.V. Koshkin, S.S. Ryzhkov, Yu.D. Zhukov, I.V. Krivtsun, V.A. Nekrasov, G.V. Egorov, V.S. Blintsov, V.F. Kvasnitsky together with Prof. B.E. Paton (in the center)

In 1998 diplomas of European Welding Engineer were presented to the first group, consisting of 24 leading specialists of welding production in shipbuilding, including G.V. Ermolaev, V.V. Kvasnitsky, L.P. Kravchenko, Ass. Profs, by Embassador of Germany in Ukraine, Profs B.E. Paton and P.I. Seyffarth, SLV-1 Director. One year later G.V. Ermolaev, V.V. Kvasnitsky, L.P. Kravchenko also received diplomas of International Welding Engineer.

Despite the economic problems faced by Ukraine, the Chair even now continues fundamental investigations together with PWI with application of unique equipment and instruments. A number of joint research activities with funding of fundamental research from State Funds of Ukraine, Russia and Belarus have been performed just during the last five years. Investigation results are published annually in the form of papers, and are highlighted in international conferences.

Awarding the state Prize of Ukraine for 2011 to staff members of the University and PWI for shipbuilding work on «Development of versatile transport ships and oceanic engineering means» can be an example of fruitful cooperation.

An important feature of all the research work performed by the Chair is introduction of these results into industry. One of them - «Advanced technologies of development of materials and coatings in shipbuilding» - received the award of President of Ukraine for young scientists in 2013. The award was presented to Al.V. Labartkava, Junior Research Member.

Chair lecturers are actively working on publishing educational literature. Just during the last 15 years, 19 manuals and teaching aids with MESU stamp and monographs have been published, and Mechanical Engineering Encyclopedia, Volume III-4: Technology of brazing and cutting, edited by B.E. Paton, as well as more than 10 volumes of Rules of Ship Classification

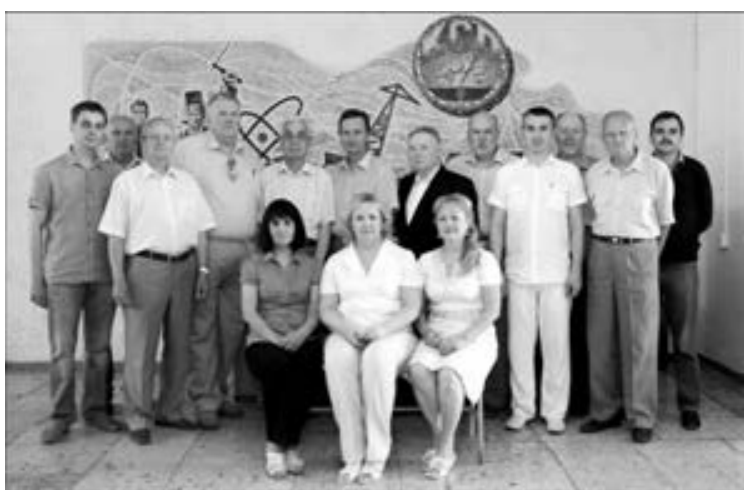

Team of Welding Production Chair (2014). Standing from left to right: V.A. Martynenko, E.N. Vereshchago, S.V. Dragan, L.P. Kravchenko, S.Yu. Maksimov (Chairman of State Examination Commission, PWI), V.F. Kvasnitsky, A.M. Kostin, A.V. Labartkava, S.Yu. Kramarenko, G.V. Ermolaev, Al.V. Labartkava

and Building (Official publication of Shipping Register of Ukraine) have been published with the Chair participation.

During the period of its existence the Chair has trained about 3 thousand welding production engineers. The graduates include more than 100 Doctors and Candidates of Science, Honoured Workers of Science and Technology, Honoured Workers of Education of Ukraine, members of the Royal Institute of Shipbuilding, Institute of Marine Engineering, Science and Technology, AS of Shipbuilding of Ukraine.

In 2004 the University received the status of National University, to which the Chair team has also made its contribution.

Chair formation and development was made possible owing to tremendous support and participation of numerous scientific and production teams and educational institutions, including PWI, IPMS, «Prometey», I.I. Polzunov CRI DCBT, TsNIITMash, N.E. Bauman MSTU, Problem Laboratory of diffusion welding in vacuum, MATI, Leningrad Shipbuilding and Polytechnic Institute, «Mashproekt», «Zarya», «Energia», «Grafit» and other organizations, where leading scientists and specialists were personally involved both in the educational process, and in scientific developments. Many scientists from the above mentioned and other organizations and institutes (universities) were chairmen of State Examination Commissions on Defense of Diploma Projects. Communication with them, their advice and recommendations on scientific and educational work ensured the Chair development. The team of Welding Production Chair is sincerely grateful to all those who were involved in cooperation and is hoping for its further progress.

V.M. Emelianov, B.V. Bugaenko, A.M. Kostin, V.A. Martynenko 


\title{
EFFECT OF STRESS-STRAIN STATE ON STRUCTURE AND PROPERTIES OF JOINTS IN DIFFUSION WELDING OF DISSIMILAR METALS
}

\author{
V.V. KVASNITSKY ${ }^{1}$, V.F. KVASNITSKY ${ }^{2}$, L.I. MARKASHOVA ${ }^{3}$ and M.V. MATVIENKO ${ }^{2}$ \\ ${ }^{1}$ NTUU «Kiev Polytechnic Institute» \\ 37 Pobedy Ave., 03056, Kiev, Ukraine. E-mail: kvas69@urk.net \\ ${ }^{2}$ Admiral Makarov National Shipbuilding University \\ 9 Geroev Stalingrada Ave., 54025, Nikolaev, Ukraine. E-mail: welding@nuos.edu.ua \\ ${ }^{3}$ E.O. Paton Electric Welding Institute, NASU \\ 11 Bozhenko Str., 03680, Kiev, Ukraine. E-mail: office@paton.kiev.ua
}

\begin{abstract}
Computer modelling of stress-strain state (SSS) considering change of physical-mechanical properties, structural transformations and creep strains determined that distribution of plastic strains along the joint butt in diffusion welding (DW) of dissimilar materials is non-uniform. The results of mechanical tests of welded joints provide estimation not for different zones of joint but welded joint integral estimation. Aim of the work is determination of effect of SSS on structure and properties of joints in different zones of joint butt at constant temperature of DW and using temperature cycling. Welding of steel $12 \mathrm{Kh} 18 \mathrm{~N} 10 \mathrm{~T}$ and electric steel 10864 (armco-iron) was carried out at constant temperature $1050{ }^{\circ} \mathrm{C}$ and two temperature cycles $700-1000{ }^{\circ} \mathrm{C}$. Welded joints were subjected to microstructural and local X-ray microanalysis. Hardness distribution was studied. Significant attention was made to study of fine structure of metal in joint zone and estimation of specific contribution of different structural constituents in total value of yield strength of the welded joints, considering dependence of dislocation density on value and intensity of plastic strain. Carried investigations confirm the results of SSS computer modelling and presence of significant zone of deformation stagnation in DW with constant temperature. It is determined that DW with temperature cycling allows controlling SSS, intensifying processes of volume interaction and providing full strength of 10864 steel joints. 12 Ref., 6 Figures.
\end{abstract}

Key words: diffusion welding, SSS modeling, temperature cycling, structure, plastic strain, mechanical properties, diffusion

Development of technologies in different branches of industry requires application of dissimilar materials in manufacture of parts and assemblies for rising of their operation efficiency. Diffusion welding (DW) in vacuum $[1,2]$ is one of the perspective methods for joining of these materials. Joints from more than 800 types of pairs of different materials have been made up to present time [3]. The main problem of DW is instability of joint formation along the butt area and in change of geometry of welded assemblies, that is explained by scale factor. Uniform distribution of compression force over the butt area is usually taken as a basis in development of welding mode and estimation of plastic strains, being the main factor of joint formation. In fact, Yu.L. Krasulin in works [4, 5] showed already that the strains have non-uniform distribution along the joint butt and form central zone without traces of interaction. Nature of fracture during testing in welding of cylinder specimens of heat-resistant alloys EI607A and EI896, taken from thesis of V.N. Stolyarov (I.I. Polzunov CRI DCBT), showed that the weakest zones of the joint appear in central zone close to the axis. Such zones were not observed in welding of large diameter billets and testing of specimen.

Investigation of dependencies of formation of joints in different zones of the joint butt in works $[5,6]$ were carried out using analytical methods of modelling applied in theory of pressure treatment of metals [7, 8], which do not allow taking into account the effect of number of alternating factors on stress-strain state (SSS) in the joint butt, including change of physical-mechanical properties, structural transformations, creep strains and other factors, which can be considered by computer modelling. Investigations [9, 10], carried out under the leadership of Prof. V.I. Makhnenko, allowed determining the dependencies of SSS formation under conditions of elasticity, instantaneous ductility and creep during DW of dissimilar materials considering their changing physical-mechanical properties, geometry and structural factors as well as possibility 
of SSS control in the joint butt in DW with changing temperature (with temperature cycling) in contrast to DW with constant temperature on classical scheme.

Efficiency of DW with temperature cycling is confirmed by results of mechanical tests of welded joints, providing for integral estimation rather than on different zones of the joint butt. It shows the relevance of performance of these investigations.

Aim of present work is determination of SSS effect on structure and properties of the joints in different zones of joint butt in DW with temperature cycling and constant temperature. The idea of performance of the investigations, described below, belonged to Prof. V.I. Makhnenko.

Welding of steels $12 \mathrm{Kh} 18 \mathrm{~N} 10 \mathrm{~T}$ and 10864 in $10^{-2} \mathrm{~Pa}$ vacuum on DW classical scheme at constant temperature $1050{ }^{\circ} \mathrm{C}$ and pressure $15 \mathrm{MPa}$ with 12 min holding, and using two temperature cycles of $750-1000{ }^{\circ} \mathrm{C}$ interval with 2 min holding at $1000{ }^{\circ} \mathrm{C}$ was studied in the work. After second cycle, heating was continued to $1050{ }^{\circ} \mathrm{C}$ for $6 \mathrm{~min}$ and further cooling as in the first case. Cylinder specimens of $12 \mathrm{~mm}$ diameter were used. $12 \mathrm{Kh} 18 \mathrm{~N} 10 \mathrm{~T}$ steel refers to nonmagnetic corrosion-resistant heat-resistant steels of austenite class and contains not more than 0.08$0.12 \% \mathrm{C}, 17-19 \% \mathrm{Cr}, 9-11 \% \mathrm{Ni}$ and up to $0.8 \% \mathrm{Ti}$. Conventional yield strength at room temperature makes not less than $200 \mathrm{MPa}$, ultimate tensile strength is not less than $500 \mathrm{MPa}$, relative elongation and reduction in area not less than $40-55 \%$. Steel 10864 refers to magnetic steels of ferrite class, which is used in manufacture of electromagnet cases, and contains to $0.035 \% \mathrm{C}, \approx 0.3 \% \mathrm{Si}$ and $\mathrm{Mn}$, up to $0.1 \% \mathrm{Ni}$ and $0.03 \% \mathrm{Cr}$. The yield strength makes not less than $215 \mathrm{MPa}$, ultimate strength and relative elongation are not less than $320 \mathrm{MPa}$ and $33 \%$, respectively.

After welding the specimens were cut along the diameter and studied along the lines parallel to the axis and passing through $0, A$ and $B$ zones, i.e. along the axis, middle of the radius and close to the side surface of specimen, respectively, as shown in Figure 1.

Welded joints were subjected to microstructural and local X-ray microanalysis as well as study of microhardness distribution.

DW is characterized by low intensities and values of plastic strains. Deformation takes place at $10^{-4}-10^{-3} \mathrm{~s}^{-1}$ rates on dislocation mechanism, plastic strain is considered as a process of formation of new dislocations and their movement along the crystal [11]. Emergence of dislocations

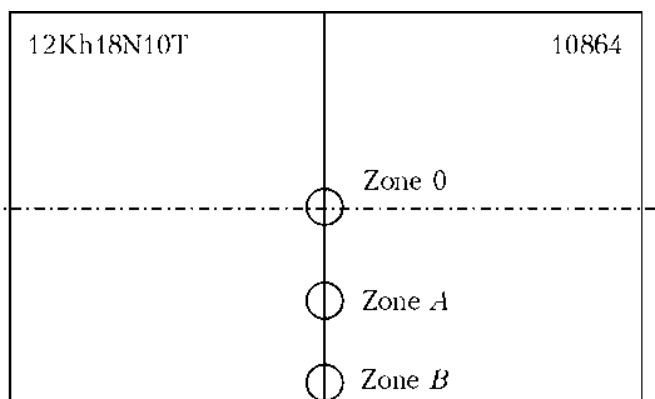

Figure 1. Scheme of welded cylinder specimen from steels 12Kh18N10T and 10864

on the surfaces being joined and their accumulation is accompanied by delivery of atoms with unlinked binding forces, forming active center of the joint. Breaking of old bonds with oxygen of oxide film and formation of new ones between subsurface atoms of parts being joined take place within the active centers. Thus, deformation activation of the surfaces and their setting (establishing of interatomic bonds) take place. Frequency of dislocations emergence is determined by intensity of plastic strain [11]. It is no change of dislocation density at the first stage of light slipping and it makes around $10^{8} \mathrm{~cm}^{-2}$. Irregular dislocation mesh emerge at the second stage. Average density of dislocation at the beginning of the first stage rises to $10^{9}$, and at the end makes $10^{10} \mathrm{~cm}^{-2}$. Local dislocation density achieves $10^{11} \mathrm{~cm}^{-2}$. Appearance of wide slip bands is observed at the third stage, that is promoted by transverse sliding of screw dislocation components, gaps between which are filled by fine, short slip lines.

Specific attention in the work is made to examination of metal fine structure in zone of the joint butt considering the clear dependence of dislocation density on value and intensity of plastic strain. Optical metallography, analytical scanning (the Philips SEM-515) and microdiffraction transmission electron microscopy using the JEOL JEM-515 assembly with energy dispersive and wave spectrometers, as well as Comebax assembly of SX-50 type were used at that. The method of transmission electron microscopy allows also detecting segregation processes, related with diffusion.

Works [9, 10] indicated presence of a zone with minimum plastic strains, where tangential stresses equal zero, in central part of the cylinder specimen at constant temperature as well as in welding of bush-to-bush assembly at some distance from the internal surface (between internal surface and average thickness of bushing). This zone is called the zone of deformation stagnation.

Figure 2 shows the fields of equivalent plastic strains considering creep deformations during 


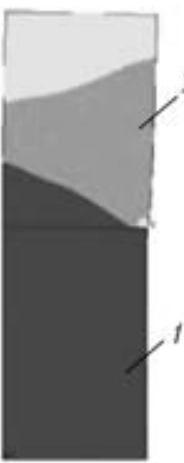

$a$

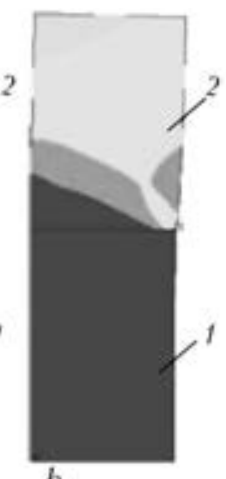

b

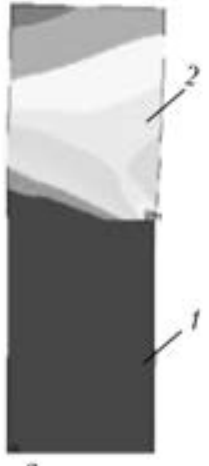

C $\varepsilon \cdot 10^{3}$

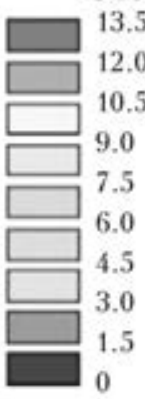

Figure 2. Change of equivalent plastic strains in section of axially symmetric part of the specimen during DW of steels $12 \mathrm{Kh} 18 \mathrm{~N} 10 \mathrm{~T}$ (1) and 10864 (2) using classical scheme at time of welding $90(a), 120(b)$ and $300(c) \mathrm{s}$

compression of specimens by $15 \mathrm{MPa}$ pressure at constant temperature. The fields of shear plastic strains are not shown due to their low level.

It can be seen in Figure 2 that plastic strains at constant temperature of welding start to develop from steel 10864 cylinder surface, slowly propagating its area to the center of specimen and intensively develop at a distance from the joint butt. Such SSS results in development of welded assembly deformations behind the zone of joint butt and are unfavorable for formation of the joint. Modelling results show that DW
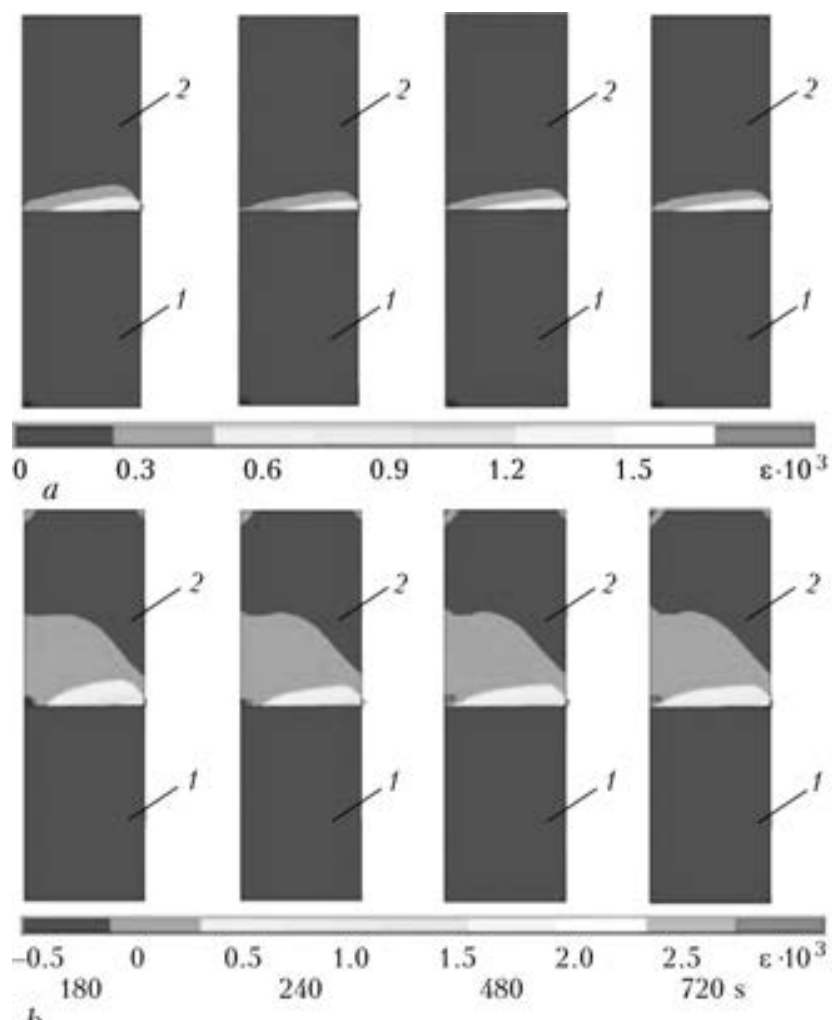

$b$

Figure 3. Change of fields of equivalent $(a)$ and shear $(b)$ plastic strains in section of axially symmetric part of the specimen during DW with temperature cycling of steels $12 \mathrm{Kh} 18 \mathrm{~N} 10 \mathrm{~T}$ (1) and 10864 (2) during of first cycle (180, $240 \mathrm{~s})$, after second (480 s) and third (720 s) cycle with temperature cycling promotes formation of SSS being favorable for surface activation and formation of joints along the whole area of joint butt (Figure 3).

Analysis of fields of plastic strains (see Figure 3) show that equivalent and shear strains at thermal loading localize in zone of the joint butt. It is close to ideal variant for providing of deformation mechanism of activation of surfaces being joined. The fields of plastic strain distribution in zone of the joint butt show small changes at the end of each cycle, but position of zone of deformation stagnation is somewhat changed in process of heating, that promotes more uniform distribution of deformations over the joint butt. It is also promoted by surface slipping at the first stage of joint formation.

Figure 4 shows the results of investigation of fine structure of $12 \mathrm{Kh} 18 \mathrm{~N} 10 \mathrm{~T}$ and 10864 steel joints at constant DW temperature and welding with temperature cycling. Study of structure of joint metal in zone 0 using electron microscope with magnification $(\times 15,000-50,000)$ showed formation of elongated 1.8-2.7 $\mu \mathrm{m}$ width band of surface layers collapsing from side of 10864 steel and preserving from side of $12 \mathrm{Kh} 18 \mathrm{~N} 10 \mathrm{~T}$ steel. Inactivity of contacting surface from the side of austenite steel is confirmed by stability of interface and presence in this interface of surface oxides (Figure 4, $a$ ), which are barriers for establishing the bonds between subsurface atoms of metals being joined and resolidification. Removal of these barriers is possible by means of their diffusion dissolving, however, this requires long time even at DW of nickel [11]. Plastic strain of metal in the joint butt promotes for removal of oxides on the mechanical failure-dispersion-diffusion dissolving of oxides scheme, that intensifies interaction (binding) of materials being joined. At that, areas of brittle cleavage, observed at the initial stage in the zone of oxide plate location, are replaced by areas of tough fracture.

Deformation along the interface in zone 0 is noted only from the side of steel 10864 with maximum depth of deformed layer $2.8 \mu \mathrm{m}$. Small rise of dislocation density, typical for initial stage of formation of block structures, is found from the side of austenite steel directly in $0-2 \mu \mathrm{m}$ contact zone. And only single, randomly located dislocations of the same density as at a distance from the joint butt are detected at increase of distance from the joint butt to $10-80 \mu \mathrm{m}$. Separate twins typical for austenite steel are found there on the background of uniform distribution of dislocations at their minimum density $10^{8} \mathrm{~cm}^{-2}$, that 

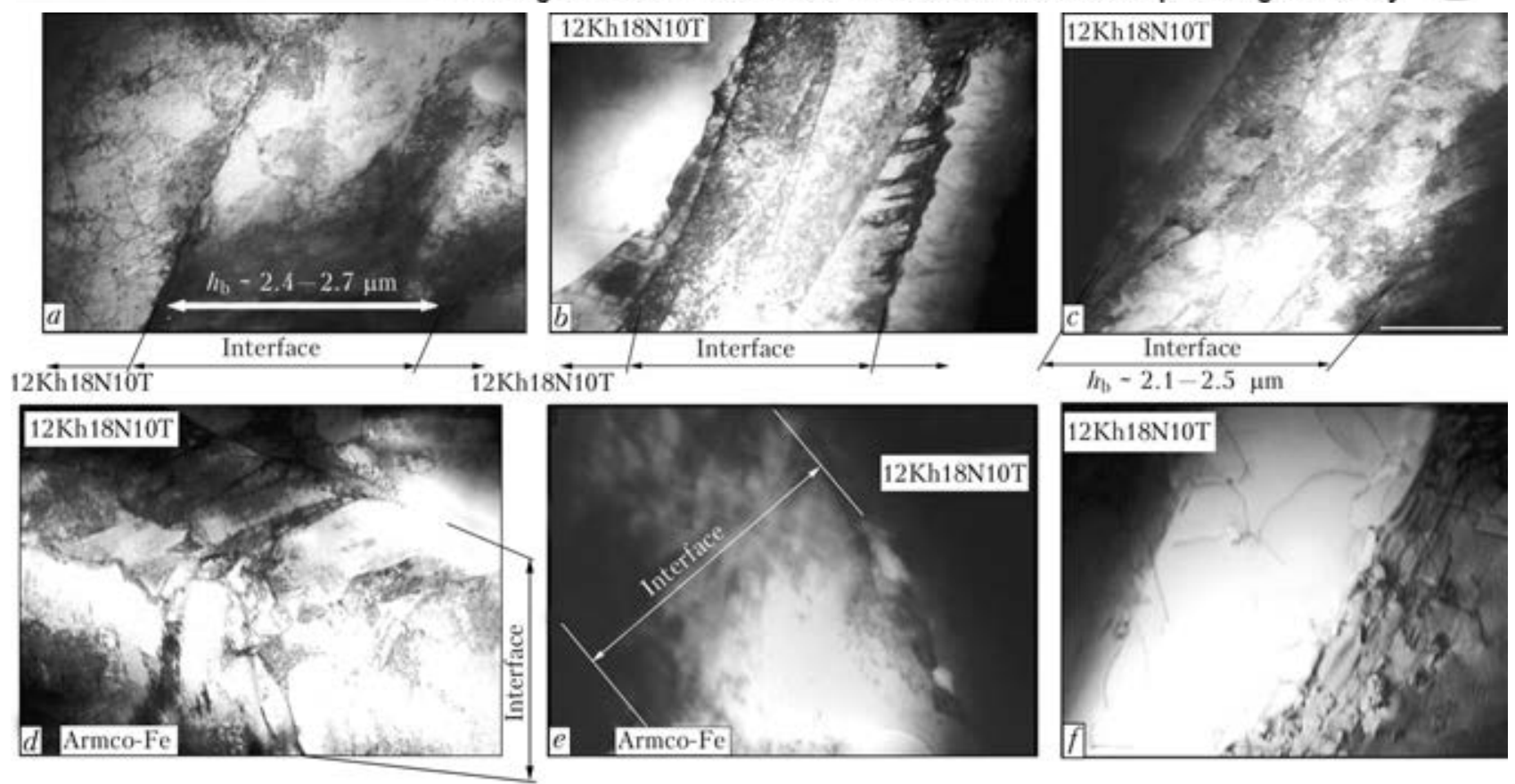

Figure 4. Fine structure of welded joint of steels 12Kh18N10T and 10864, produced at constant temperature of DW in zone of joint butt $0(a), A(b), B(c)$ and in DW with temperature cycling in zone of joint butt $0(d), A(e)$ and $B(f)$ $(a, c, d-\times 20000 ; b, e, f-\times 30000)$

indicates insignificant deformation on the surface of steel $12 \mathrm{Kh} 18 \mathrm{~N} 10 \mathrm{~T}$.

Elongated band structures with rapidly rising dislocation density, indicating high deformation intensity, are observed in zone $A$ of the joint butt (Figure $4, b$ ). It is important that subsurface activation of deformation processes from the side of austenite steel takes place in indicated zone. Intergrain density dislocation rise to $10^{11} \mathrm{~cm}^{-2}$, number of slip systems increases as well as processes of phase formation are observed. Formation of high-dispersion phases of $d_{\mathrm{ph}}=0.03-0.05 \mu \mathrm{m}$ diameter is noted in the zone of dislocation accumulation and development of slip systems. Structural changes in austenite steel are observed in layer of to $100 \mu \mathrm{m}$ depth from the joint butt.

Cell and subgrain structure of $d_{\mathrm{s}}=0.13-$ $0.30 \mu \mathrm{m}$ size are formed in zone $A$ from the side of steel 10864. Intensification of deformation activation of metal is observed in near-contact zone, that is indicated by rise of total dislocation density and formation of elongated dispersion band structures with clear intergrain boundaries.

Nature of metal structures indicates accumulation of energy in zone $A$, but relaxation processes are at initial stage.

Metal structure in zone $B$ (Figure $4, c$ ) of the joint butt indicates that active processes of plastic strain move to the stage of relaxation development, namely redistribution of general dislocation density is observed with rise of sizes and equiaxial nature of the structure (grain and subgrain), formation of more uniform equilibrium high-angle boundaries and areas with common grains, i.e. with set intercrystalline interatomic bonds of metals being joined.

Processes of relaxation (redistribution of dislocations, rise of sizes of grain and subgrain structure) and redistribution of defects of crystalline structure (reduction of dislocation density in grain body and improvement of grains) actively take place. Intensity of relaxation processes from the side of steel $12 \mathrm{Kh} 18 \mathrm{~N} 10 \mathrm{~T}$ is traced at up to $150 \mu \mathrm{m}$ distance from the joint butt. Increase of sizes of forming phases with diametar to $0.3 \mu \mathrm{m}$ takes place in this zone, that also confirms activating role of thermo-deformation processes in zone $B$ of the welded joints.

Figure $4, d-f$ gives the results of study of structure of joints from $12 \mathrm{Kh} 18 \mathrm{~N} 10 \mathrm{~T}$ and 10864 steels at DW with temperature cycling.

Area of interaction of steels in zone 0 has around $2.1 \mu \mathrm{m}$ width with clearly observed block structure of elongated shape and sizes of blocks approximately $0.25 \times 2 \mu \mathrm{m}$ (Figure $4, d$ ). Elongation and shape of blocks, as well as lamellar nature of their distribution in zone of the joint butt, are the evidence of orientation and high intensity of local plastic deformation under effect of external compression and thermal loading, caused by different physical-chemical properties of materials being joined.

Dispersion of structure, high dislocation density with maximum value to $10^{11} \mathrm{~cm}^{-2}$, block morphology with clear interblock interface confirm high level of deformation. 
Areas of segregation of high-dispersion accumulations having $0.05-0.12 \mu \mathrm{m}$ size particles are observed in some zones of the joint butt that is the evidence of active processes of mass-transfer.

Processes of intensive dislocation redistribution with multiple slip traces as well as decoration of dislocations by alloying elements and development of phase formations of $d_{\mathrm{ph}}=0.10^{-}$ $0.15 \mu \mathrm{m}$ size are observed directly near the joint butt from the side of austenite steel in area of to $70 \mu \mathrm{m}$ depth. State of equilibrium of metal structure is indicated at a distance around $300 \mu \mathrm{m}$ from the joint butt.

Dislocation density of $10^{9}-10^{10} \mathrm{~cm}^{-2}$ with formation of dislocation accumulations, cells and dispersion blocks is observed from the side of 10864 steel in area of contact interaction. At a distance from the joint butt the dislocation density drops to $10^{8} \mathrm{~cm}^{-2}$ that indicates activation of relaxation processes. Formation of fine as well as coarser phase precipitates takes place directly in contact zone and at some distance from the joint butt in addition to segregations on separate dislocations. New phases are in particular actively formed along the intergrain boundaries.

New disperse more equiaxial structures of relaxation nature are formed in zone $A$ (Figure 4, $e)$. Traces of active plastic strain are typical for structure from the side of steel $12 \mathrm{Kh} 18 \mathrm{~N} 10 \mathrm{~T}$ at 5-10 $\mu \mathrm{m}$ distance from the joint butt at significant level of dislocation density with clear twinning of grain microvolumes. The processes, related with segregation of elements and additives (diffusion) as well as nucleation of new phases on dislocations accumulations at initial stage, and phases having clear morphology and size, are also observed.

The traces of slipping, formation of segregation and new dispersion phases are found along the whole width of band of plastic strain of steel in zone of the joint butt.

Metal structure in zone $B$ of the joint butt is characterized by indistinct equiaxial grains of $d_{\mathrm{s}} \sim 1.3-3.0 \mu \mathrm{m}$ with sub- and intergrain boundaries (Figure 4, $f$ ). Active phase formation, dispersion of which makes $d_{\mathrm{ph}}=0.01-0.04 \mu \mathrm{m}$, and accumulation of dislocations in body as well as along the boundaries of structural elements are typical for this zone. The structure in microvolumes of austenite steel at 5-10 $\mu \mathrm{m}$ distance from the joint butt is similar to one that is formed directly near the joint butt on appearance, distribution and size of phase precipitations $\left(d_{\mathrm{ph}}=\right.$ $=0.03-0.08 \mu \mathrm{m})$. Dislocation density makes around $10^{10} \mathrm{~cm}^{-2}$. However, rapid increase of grain structure and drop of dislocation density to $6 \cdot 10^{8} \mathrm{~cm}^{-2}$ take place already at around $20 \mu \mathrm{m}$ distance from the joint butt. The phase precipitates became coarser approximately by order $\left(d_{\mathrm{ph}}=0.3-0.7 \mu \mathrm{m}\right)$ and their quantity reduces. Structure of steel 12Kh18N10T shows no difference from structure of the base metal at increase of distance from the joint butt to $250-400 \mu \mathrm{m}$.

Steel structures in zones $B$ and $A$ in DW with temperature cycling and $B$ at constant welding temperature are similar, that indicate intensive development of relaxation processes. It is also confirmed by steel microhardness. Microhardness of both steels in section along the zone $B$ is lower than in zones $A$ and 0 , where relaxation processes do not develop at constant DW temperature.

Depth of mutual diffusion in zones $A$ and $B$ of steels being joined makes 8-14 $\mu \mathrm{m}$ on different elements. Width of diffusion zone (Figure 5, $a$ ) significantly exceeds accepted in literature criterion of strength on width of diffusion zone 3$5 \mu \mathrm{m}$ [1] in DW with temperature cycling even in zone 0 . Formation of transition layer between
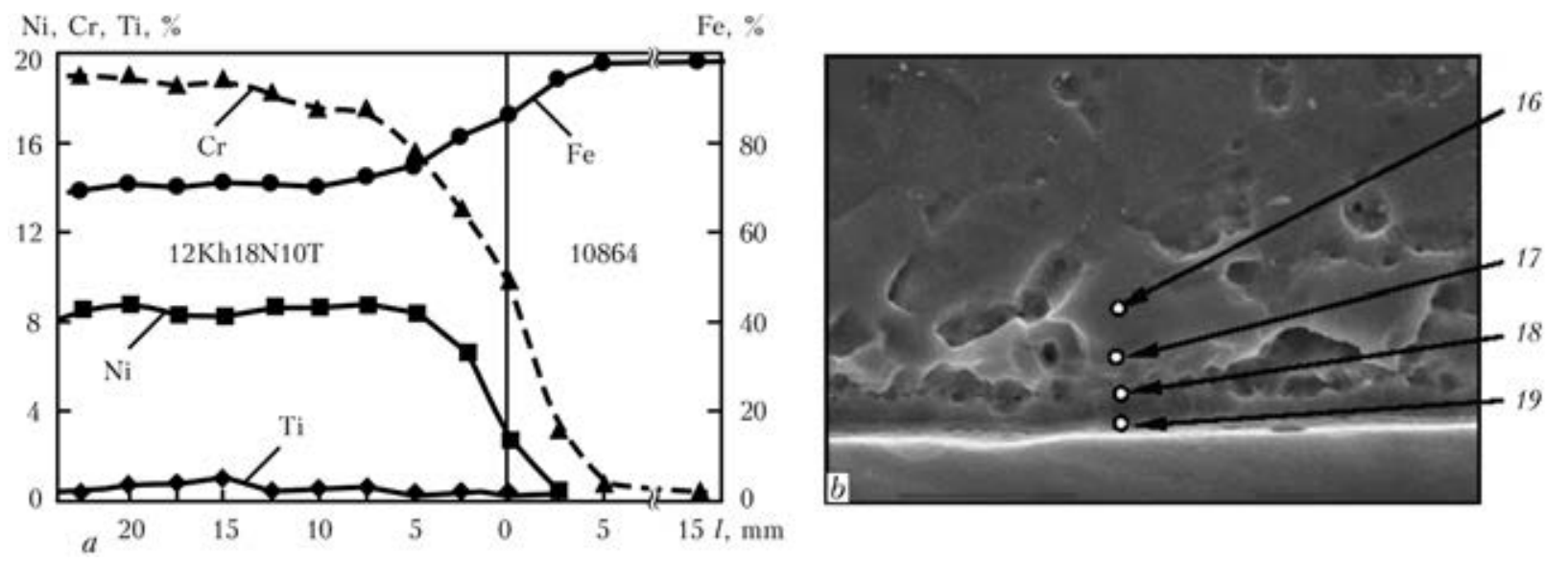

Figure 5. Distribution of elements $(a)$, and microstructure $(b-\times 4020)$ of metal in zone of joint butt of steels $12 \mathrm{Kh} 18 \mathrm{~N} 10 \mathrm{~T}$ and 10864 (chemical composition, wt.\%, in points $16-78.7 \mathrm{Fe}, 5.36 \mathrm{Ni}, 14.3 \mathrm{Cr}, 0.56 \mathrm{Ti} ; 17-79.9 \mathrm{Fe}, 5.36 \mathrm{Ni}, 12.27 \mathrm{Cr}$, $0.53 \mathrm{Ti} ; 18-86.4 \mathrm{Fe}, 3.2 \mathrm{Ni}, 9.8 \mathrm{Cr} ; 19-92.47 \mathrm{Fe}, 1.3 \mathrm{Ni}, 6.2 \mathrm{Cr})$ 
steels $12 \mathrm{Kh} 18 \mathrm{~N} 10 \mathrm{~T}$ and 10864 is shown in $\mathrm{Fi}$ gure $5, b$.

Analysis of received results of study of fine structure and chemical composition of metal in zone of the joint butt shows that DW with temperature cycling provides for formation of joints without defects and brittle phases along the whole area of the joint butt. Diffusion porosity in the diffusion zone is absent. Mechanical tests showed that fracture of welded joints has brittle nature and occurs in steel 10864 out of the joint zone.

Results of study of fine structure and formation of joints verify the results of computer modelling of SSS in DW of steels $12 \mathrm{Kh} 18 \mathrm{~N} 10 \mathrm{~T}$ and 10864, received in work [6] as well as given in Figures 2 and 3. Plastic strains take place along the whole area of the joint butt in DW with temperature cycling in contrast to DW at constant temperature that guarantees welded joint quality.

Performed complex of experimental investigations of structural constituents (sizes of grains and sub-grains, dislocation density, size and distribution of phase precipitates), formed in metal under different thermal-deformation conditions, allows carrying out analytical estimations of specific contribution of different structural constituents in total value of mechanical characteristic of the welded joints of steels $12 \mathrm{Kh} 18 \mathrm{~N} 10 \mathrm{~T}$ and 10864 in different zones of the joint butt at constant DW temperature (traditional scheme) and in DW with temperature cycling. Yield strength of metal in joining zone is taken as such a characteristic [12]. At that, it was accepted that $\sigma_{0.2}$ value, according to Archard equation, including known Hall-Petch, Orowan, Ashby, Armstrong,

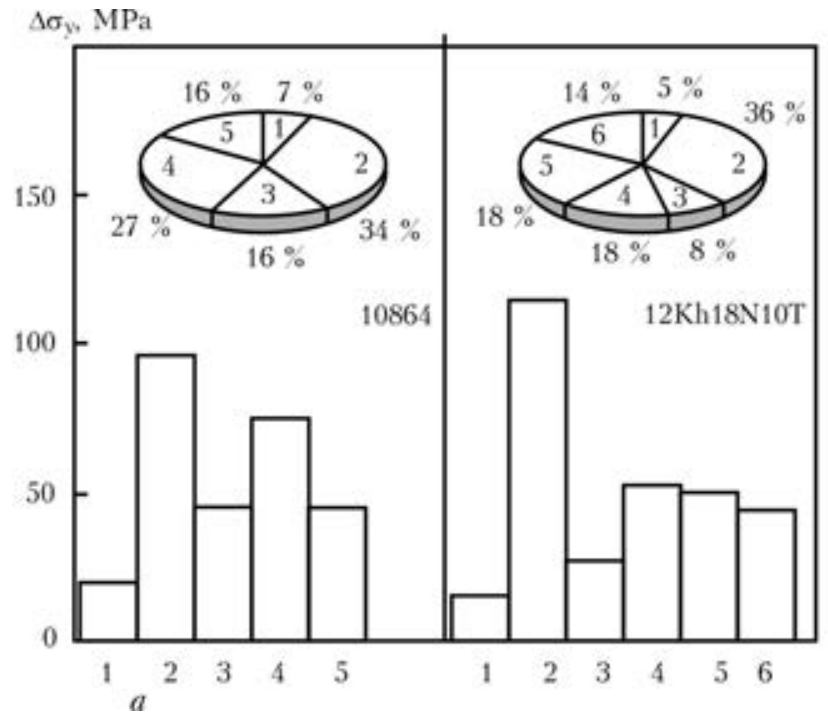

Peierls-Nabarro and Conrad dependencies is written by formula

$$
\Sigma \sigma_{0.2}=\Delta \sigma_{0}+\Delta \sigma_{\mathrm{s} . \mathrm{s}}+\Delta \sigma_{\mathrm{g}}+\Delta \sigma_{\mathrm{s}}+\Delta \sigma_{\mathrm{d}}+\Delta \sigma_{\mathrm{d} . \mathrm{s}}
$$

where $\Delta \sigma_{0}$ is the resistance of metal lattice to movement of free dislocations (stress of lattice friction or Peierls-Nabarro stress); $\Delta \sigma_{\text {s.s }}$ is the strengthening of solid solution with alloying elements and additives (solid solution strengthening); $\Delta \sigma_{g}, \Delta \sigma_{\mathrm{s}}$ are the strengthening due to change of value of grain and subgrain (HallPetch dependencies, grain and substructural strengthening); $\Delta \sigma_{d}$ is the dislocation strengthening caused by interaction between dislocations; $\Delta \sigma_{\text {d.s }}$ is the strengthening due to dispersion particles by Orowan (dispersion strengthening).

Results obtained during study of metal fine structure in zone of the joint butt were used for quantitative estimation of effect of different structural factors on yield strength of metal in zones $0, A, B$ using traditional scheme of DW and DW with temperature cycling. Constituents of stresses in Archard equation were determined according to work [12]. Figure 6 shows the calculation results.

Analytical estimations of specific (differential) contribution of different structural-phase parameters in change of strength characteristics $\left(\Sigma \sigma_{0.2}\right)$ showed that the most significant increase of total (integral) value of yield strength $\Sigma \sigma_{0.2}$ is observed in zone $B$ at constant temperature of DW and in zone $A$ in DW with temperature cycling. According to analytical estimations, higher values of yield strength are observed in zone $A$ in DW with temperature cycling in comparison with zone $B$ without temperature cycling due to larger subgrain strengthening from the

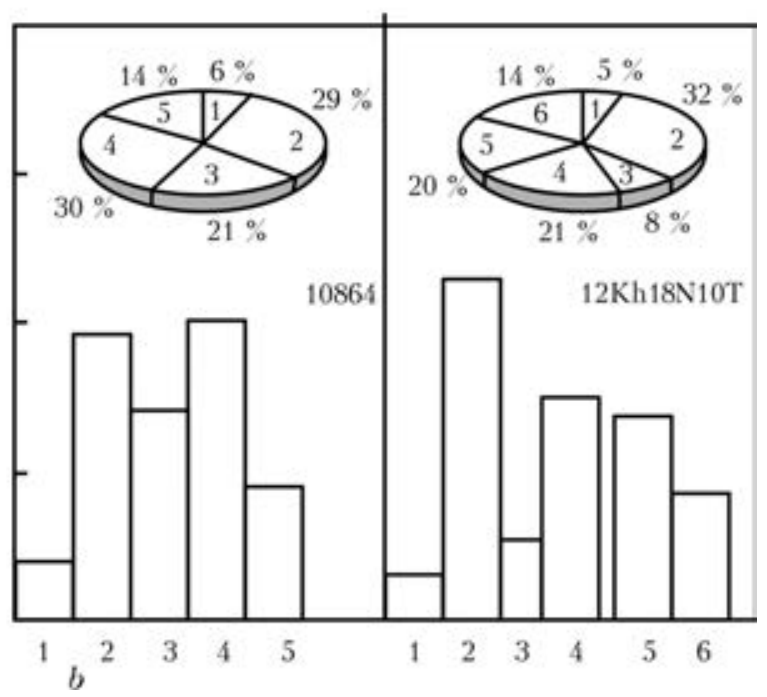

Figure 6. Effect of structural factors on metal yield strength and fraction of constituents of yield strength in joint butt during DW using traditional scheme at constant temperature $(a)$ and DW with temperature cycling $(b)$ in zone 0 : 1 $\Delta \sigma_{0} ; 2-\Delta \sigma_{\mathrm{s} . \mathrm{s}} ; 3-\Delta \sigma_{\mathrm{g}} ; 4-\Delta \sigma_{\mathrm{s}} ; 5-\Delta \sigma_{\mathrm{d}} ; 6-\Delta \sigma_{\mathrm{d} . \mathrm{s}}$ 
side of steel 10864 and steel 12Kh18N10T as well as because of rise of dislocation density and phase precipitates from the side of steel 12Kh18N10T.

Analytical estimation was not carried out in zone $B$ of the specimen, produced by DW with temperature cycling, since high quality of joint formation in this zone is out of doubts on any parameter.

The worst conditions of joint formation using traditional scheme of welding is observed in zone 0 , which has no shear deformations and oxide films are preserved. Fracture of specimen starts in this zone and it is, in particular, obvious at life duration testing.

Results of analytical estimation of joint strength in different zones of the joint butt are well correlated with the results of SSS modelling during DW and they confirm efficiency of DW with temperature cycling of dissimilar materials.

Developed technology was used for production of commercial products including welding of five parts on four ends simultaneously.

\section{Conclusions}

1. Experimental investigations of structure, distribution of microhardness in metal joints, caused by plastic strain, and analytical estimation of joint strength in different zones confirm the results of computer modelling of SSS, showing non-uniform distribution of plastic strains along the area of the joint butt in DW of dissimilar materials and different conditions of joint formation, including presence of zone of deformation stagnation.

2. Analytical estimation of effect of different structural factors on strength characteristics of metal showed that yield strength in the central zone of the joint butt (zone 0) has the lowest value from the side of steel 10864 as well as
$12 \mathrm{Kh} 18 \mathrm{~N} 10 \mathrm{~T}$ in DW of these steels using traditional scheme.

3. Sub-grains, grain and dislocation strengthening make the largest contribution in rise of metal yield strength of the same zone in DW with temperature cycling.

4. DW of dissimilar metals with temperature cycling allows controlling SSS, intensifying plastic strain over the joint butt, processes of resolidification and diffusion, and full strength of the joints with steel 10864 .

1. Kazakov, N.F. (1976) Diffusion welding of materials. Moscow: Mashinostroenie.

2. Derby, B. (1998) Solid state diffusion bonding: A joining and materials fabrication process. In: Vortrage und Posterbeitrage des 5. Kolloquium in der Hart- und Hochtemperaturloten und Diffusionsschweissen (Aachen 16-18 June 1998), 192, $100-103$

3. Lyushinsky, A.V. (2006) Diffusion welding of dissimilar materials. Moscow: Akademia.

4. Krasulin, Yu.L. (1971) Interaction of metals with semiconductors in solid phase. Moscow: Nauka.

5. Krasulin, Yu.L., Nazarov, G.V. (1976) Pressure microwelding. Moscow: Metallurgiya.

6. Ermolaev, G.V., Zhitnikov, N.P., Zabolotsky, V.M. et al. (1988) Vacuum diffusion welding of dispersionhardened heat-resistant alloys with gaskets. Sudostroit. Promyshlennost, Series Welding, Issue 6, 13-23.

7. Unksov, E.P. (1955) Engineering methods of calculation of efforts in pressure treatment of metals. Moscow: Mashgiz.

8. Tarnovsky, I.Ya., Levanov, A.N., Poksevatkin, M.I. (1966) Contact stresses in plastic deformation. Moscow: Metallurgiya.

9. Makhnenko, V.I., Kvasnitsky, V.V. (2009) Stressstrain state of assemblies of the cylindrical shape in diffusion bonding. The Paton Welding J., 2, 2-7.

10. Makhnenko, V.I., Kvasnitsky, V.V. (2009) Peculiarities of formation of stress-strain state in diffusion bonds between dissimilar materials. Ibid., 8, 7-11.

11. Bokshtejn, S.Z. (1971) Structures and properties of metal alloys. Moscow: Metallurgiya.

12. Goldshtejn, M.I., Litvinov, V.S., Bronfin, B.M. (1986) Physics of metals of high-strength alloys. Moscow: Metallurgiya. 


\title{
REGULARITIES OF CREATION OF MODIFIED INTERLAYERS IN USING OF HIGHLY-CONCENTRATED ENERGY FLOWS
}

\author{
V.F. KVASNITSKY ${ }^{1}$, V.V. KVASNITSKY ${ }^{2}$, N.N. CHERENDA ${ }^{3}$, N.N. KOVAL ${ }^{4}$ and I.L. LEVCHENKO ${ }^{2}$ \\ ${ }^{1}$ Admiral Makarov National Shipbuilding University \\ 9 Geroev Stalingrada Ave., 54025, Nikolaev, Ukraine. E-mail: welding@nuos.edu.ua \\ ${ }^{2}$ NTUU «Kiev Polytechnic Institute» \\ 37 Pobedy Ave., 03056, Kiev, Ukraine. E-mail: kvas69@ukr.net \\ ${ }^{3}$ Belarusian State University \\ 4 Nezavisimosti Ave., 220030, Minsk, Belarus. E-mail: cherenda@bsu.by \\ ${ }^{4}$ Institute of High Current Electronics, SB RAS
}

2/3 Akademichesky Ave., 634055, Tomsk, Russia. E-mail: contact@hcei.tsc.ru

\begin{abstract}
Radiation-beam technologies applied for modifying, including those with alloying of surfaces, provide necessary topography of surface, its activation, improvement of adhesion properties, required structure and chemical composition of the surface. These characteristics are further determining in diffusion welding, brazing and deposition of coatings. In the work the low-energy high-current electron beams and high-energy plasma flows for modifying and alloying of the joined surfaces of steels and heat-resistant alloys were used. These types of surface treatment belong to the radiation-beam technologies. The treatment was carried out using low-energy high-current electron beams in vacuum $10^{-2} \mathrm{~Pa}$ in the installation SOLO of the Institute of High Current Electronics of the SB RAS, and also high-energy plasma flows using magnetic plasma compressor of a compact geometry of the Belarusian State University at the pressure of hydrogen and nitrogen of $3 \cdot 10^{2} \mathrm{~Pa}$, and welding and brazing were performed in the installation UDSV-DT in vacuum of $10^{-2} \mathrm{~Pa}$ or super-high vacuum universal technological complex VVU-1D in vacuum of $10^{-5} \mathrm{~Pa}$. Independently of metals being investigated the formation of sub-microcrystalline structure, presence of high density of dislocations ( up to $10^{11} \mathrm{~cm}^{-2}$ ), appearance of stresses of the 3rd kind, being the evidence of immense increase in level of energy accumulated in modified layer, are characteristic for all the modified layers. The surfaces of heat-resistant nickel alloys were alloyed by zirconium and hafnium, which are the most challenging depressants of nickel brazing alloys. For this purpose the layers of alloying element of 1-3 $\mu \mathrm{m}$ thickness was deposited on the surface using method of ion-plasma spraying and then the surface layer was remelted using low-energy high-current electron beams and high-energy plasma flows. The investigations of processes of formation of modified and alloyed surfaces showed the possibility of efficient control of structure and composition of the modified layer. Diffusion welding in a solid state and with a melting interlayer provides the high quality of joints, which can be confirmed by the structures and mechanical properties of joints. The application of radiation-beam technologies allows expanding the capabilities of joining metals and hardening the materials. 13 Ref., 6 Figures.
\end{abstract}

Key words: surface modifying, electron beam, highpower plasma flow, diffusion welding, brazing

The operation parameters of the modern gas-turbine engines, products of the new engineering, can be increased by application of composite and dissimilar structural materials, and also technologies of formation of modified layers and coatings on their surface. For example, in manufacture of gas turbine blades the cast heat-resistant nickel alloys with corrosion-resistant and thermal barrier protective coatings are used. The serviceability of coatings, having a direct contact with the working environment, depends on strength of adhesion of alloys with a base, structure and relief of coatings. For joining of cast alloys dif- fusion welding is applied, including that with melting interlayers. The serviceability of joints and strength of adhesion of coatings with blades are considerably affected by activation of the surfaces being joined and coated. The challenging direction for increase of service life of parts is the modifying and alloying of their surfaces applying highly-concentrated energy pulsed sources [1-4]. In the recent years for modifying and alloying the low-power high-current electron beams (LHEB) and high-power plasma flows (HPF) are successfully used. The technologies for modifying and alloying of surfaces applying highly-concentrated sources of energy are generally called radiation-beam technologies (RBT) 

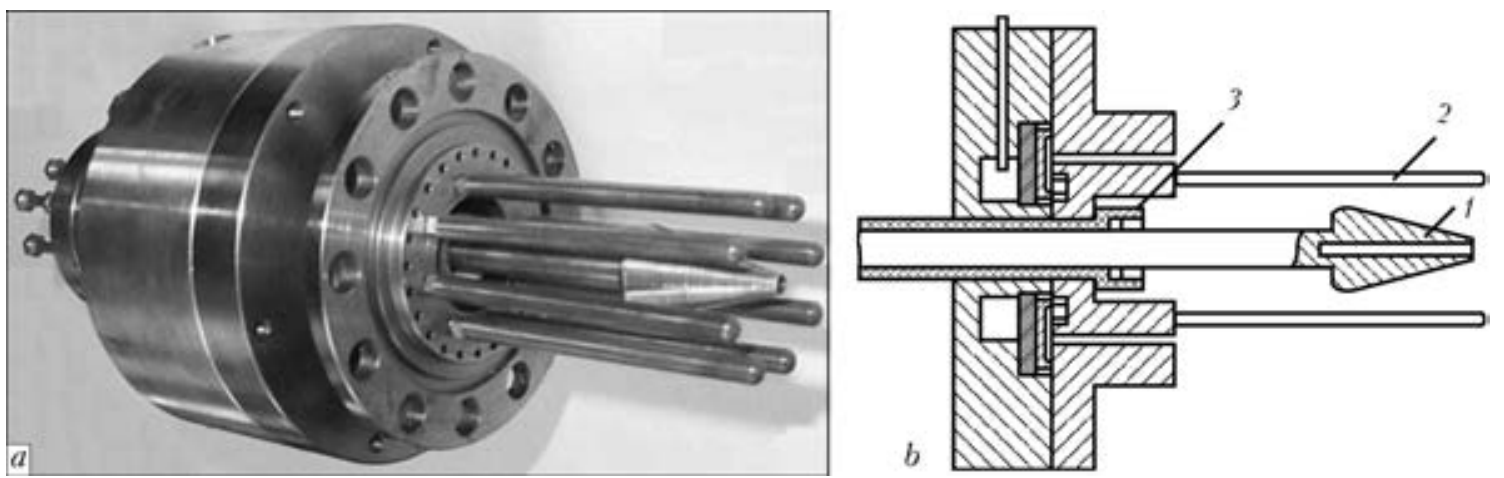

Figure 1. General appearance of discharge device MPCCG $(a)$ and its scheme $(b): 1-$ cathode; $2-\operatorname{rod}$ anode; $3-$ insulator

[1]. Due to application of RBT the change in topography of the surface, its activation, increase in adhesion capability, correction of surface defects, required chemical composition are provided, which are the decisive factors in the processes of deposition of coatings and joining of metals in the solid state using interlayers including melting ones.

The aim of the present investigations is the determination of regularities for creation of modified interlayers at the surfaces of materials applying LHEB and HPF, their influence on structure and properties of coatings, formation of joints of steels of different structural classes and heat-resistant nickel alloys.

The treatment of surfaces using LHEB was carried out in the installation SOLO of the Institute of High Current Electronics of the SB RAS, the design and principle of which are described in [2]. The modifying of surfaces was carried out in vacuum of $10^{-2} \mathrm{~Pa}$. The installation provides a super-rapid heating of surface of materials $\left(10^{6}-10^{9}{ }^{\circ} \mathrm{C} / \mathrm{s}\right)$ using electron beam of 10-30 mm diameter at the current of 20-200 A. The duration of a pulse was $50-150 \mu$ s, frequency of pulses was $1-5 \mathrm{~s}^{-1}$. The acceleration of electrons was provided by electric field at the voltage of $15-20 \mathrm{kV}$.

The modifying using HPF was carried out using magnetic plasma compressor of a compact geometry (MPCCG) of the Belarusian State University [3]. In the MPCCG the acceleration of plasma was performed in the axially-symmetrical system of two electrodes and accompanied by its compression due to interaction of longitudinal component of current with its own azimuth magnetic field (Figure 1). As a result, at the output of the discharge device the compression plasma flow of $10-12 \mathrm{~cm}$ length and up to $20 \mathrm{~mm}$ diameter in the field of maximum compression is formed.

Welding and brazing of the specimens with a modified surface was carried out in the installation for arc welding UDSV-DT in vacuum of
$10^{-2} \mathrm{~Pa}$ or in the super-high vacuum universal technological complex VVU-1D in vacuum of not worse than $10^{-5} \mathrm{~Pa}$ of the Admiral Makarov National Shipbuilding University.

By variation of distance from the cathode edge to the treated product from 6 to $12 \mathrm{~cm}$, the power density at the constant voltage on the capacitor battery of $3 \mathrm{kV}$ is changed from 15 to $21 \mathrm{~J} / \mathrm{cm}^{2}$ in one pulse. The duration of a pulse amounts to $100 \mu \mathrm{s}$. Cooling rate of a melt is $10^{6}-10^{9}{ }^{\circ} \mathrm{C} / \mathrm{s}$. Depending on the material of substrate and coating the HPF modifying was performed in the nitrogen or hydrogen atmosphere at the pressure of working environment of $3 \cdot 10^{2} \mathrm{~Pa}$. Before filling with gas the chamber is evacuated.

The main mechanism of surface modifying is a super rapid hardening, including also that from molten state, accompanied by amorphisation, formation of sub-microcrystaline structure, close to nanostructure, defects of crystalline lattice, stresses of the 3rd kind, change of chemical composition, etc.

Investigations of structure of the modified surface of steels and alloys showed that there is no difference between LHEB and HPF treatment as to the structure of metal. Figure 2 shows structures of base metal, modified layer of steel 10895 and also heat-resistant nickel alloy ChS88U-VI for comparison.

The analysis of results of investigations of structure and properties of modified surfaces of the investigated steels and alloys applying LHEB and HPF showed that they have a number of common regularities: formation of sub-microcrystalline structure, increase of density of dislocations, presence of treatment modes, providing smooth surface of the modified layer. High dispersion of structure (grains and subgrains), density of dislocations and stresses of the 3rd kind evidence of high level of energy, accumulated in the modified layer.

The investigated materials have also their own peculiarities influencing the results of modifying. 

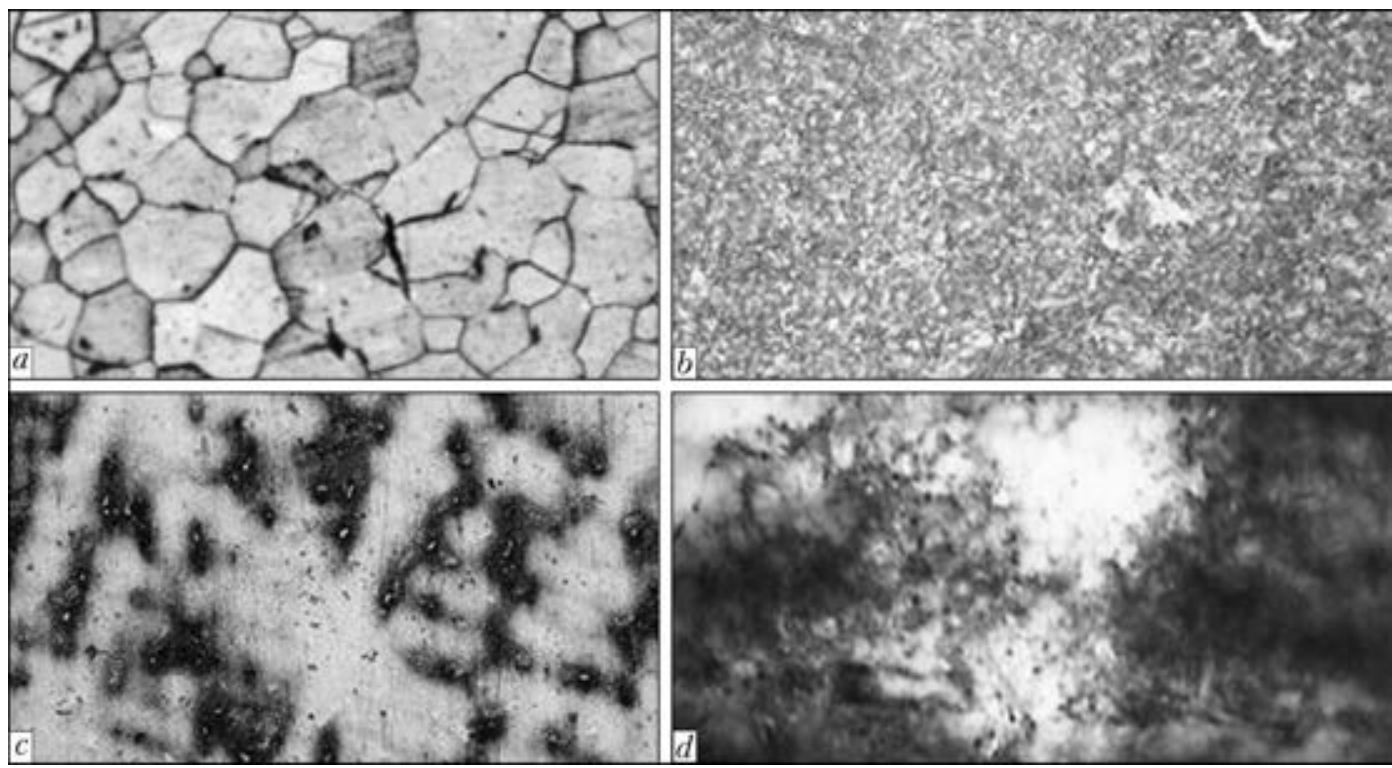

Figure 2. Microstructure of steel $10895(a-\times 160)$ and modified layer $(b-\times 250)$, alloy ChS88U-VI $(c-\times 50)$ and fine structure of LHEB-modified layer of the same alloy $(d-\times 30,000)$

On steel 10895 ( $\alpha$-Fe structure) the highest hardening of the surfaced modified layer (increase of hardness by $74 \%$ ) was obtained. On steel $12 \mathrm{Kh} 18 \mathrm{~N} 10 \mathrm{~T}$ ( $\gamma$-Fe structure) it is negligible (increase of hardness by $12 \%$ ), on the heat-resistant alloy microhardness decreased by $20 \%$. As far as phase composition of steels in modifying is not changed and dispersion of new structure of both steels is approximately the same, then, it is obvious that the level of hardening of these both metals is influenced by difference in energy of stacking defects, which is considerably lower for steel $12 \mathrm{Kh} 18 \mathrm{~N} 10 \mathrm{~T}$ (to $40 \mathrm{~mJ} / \mathrm{m}^{2}$ ) than for iron, containing some hundred percents of carbon $\left(140-240 \mathrm{~mJ} / \mathrm{m}^{2}\right)$. Here it should be considered also the fact that in hardening of steel $12 \mathrm{Kh} 18 \mathrm{~N} 10 \mathrm{~T}$ the amount of titanium carbides, influencing the hardness and ductility of steel, is decreased.

The reduction in microhardness of heat-resistant dispersion-hardening alloy after tempering from the molten state is, probably, predetermined by dissolution of the hardening $\gamma^{\prime}$-phase, which is precipitated not only in the process of holding of alloy at the temperature of ageing but also during cooling of a casting. It is characteristic that on the background of the general increase of level the highest densities of dislocations are formed along the boundaries of phase precipitates inside the matrix grains. Growth of stresses in the modified surfaces is proved also by the type of microdiffraction reflections having azimuthal diffuse of reflexes.

The investigation of a thin structure of alloy ChS88U-VI showed that the same as in the base metal, the dispersion of the hardening phase in the modified layer is not similar in different areas. In the modified layer both coagulation of hardening phase as well as formation of fine-dispersed particles of the sizes of $0.1 \mu \mathrm{m}$ under the effect of thermal shock are possible.

The influence of modified surfaces on the formation of joints was investigated using diffusion welding of the following specimens: specimens, where both joining surfaces were modified by LHEB and HPF treatment; specimens, where both surfaces not subjected to modifying, were cleaned before welding using fine abrasive paper, and also specimens, where surface of one of them was modified and another one was cleaned using abrasive paper.

The investigations of microstructure of metal of ChS88U-VI welded joints with both surfaces, cleaned with abrasive, showed that the depth of zone of active running of processes in joining of non-modified surfaces is small and equal to 20$45 \mu \mathrm{m}$ on both sides from the butt. Along the butt the volumetric fraction of recrystallized grains amount to about $10 \%$. Microhardness of metal on both sides of the butt is equal on average to $3860 \mathrm{MPa}$.

In joining of specimens of alloy ChS88U-VI with modified and mechanically prepared surfaces the depth of zone of active processes of recrystalliziation on the side of modified surface grows to $80-120 \mu \mathrm{m}$. The volumetric fraction of recrystallized grains along the butt on the side of modified surface amounts to $45 \%$, microhardness is equal to $4120-4410 \mathrm{MPa}$, size of grains is changed from $50 \times 85$ to $120 \times 350 \mu \mathrm{m}$. The volumetric fraction of recrystallized grains on the non-modified side amounts to $10 \%$, micro- 


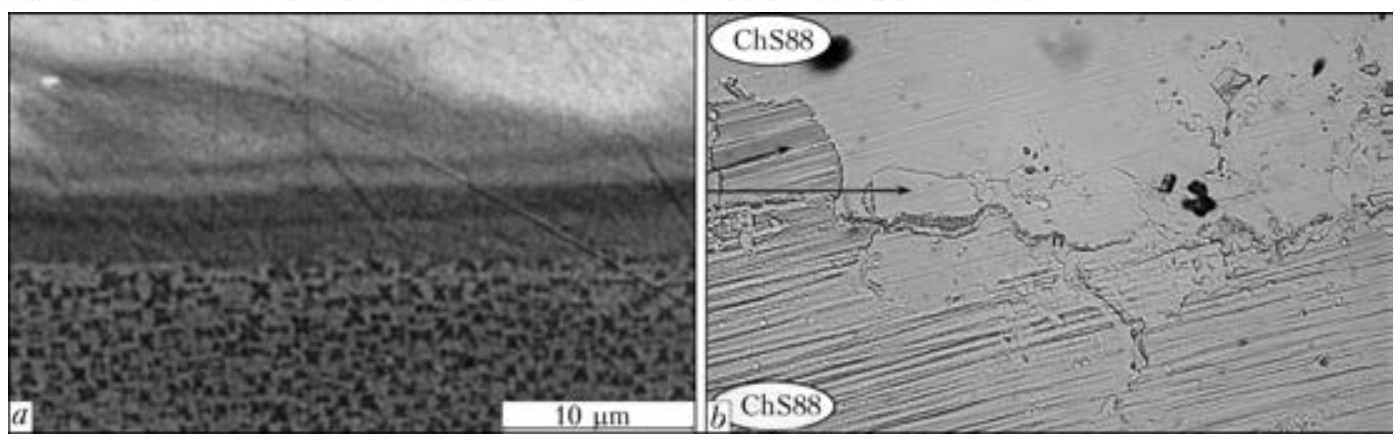

Figure 3. Microstructure of modified layer of alloy ChS88U-VI $(a)$ and welded joint $(b-\times 500)$

hardness is $3910-4400 \mathrm{MPa}$, size of grains is changed from $20 \times 40$ to $40 \times 125 \mu \mathrm{m}$.

The peculiarity of structure in the zone of butt of modified and non-modified surfaces is the presence of a great number of common fine grains in a butt, that are good seen at great magnifications in radiographic control of foil.

The microstructure of modified layer and metal of ChS88U-VI welded joint with both modified surfaces is presented in Figure 3. The size of grains in the butt zone is in the range from $25 \times$ $\times 50$ to $100 \times 180 \mu \mathrm{m}$, the depth of zone of intensive recrystallization is equal to $100-170 \mu \mathrm{m}$.

Having compared the structure of welded joints in the zone of butt of the alloy ChS88U-VI, it should be noted that recrystallization of metal is running more intensively and completely in the zone of modifying. The fracture of welded joints occurs on the base metal. The given results were obtained by diffusion welding at the temperature of $1150{ }^{\circ} \mathrm{C}$ and pressure of $20 \mathrm{MPa}$ with 3 min holding, which is considerably lower than the parameters of the mode recommended for heat-resistant alloy in [5, 6]. For example, for dispersion-hardening alloy EP99 the optimally recommended are $T_{\mathrm{w}}=1150-1175{ }^{\circ} \mathrm{C}, P=40-$ $35 \mathrm{MPa}, t_{\mathrm{w}}=6 \mathrm{~min}$, for austenite alloy EI602 $T_{\mathrm{w}}=1150-1175{ }^{\circ} \mathrm{C}, P=30-25 \mathrm{MPa}$, for alloy $\operatorname{VZh} 98 T_{\mathrm{w}}=1175-1200^{\circ} \mathrm{C}, P=20-25 \mathrm{MPa}, t_{\mathrm{w}}=$ $=30 \mathrm{~min}$.

The characteristic feature of LHEB and HPF treatment of dispersion-hardening heat-resistant nickel alloys is the crack formation, the amount and sizes of which depend on power density and vary from micro- to macrosizes. This is obviously connected with a low technological strength of alloys, determining the resistance to formation of hot cracks in fusion welding. Improvement of resistance against hot cracks facilitates the decrease in energy input of welding. During decrease in energy density and increase in a number of pulses, a number of cracks is decreased, and at energy density of $15 \mathrm{~J} / \mathrm{cm}^{2}$ it is possible to succeed in avoiding them, but even at the presence of cracks after modifying they are absent in welded joint [7].

In the course of investigations of influence of HPF treatment of surfaces on the preliminary deposited plasma surfaces, it was established that for modifying of corrosion-resistant sublayer (SDP-8) the energy density of $15-21 \mathrm{~J} / \mathrm{cm}^{2}$ can be recommended, and for thermal barrier $\left(\mathrm{ZrO}_{2}\right.$ stabilized by $\mathrm{Y}_{2} \mathrm{O}_{3}$ ) it should be not more than $15 \mathrm{~J} / \mathrm{cm}^{2}$. Here the smoothing of relief $\left(\mathrm{Fi}^{-}\right.$ gure 4) and packing of a thin, up to $10 \mu \mathrm{m}$, surfaced layer are observed, thus contributing to increase of erosion resistance of coating in the process of service.

The investigations of composition of modified layer using $\mathrm{X}$-ray spectral analysis from the surface showed that its chemical composition is close to the composition of base metal. HPF treatment of thermal barrier coatings in $\mathrm{H}_{2}$ environment results in formation of a glittering surface layer, and in the environment of $\mathrm{N}_{2}-$ in formation of nitrides.

The surfaces of alloy ChS88U-VI were alloyed with elements decreasing the temperature of melting of the surface layer. It is known [8-11] that brazing alloys with zirconium and hafnium at comparatively low concentrations do not negatively influence the properties of heat-resistant

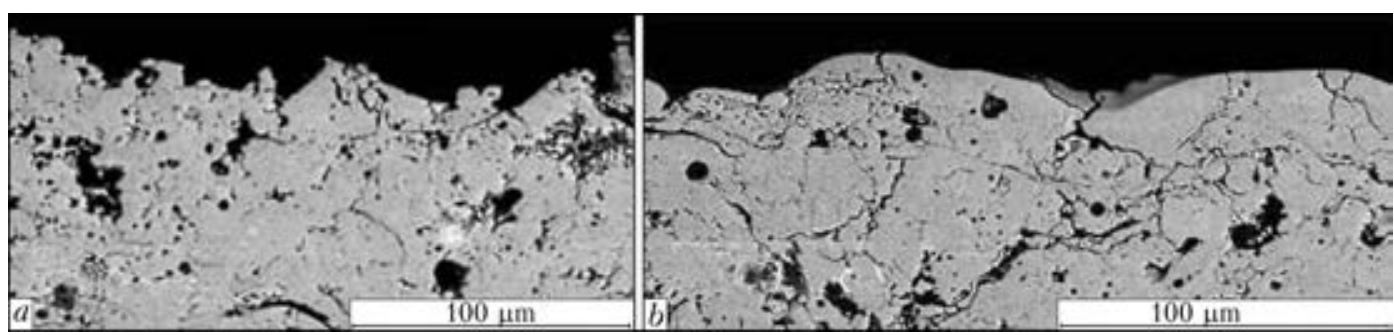

Figure 4. Microstructure of thermal barrier plasma coating before $(a)$ and after $(b)$ HPF treatment 

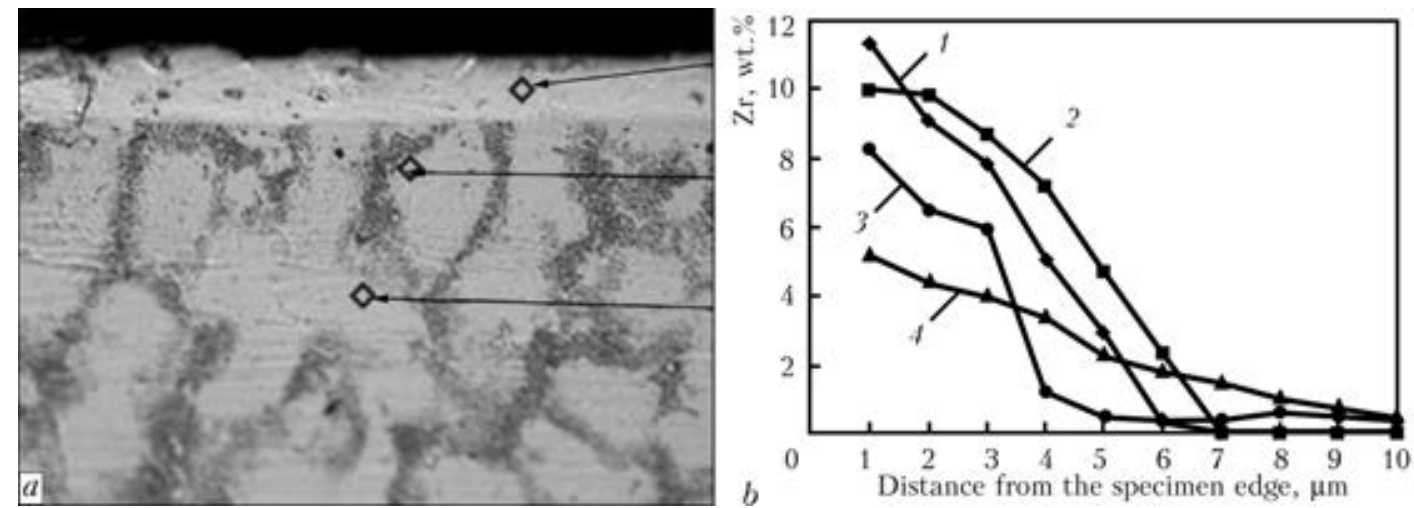

Figure 5. Microstructure $(a-\times 500)$ of Zr-alloyed surface layer of alloy ChS88U-VI, and distribution of zirconium concentration $(b)$ at different modes of HPF treatment (1-4)

nickel alloys and provide high mechanical properties to the joints. In the alloys of ChS70 type zirconium negligibly decreases and hafnium increases the resistance against high-temperature salt corrosion.

Investigations of modified surfaces showed that formation of fused layer depends, in the first turn, on thickness of sprayed layer of the alloying element, energy density, number of pulses. Microstructure of the modified layer and distribution of the alloying element in the layer at different modes of treatment are shown in Figure 5.

At one and the same thickness of the sprayed alloying element and growth in number of pulses, the uniformity of distribution of zirconium and hafnium is increased, but their concentration at the surface of layer is decreased. As is seen from Figure 5, concentration of zirconium near the surface is close to eutectics one only for curves 1 and 2. At the same time it is known $[8,12]$ that in nickel alloys the eutectic concentration of hafnium is somewhat decreased as compared to the $\mathrm{Ni}-\mathrm{Hf}$ system. At high rates of cooling $\left(10^{4}\right.$ $10^{5}{ }^{\circ} \mathrm{C} / \mathrm{s}$ ) the equivalent concentration of hafnium is widened and temperature of melting is decreased to $1178{ }^{\circ} \mathrm{C}$. Besides, it is established that melts filling interdendritic capillaries of super-strength nickel alloys even at 16 wt.\% Hf represent eutectics $\mathrm{Ni}_{a_{11}}-\mathrm{Ni}_{5} \mathrm{Hf}$ [13]. The similar effect can be also present in the system $\mathrm{Ni}_{\text {all }}-\mathrm{Zr}$. In any case at $1200{ }^{\circ} \mathrm{C}$ the liquid in a butt is sufficient even to form fillets.

At the compression pressure of $10-15 \mathrm{MPa}$ in joint of alloys ChS88U-VI the butt is not revealed in the microstructure (Figure 6, $a$ ). Distribution of microhardness in the joint area is shown in Fi-
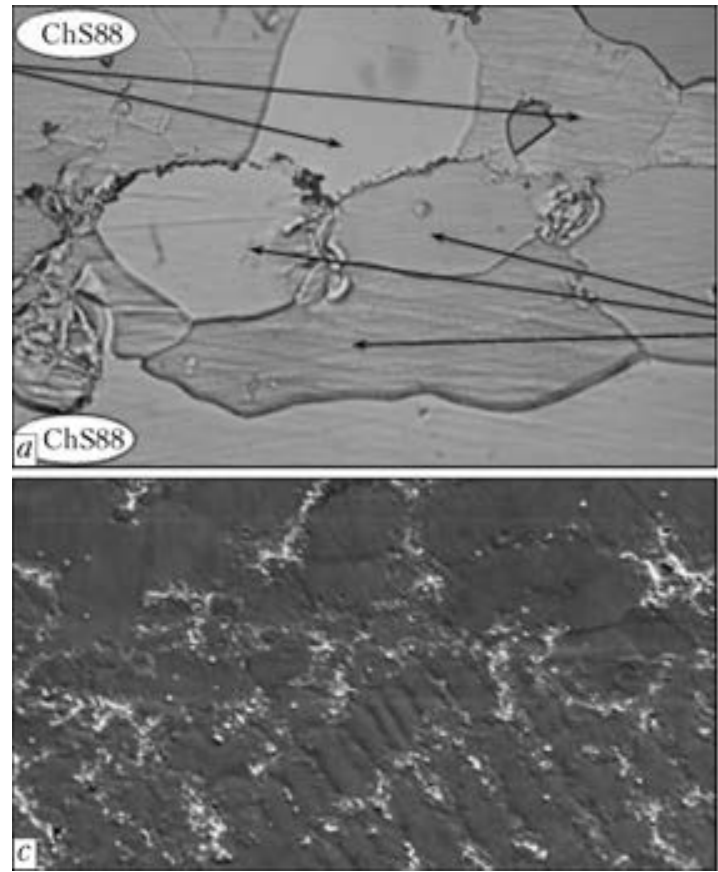
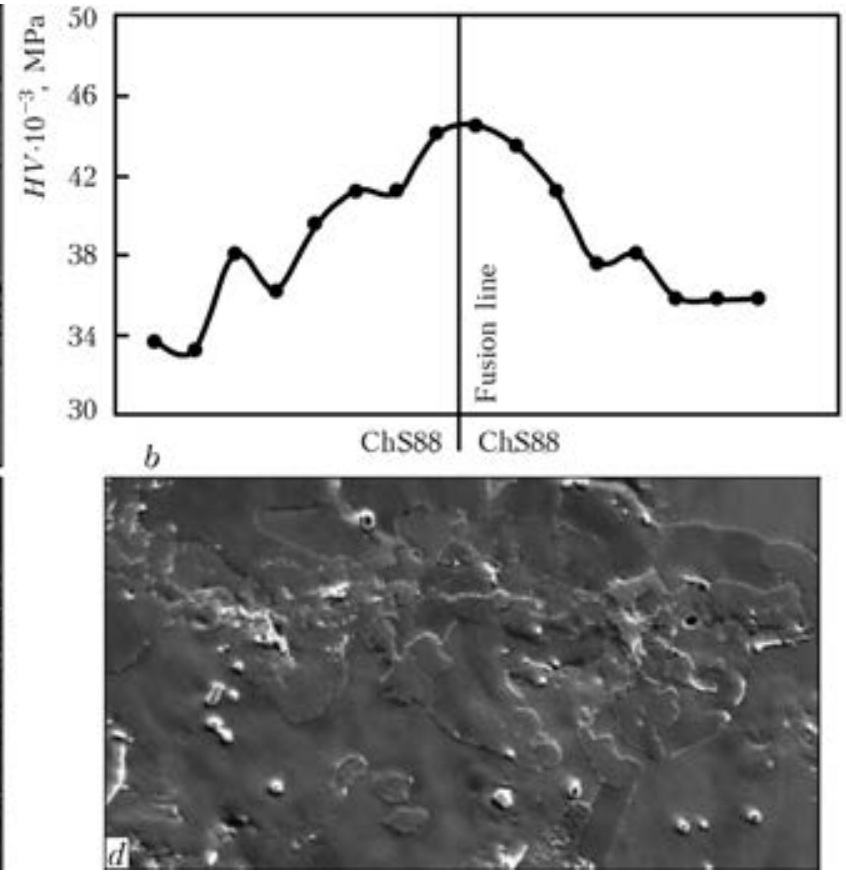

Figure 6. Microstructure of joint with Zr-alloyed surfaces of alloy ChS88U-VI in brazing under pressure $(a-\times 500)$, integral distribution of microhardness $(b)$, microstructure of joints with after heat treatment, Hf- $(c-\times 150)$ and Zr-alloyed $(d-\times 300)$ surfaces 
gure $6, b$, and the structure of welded joints with surfaces alloyed with hafnium and zirconium after heat treatment - in Figure 6, $c, d$.

Investigations of structure of joints of alloy ChS88U-VI showed that in the butt zone the structure is formed similar to the structure of base metal. Mechanical tests confirmed the high quality of joints both at modified and also at alloyed surfaces. The tensile strength of joints at $900{ }^{\circ} \mathrm{C}$ is not lower than $90 \%$ of base metal.

Similar results were obtained also in joining with alloyed surfaces of alloy Inconel 718. The tensile strength of the joints at the test temperature of $550{ }^{\circ} \mathrm{C}$ exceeded $900 \mathrm{MPa}$, which is $90 \%$ higher than the strength of base metal, and in fatigue test at $785{ }^{\circ} \mathrm{C}$, standard stresses and duration, the welded specimens were released without fracture.

Therefore, LHEB and HPF treatment of materials surface provides formation of a necessary topography, structural, chemical and phase composition of surface layers, being the main factors for formation of quality joints in arc welding and deposition of coatings.

The layers modified using LHEB and HPF are characterized by a high density of dislocations (to $10^{11} \mathrm{~cm}^{-2}$ ), increased level of stresses of the 3rd kind and also high level of intergranular energy, that positively effects the formation of joints in arc welding and deposition of plasma coatings. Smoothing of surface and packing of structure of the HPF-modified layer of thermal barrier coatings facilitates the improvement of their erosion resistance in the process of operation.

The application of HPF is the challenging trend in development of diffusion welding, brazing and deposition of coatings.

The work was performed with the help of partial financial support of grants of the Ukrainian State Fund for Fundamental Research ( $F$ 28/429, F 41/191), Russian Fund ( Ukr f a 0902-90456), Belarusian Republican Foundation of Fundamental Research (F11K-049).
1. Gribkov, V.G., Grigoriev, F.I., Kalin, B.A. et al. (2001) Advanced radiation-beam technologies for treatment of materials: Manual. Ed. by B.A. Kalin. Moscow: Krugly God.

2. Kvasnitskii, V.V., Kuznetsov, V.D., Koval, N.N. et al. (2009) A high-current electron beam application for the surface modification of iron. Stainless steel and heat resistant alloys. Surface Eng. and Applied Electrochem., (45)3, 180-185.

3. Kvasnitsky, V.F., Kvasnitsky, V.V., Cherenda, N.N. et al. (2011) Effect of surface modification using concentrated energy beams on formation of solid phase joints. In: Proc. of 9th Int. Conf. on Interaction of Emissions with Solid (Minsk, 20 Aug.-2 Sept., 2011), 228-230. Minsk: Tsentr BGU.

4. Belov, A.B., Britsenko, O.A., Krajnikov, A.V. et al. (2012) High-current pulsed electron beams for aeronautical engine engineering. Moscow: DIPAK.

5. Musin, R.A., Antsiferov, V.N., Kvasnitsky, V.F. (1979) Diffusion welding of heat-resistant alloys. Moscow: Metallurgiya.

6. Ermolaev, G.V., Zhitnikov, N.P., Zabolotsky, V.M. et al. (1988) Vacuum diffusion welding of dispersion-hardened heat-resistant alloys with inserts. Sudostroit. Promyshlennost, Series Welding, Issue 6, 13-23.

7. Cherenda, N.N., Uglov, V.V., Kvasnitsky, V.F. et al. (2014) Elemental composition of surface layer of heat-resistant nickel alloy alloyed with zirconium atoms under action of compression plasma flows. $P_{O^{-}}$ verkhnost. Rentgen., Sinkhron. i Nejtron. Issledov., 2, 74-79

8. Khorunov, V.F., Ivanchenko, V.G., Kvasnitsky, V.V. (1999) Structure and phase composition of $\mathrm{Ni}-\mathrm{Cr}-\mathrm{Zr}$ and $\mathrm{Ni}-\mathrm{Cr}-\mathrm{Hf}$ alloys applied as braze filler materials. Avtomatich. Svarka, 11, 14- 21 .

9. Kvasnitsky, V.F., Kostin, A.M., Kvasnitsky, V.V. (2002) Effect of elements-depressants on properties of nickel braze materials and heat-resistant alloys. Adgeziya Rasplavov i Pajka Materialov, 35, 129-139.

10. Lugscheider, E., Bushke, I., Daichend, D.M. et al. (1998) Evaluiring des Eizatzpotential und rostfreien Edelstahlen. In: Vortrage und Posterbeitrage des 5. Kolloquium in der Hart- und Hochtemperaturloten und Diffusionsschweissen (Aachen, 16-18 June, 1998), 192, 242-245. Duesseldorf: DVS.

11. Zeng Yun-Rong, Ca Yu-Lin, Ruan Zong-Ci et al. (2006) Investigation of effect mechanism of hafnium and zirconium in high temperature materials. J. Aeronaut. Mat., 26(3), 25-34.

12. Sircars, S., Mazumder, J. (1989) Microstructure evolution and nonequilibrium phase diagram $\mathrm{Ni}-\mathrm{Hf}$ binary alloy produced by laser cladding. Acta Metallurgica, 37(1), 1167-1176.

13. Zehg, Y., Ruan, Z. (1990) Microstructure and performance of $\mathrm{Ni}-\mathrm{Hf}$ brazing filler alloy. Acta Metall. Sinica, 10, 335-340. 


\title{
STRESS-STRAIN STATE AT FORCE AND TEMPERATURE LOADING OF ASSEMBLES FROM DISSIMILAR STEELS WITH SOFT INTERLAYER
}

\author{
I.A. KOLESAR and G.V. ERMOLAEV \\ Admiral Makarov National Shipbuilding University \\ 9 Geroev Stalingrada Ave., 54025, Nikolaev, Ukraine. E-mail: welding@nuos.edu.ua
}

\begin{abstract}
We have studied the stress-strain state (SSS) at loading by compression and temperature variation, in order to optimize the process of diffusion welding and brazing of assembles from dissimilar materials with soft interlayers. Materials having different thermal coefficient of linear expansion (TCLE) and the same moduli of elasticity were joined. An example of such joints can be those of magnetic and nonmagnetic steels produced with application of diffusion welding with soft interlayers or pressure brazing using filler metals based on copper with silicon, manganese and boron additives. Sufficient strength of materials in the brazed assembly is combined with plastic deformation of just the interlayer. Fields of all the components of stresses and strains, as well as their diagrams in different assembly sections were studied. Analysis of simulation results showed that tangential and equivalent stresses in the butt zone (on the interface), determining formation of physical contact and activation of the process of joint formation in diffusion welding, at simultaneous loading of assemblies with a soft interlayer rise considerably in material with higher TCLE at cooling and in material with lower TCLE at heating. Distribution of plastic deformations in the interlayer is more uniform, i.e. thermal cycling under pressure promotes formation of physical contact and activation of processes of joint formation in such assembles. 8 Ref., 10 Figures.
\end{abstract}

$\boldsymbol{K} \boldsymbol{e} \boldsymbol{y} \boldsymbol{w} \boldsymbol{o} \boldsymbol{d} \boldsymbol{s}:$ diffusion welding, brazing, dissimilar materials, soft interlayers, SSS simulation, temperature and force loading

Diffusion welding (DW) and brazing are the main methods to join many materials, which cannot be joined by fusion welding in connection with the loss of their structure and properties.

One of the important problems of joining dissimilar materials by these methods is plastic deformation and activation of the stronger material surface. The existing problems are solved through application of DW with intermediate interlayers and with controlled stress-strain state (SSS) [1]. In the case of application of brazing, the braze metal proper often is the intermediate interlayer, which can have different physico-mechanical properties both before brazing, and after interaction with the base material.

Over the recent years a lot of attention has been given to studying the SSS in DW and brazing of assembles from dissimilar materials [2-7], that is why investigation of the influence of strength ratios of materials being joined and the interlayer on SSS of the assembles and establishing the general regularities is urgent.

The objective of this work is determination of the influence of low strength of material of intermediate interlayers, compared to that of materials being joined (soft interlayers) and SSS

(C) I.A. KOLESAR and G.V. ERMOLAEV, 2014 formation both during DW and during cooling after welding and brazing.

Investigations were conducted by computer simulation method with application of licence ANSYS software (version 10). Axisymmetric problems were solved with application of finite elements (FE) of PLANE 182 type. Adequacy of simulation results was tested experimentally [8].

Assembly types most often encountered at DW and brazing were studied, namely bushingbushing $(\mathrm{B}-\mathrm{B})$ and cylinder-cylinder $(\mathrm{C}-\mathrm{C})$ type. The latter type of assembly can be regarded as a particular case of the first one, when inner diameter is turned to zero. General view of physical and FE models is shown in Figure 1. Interlayer thickness was taken to be equal to $1 \mathrm{~mm}$, total height of all the assembles $2 h-20 \mathrm{~mm}$, cylinder radius and bushing thickness $-10 \mathrm{~mm}$.

Investigations were performed on assembles from materials of the same rigidity (modulus of elasticity $E=2 \cdot 10^{5} \mathrm{MPa}$ ) and strength (yield point $\sigma_{y} \geq 200 \mathrm{MPa}$ ) with interlayers of the same rigidity, but lower strength than that of base materials $\left(\sigma_{\mathrm{y}}=38 \mathrm{MPa}\right)$. For material 1 thermal coefficient of linear expansion (TCLE) $\alpha \cdot 10^{6}=$ $=20 \mathrm{deg}^{-1}$; for material $2-10$; for interlayer 15. Material phisico-mechanical properties and load level were selected so that only interlayer material was plastically deformed, and deformation affected the greater part of interlayer.

Force (compression up to $40 \mathrm{MPa}$ ), temperature (cooling by $100{ }^{\circ} \mathrm{C}$, when SSS is induced due to 

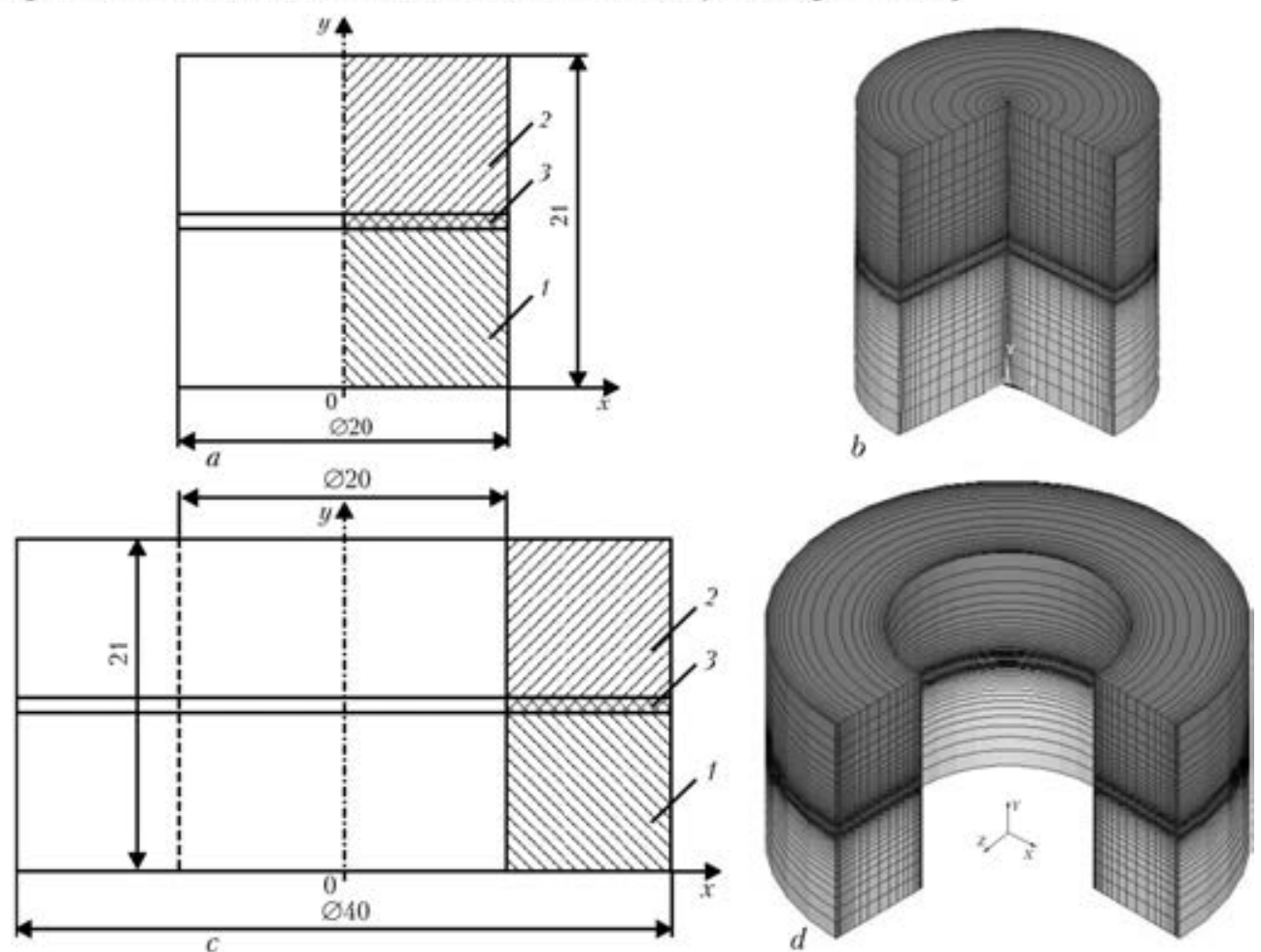

Figure 1. Physical $(a, c)$ and FE $(b, d)$ models of assemblies of $\mathrm{C}-\mathrm{C}(a, b)$ and $\mathrm{B}-\mathrm{B}(c, d)$ type with an interlayer: 1 , 2 - materials 1 and 2 , respectively; 3 - interlayer

difference in TCLE of materials being joined) and simultaneous temperature-force loading of the assembly (after joint formation) was considered. It is obvious that results obtained at such a loading are found also when cooling is replaced by heating (in welding with thermal cycling), but materials 1 and 2, having different TCLE, will change places in this case. Simulation results were compared with those for similar assembles at different kinds of loading and with each other.

Fields and diagrams of all the components of stresses and plastic deformations of assemblies were analyzed. As shown by analysis of results of simulation in $\mathrm{C}-\mathrm{C}$ and $\mathrm{B}-\mathrm{B}$ assemblies, the nature of SSS on the whole corresponds to general principles of mechanics and earlier established regularities [2, 5-7]. Here, SSS of $\mathrm{C}-\mathrm{C}$ and $\mathrm{B}-\mathrm{B}$ assemblies differs only near the bushing inner surface, which is absent in $\mathrm{C}-\mathrm{C}$ assemblies. Therefore, Figures 2-4 give only the fields in B-B assembles.

In the interlayer region a bulk stressed state is induced, which is the most clearly expressed at temperature and simultaneous temperatureforce loading. At purely force loading, the stressed state changes only slightly, remaining close to the linear one.

In assemblies of both types, the effects of temperature and force loading are summed up algebraically, as a result of which the fields of radial and circumferential stresses remain practically the same, as at purely temperature loading. Axial
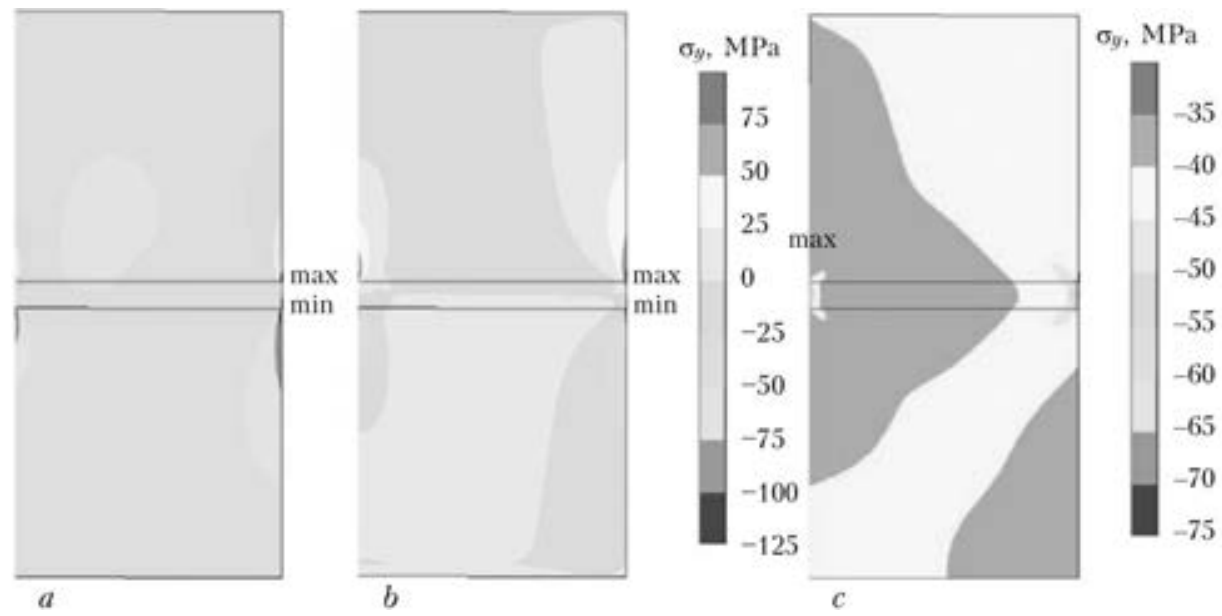

Figure 2. Fields of axial stresses in assemblies B-B with soft interlayer at temperature-force $(a)$, temperature $(b)$ and force $(c)$ loading 

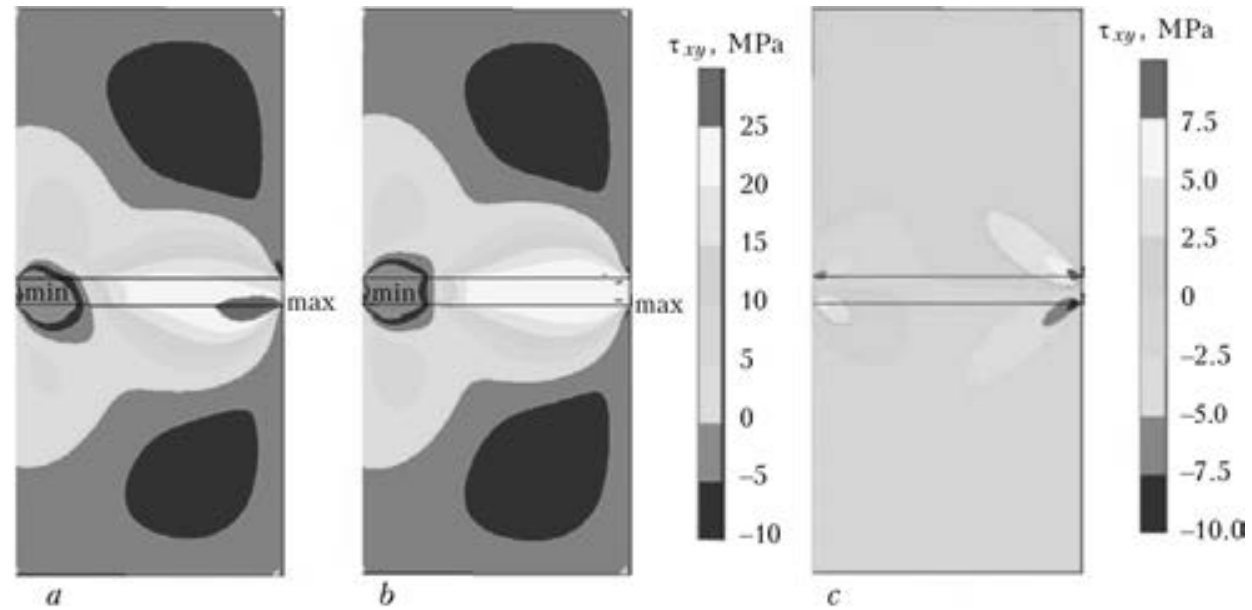

Figure 3. Fields of tangential stresses in assemblies B-B with soft interlayer at temperature-force $(a)$, temperature $(b)$ and force $(c)$ loading

compressive stresses in material 1 increase, and tensile stresses in material 2 decrease by the magnitude of compressive load (see Figure 2).

Tangential stresses are noticeably increased on the interface of the soft interlayer and material 1 and decrease on the interface with material 2 (see Figure 3), compared to purely temperature loading. Here, algebraic summation of effects due to the difference of TCLE and plastic deformation of the interlayer is clearly manifested.

Field of equivalent stresses changes in a similar fashion (see Figure 4). The latter noticeably rise in material 1 and decrease in material 2 at simultaneous loading compared to purely temperature loading.

The field of plastic deformations also changes in keeping with equivalent stresses (Figure 5). Similar to purely temperature loading, the maximum of deformations is concentrated near the assembly outer surface, but their distribution across the interlayer thickness changes markedly. They are maximum at the interface with material 1 and decrease with increasing distance from it.

Shape of diagrams of distribution of radial, circumferential and tangential stresses in the ma- terials being joined at simultaneous temperature and force loading coincides with the shape of the respective diagrams at purely temperature loading. Maximum radial stresses in materials being joined decrease by 15-20 $\mathrm{MPa}$, and circumferential stresses - by 10-15 MPa. Diagrams of axial stresses shift towards compression by $40 \mathrm{MPa}$ (Figure 6).

Maximum tangential stresses near the outer cylindrical surface increase from the side of material 1 by $10 \mathrm{MPa}$ (Figure 7, $a$ ) and decrease by $10 \mathrm{MPa}$ from the side of material 2 (Figure $7, b$ ).

Diagrams of equivalent stresses change accordingly. The level of these stresses increases by the magnitude of applied pressure of $40 \mathrm{MPa}$ in material 1 and decreases by $40 \mathrm{MPa}$ in material 2 (Figure 8). Their distribution in both the materials being joined remains close to the uniform one.

In the soft interlayer material, which is plastically deformed, the magnitude of equivalent stresses remains on the level of about $40 \mathrm{MPa}$ from the side of material 2 on the greater part of the joint. From the side of material 1 the distribution is nonuniform with clearly outlined stagnation zones (near axis of assemblies $\mathrm{C}-\mathrm{C}$
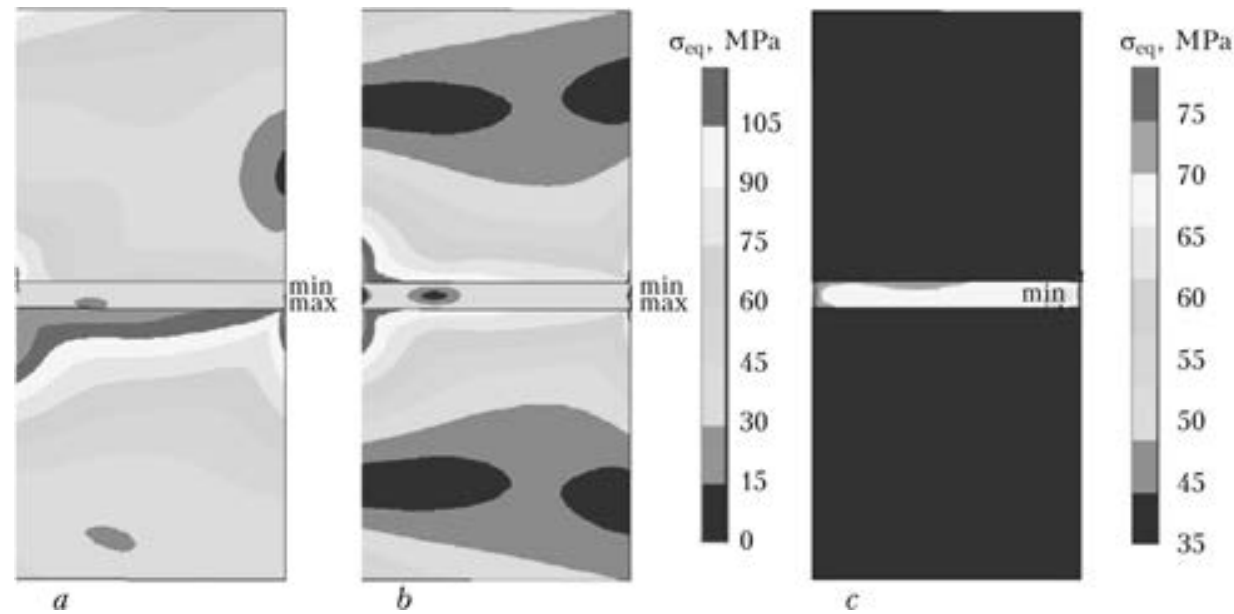

Figure 4. Fields of equivalent stresses in assemblies B-B with soft interlayer at temperature-force $(a)$, temperature $(b)$ and force $(c)$ loading 
Welding Production Chair of Admiral Makarov National Shipbuilding University

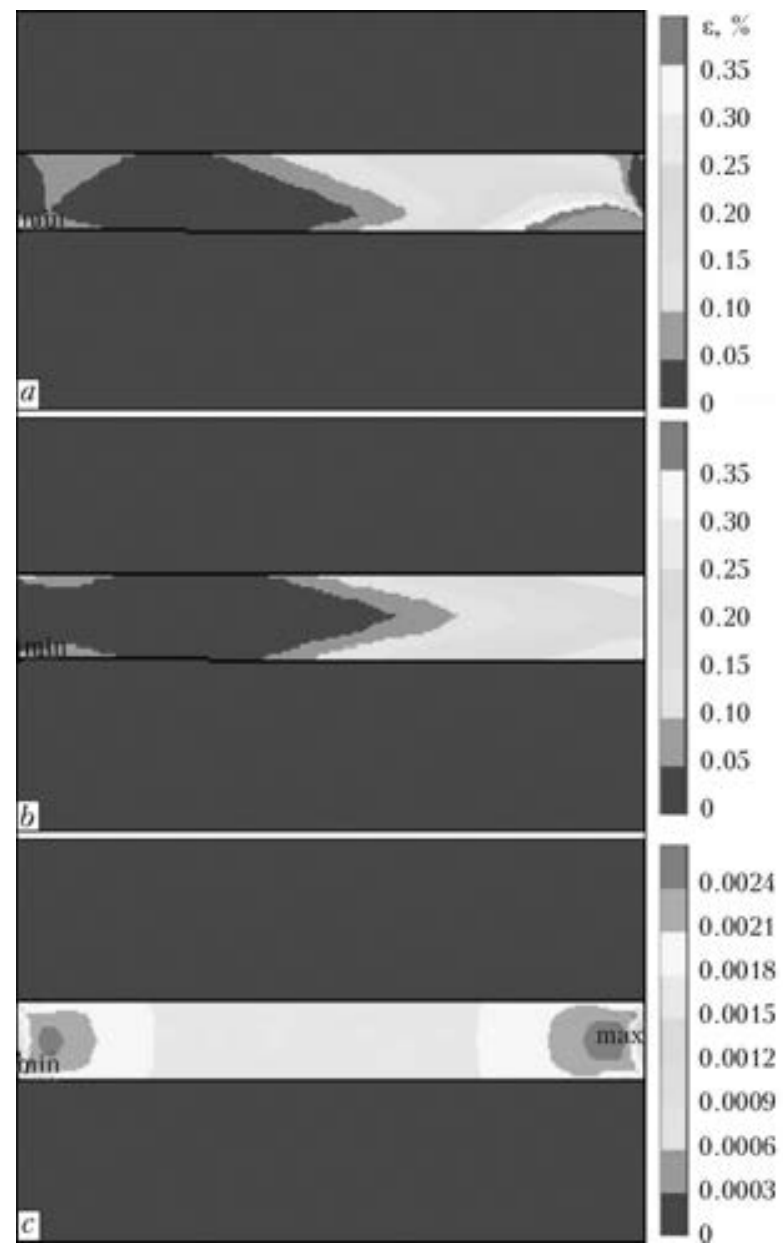

Figure 5. Fields of plastic deformations in soft interlayer of assemblies B-B at temperature-force (1), temperature (2) and force (3) loading

and at $1 / 3$ of thickness from inner side of assemblies B-B), in which equivalent stresses drop to 10-25 MPa. Near the assembly outer surface they, contrarily, rise owing to work hardening at high plastic deformations.
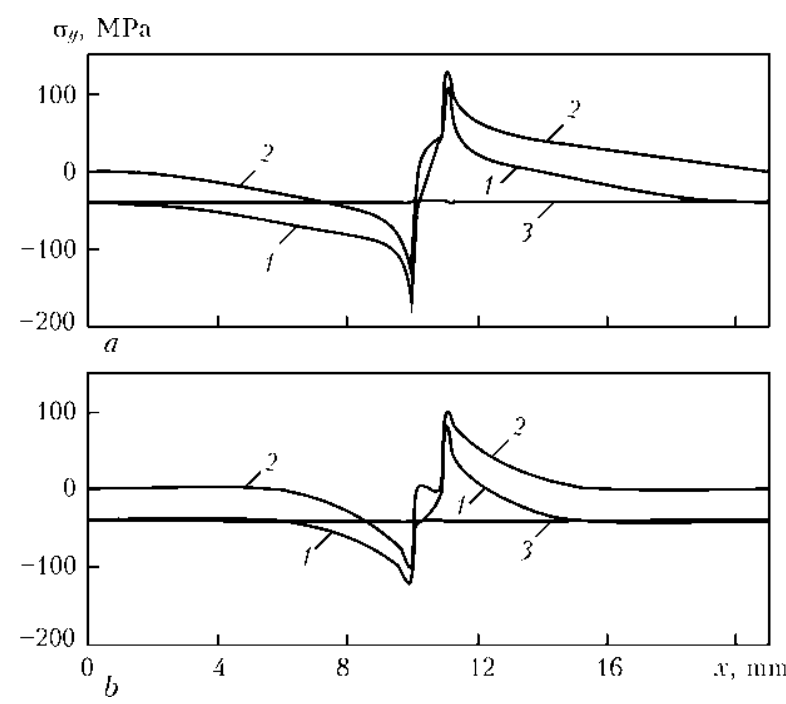

Figure 6. Axial stress diagrams along outer $(a)$ and inner (b) surfaces of assembly B-B with soft interlayer at temperature-force (1), temperature (2) and force (3) loading
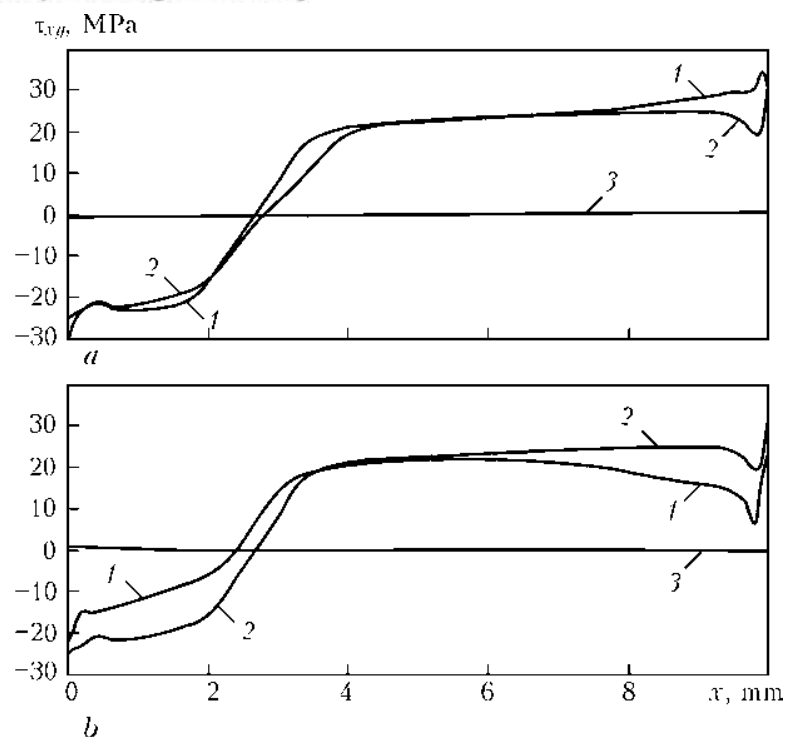

Figure 7. Diagrams of tangential stresses along the interfaces of materials $1(a)$ and $2(b)$ being joined with interlayer in assemblies B-B at temperature-force (1), temperature (2) and force (3) loading

Analysis of plastic deformation diagrams in the soft interlayer material also shows that they are distributed nonuniformly, rising gradually from those close to 0 in the stagnation zone up to $1 \%$ and more near the outer surface. Here, on the boundary with material 1 in this zone they are several times higher at simultaneous loading than at purely temperature loading (Figure 9, $a$ ). On the boundary with material 2 , contrarily, their distribution is more uniform than at purely temperature loading (Figure 9, b), but their level is lower.

Thus, simultaneous force (compression) and temperature (cooling) loading creates more favourable conditions for inducing plastic deformations in the soft interlayer than the purely thermal loading does. From the side of material 1 (with higher
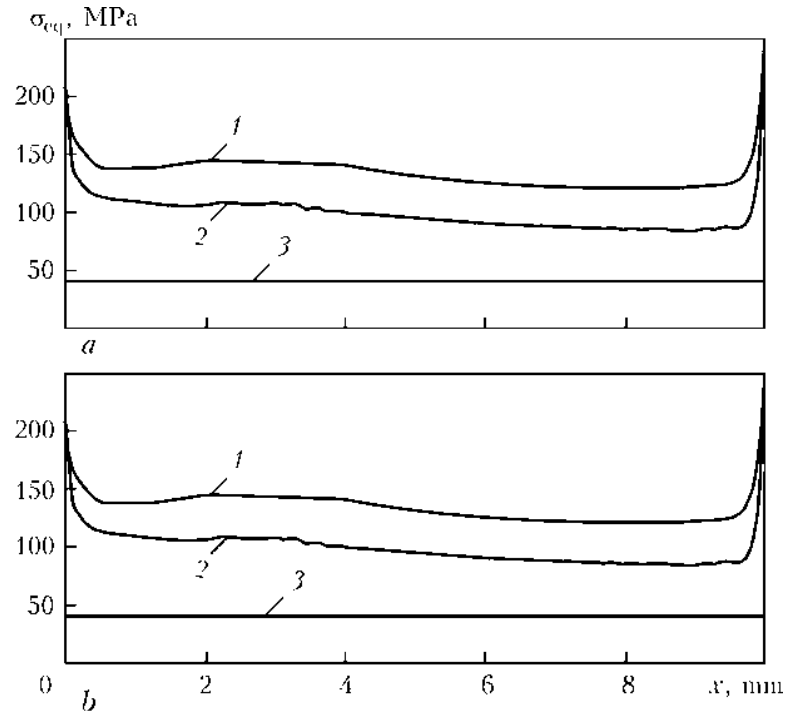

Figure 8. Diagrams of equivalent stresses in materials 1 and 2 being joined along the interfaces with interlayer in assemblies B-B at temperature-force (1), temperature (2) and force (3) loading 

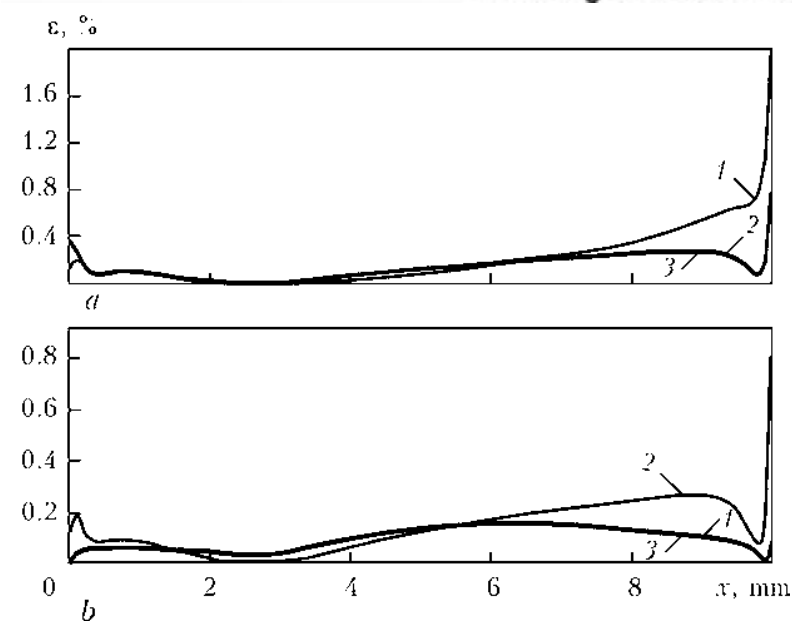

Figure 9. Diagrams of plastic deformations in interlayer material at the interface with materials $1(a)$ and $2(b)$ being joined in assemblies B-B at temperature-force (1), temperature (2) and force (3) loading

TCLE) their level and distribution nonuniformity rise, from the side of material 2 (with lower TCLE) they decrease, but their distribution becomes more uniform. It is obvious that when cooling is replaced by heating, the materials change places, i.e. thermal cycling under pressure should promote formation of physical contact and activation of the processes of joint formation.

For convenience of comparison, Figure 10 gives diagrams of stresses maximum by their modulus in the materials being joined and the interlayer at different loading variants.

Diagram analysis confirms that the effect of simultaneous temperature and force loading of assemblies with soft interlayers is manifested in a certain increase of radial and tangential stresses in all the materials, increase of equivalent stresses in material 1 and the interlayer and of axial stresses in materials being joined, and lowering of equivalent stresses in material 2 and axial stresses in the interlayer material, respectively, tangential stresses remaining practically the same as at purely temperature loading.

\section{Conclusions}

1. Tangential and equivalent stresses in the butt zone (on the interface), determining formation of physical contact and activation of the process of joint formation in DW, at simultaneous loading of assembles with soft interlayer noticeably increase in the material with higher TCLE values at cooling and in material with lower TCLE at heating. Distribution of equivalent stresses is close to the uniform one, i.e. thermal cycling under pressure should promote formation of physical contact and activation of the processes of joint formation in assemblies with a soft interlayer.

2. Plastic deformations in material of soft interlayer on the interface with material with lower
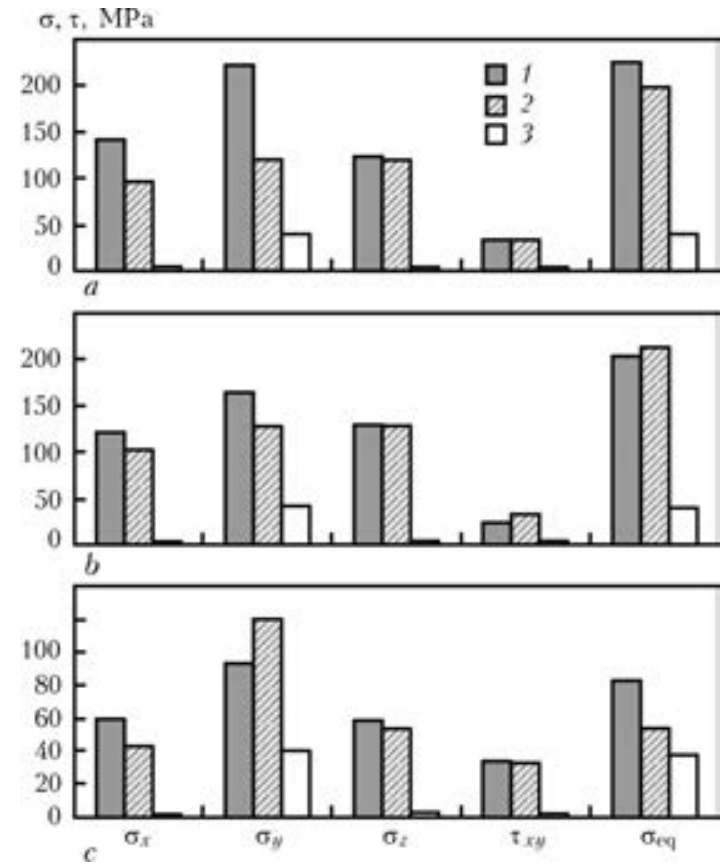

Figure 10. Maximum (by modulus) stresses in materials 1 $(a), 2(b)$ and soft interlayer (c) of assemblies B-B at temperature-force (1), temperature (2) and force (3) loading

TCLE at simultaneous loading by compression and cooling are distributed more uniformly, but their level is lower than at purely temperature loading. At simultaneous compression and heating the same takes place on the interface with material with higher TCLE, i.e. welding with thermal cycling under pressure in assembles with a soft interlayer provides a more uniform distribution of plastic deformations in the interlayer.

1. Kvasnitsky, V.V., Matvienko, M.V., Ermolaev, G.V. et al. Method of diffusion welding of materials. Pat. 81583 Ukraine. Int. Cl. B23K 20/14. Fil. 21.11.2006. Publ. 10.01.2008.

2. Kvasnitsky, V.V., Ermolaev, G.V., Matvienko, M.V. (2007) Principles of formation of stress-strain state in diffusion welding of dissimilar materials for cylindercylinder and bush-bush assemblies. Zbirnyk Nauk. Prats NUK, 5, 57-65.

3. Zhong, Z., Zhou, Z., Ge, C. (2004) Residual stress distribution and effect of interlayer in doped graphite / copper joints. Welding Technology, 6, 14-16.

4. Zhong, Z., Zhou, Z., Ge, C. (2009) Brazing of doped graphite to $\mathrm{Cu}$ using stress relief interlayers. J. $\mathrm{Ma}$ terials Proc. Techn., 209, 2662-2670.

5. Makhnenko, V.I., Kvasnitsky, V.V. (2009) Stressstrain state of assemblies of the cylindrical shape in diffusion bonding. The Paton Welding J., 2, 2-7.

6. Makhnenko, V.I., Kvasnitsky, V.V. (2009) Peculiarities of formation of stress-strain state in diffusion bonds between dissimilar materials. Ibid., 8, 7-11.

7. Kvasnitsky, V.V., Ermolaev, G.V., Kolesar, I.A. (2011) Stress-strain state of welded and brazed joints of same rigidity dissimilar materials with interlayers. Zbirnyk Nauk. Prats NUK, 5, 36-43.

8. Kvasnitsky, V.V., Zolotoj, Yu.G., Labartkava, A.V. et al. (2008) Experimental investigation of deformation of welded joint of bush-bush type from dissimilar materials. Ibid., 4, 65-73. 


\title{
EFFECT OF WELD CONVEXITY SIZES ON STRESS STATE OF BUTT JOINT DURING TENSION
}

\author{
G.V. ERMOLAEV, V.A. MARTYNENKO and I.V. MARUNICH \\ Admiral Makarov National Shipbuilding University \\ 9 Geroev Stalingrada Ave., 54025, Nikolaev, Ukraine. E-mail: welding@nuos.edu.ua
}

\begin{abstract}
To find out the possibility of compensation of decreased strength of weld metal by increase in sizes of convexity of butt joint and establishment of dependence of required height of convexity on strength ratio of weld and base metal, the investigation of level and nature of distribution of stresses in butt joints at their tension loading using different sizes of convexities was carried out. The investigations were made by the method of computer modeling on butt joints of C25 and C21 types. Height and width of convexity were varied at constant thickness of base metal. Convexity shape was taken in the form of arc. Fields of all components of stresses, and also their diagrams in different sections of weld were studied. The obtained values of coefficients of concentration (1.8-2.3) in varying the sizes of convexity within the rather wide ranges confirmed the adequacy of modeling. At the same time it was shown that the presence of convexity in symmetric joint of C25 type decreases somewhat the level of maximum tensile and equivalent stresses inside the weld metal, that gives possibility to compensate its strength as compared with base metal, but this decrease is non-proportional to the increase of section area. The expression was obtained, which allows calculating the required value of convexity in joint of C25 type at a known degree of decrease in strength of deposited metal as compared with base metal. The presence of convexities and their size in non-symmetric joint of $\mathrm{C} 21$ type does not almost influence the level of maximum equivalent stresses in section along weld axis, therefore it is impossible to compensate the decreased strength of weld metal by increase of convexities in such joint. The obtained results can be used in design of butt joints of materials, in particular high-strength steel joints made by austenitic materials, which encounter problem in providing equal strength of weld and base metal. 12 Ref., 4 Tables, 7 Figures.
\end{abstract} Ke $\boldsymbol{y}$ word $\boldsymbol{s}:$ butt joint, distribution of stresses, con-
vexity sizes, static loading

Classic shape of transverse section of butt joint, made by arc methods of welding, assumes the presence of weld convexity, whose sizes are regulated by all the standards for welded joints [1-3]. Long time this convexity was called a weld reinforcement as it was supposed that the increase in metal thickness in weld axis can compensate the possible decrease in its strength as compared to base metal.

With development and improvement of welding technology and welding consumables, the producing of weld metal, fully equal to base metal for the majority of materials used in welded structures, is not a problem any more. Respectively, the requirements to weld convexity sizes in most cases remained purely symbolic. In present effective interstate standards (GOST) the height of convexity has been established for all the thicknesses within the interval from 1.5 up to $4 \mathrm{~mm}$ at width from 5-6 up to $60 \mathrm{~mm}$ [1-3].

However, for some materials, for instance high-strength steels, the problem of producing welds of strength fully equal to that of base metal remains actual also at the present time. If it is not possible to produce the full-strength weld metal, for example, in applying of welding consumables of austenitic class, it is necessary to decrease the admissible load or stresses in it due to increase of the convexity height. It is the latter that is envisaged by appropriate technical requirements to welded butt joints of high-strength steels used in construction of hulls of military ships and submarines. But in this case another problem arises: concentration of stresses in site of transition from base to weld metal. That is why in the present effective standards for welding terminology the term «reinforcement» is referred to inadmissible and replaced by term «convexity» $[4,5]$.

Analysis of stressed state of joint in loading by tension using methods of theory of elasticity $[6,7]$ showed that in the presence of convexity in the weld zone the uniformity of distribution is violated, maximum stresses in site of concentration (transition from base to deposited metal) exceed the average ones by 1.6 up to 2 and more times. At the same time the majority of structure elements of high-strength steels, for example, lining of hulls of above-water ships and submarines are designed for strength at static axial loading. As the experimental investigations showed during loading by static load and sufficient plasticity 
Table 1. Variants of investigated models of joints of C25 type

\begin{tabular}{|c|c|c|c|c|c|c|}
\hline $\begin{array}{l}\text { Number of } \\
\text { variant }\end{array}$ & $\begin{array}{l}\text { Height of convexity } \\
\qquad a, \mathrm{~mm}\end{array}$ & $\begin{array}{l}\text { Width of convexity } \\
\qquad b, \mathrm{~mm}\end{array}$ & Relative height $a / b$ & Relative width $b / s$ & $\begin{array}{l}\text { Full section } \\
\qquad+2 a\end{array}$ & $\begin{array}{l}\text { Coefficient of } \\
\text { reinforcement } K_{\mathrm{r}} \\
\quad(s+2 a) / s\end{array}$ \\
\hline 1 & 2.5 & 23 & 0.11 & 0.77 & 35 & 1.17 \\
\hline 2 & 4.5 & 43 & 0.10 & 1.43 & 39 & 1.30 \\
\hline 3 & 7.5 & 73 & 0.10 & 2.43 & 45 & 1.50 \\
\hline 4 & 2.5 & 25 & 0.10 & 0.83 & 35 & 1.17 \\
\hline 5 & 4.5 & 45 & 0.10 & 1.50 & 39 & 1.30 \\
\hline 6 & 7.5 & 75 & 0.10 & 2.50 & 45 & 1.50 \\
\hline 7 & 2.5 & 29 & 0.09 & 0.97 & 35 & 1.17 \\
\hline 8 & 4.5 & 49 & 0.09 & 1.63 & 39 & 1.30 \\
\hline 9 & 7.5 & 79 & 0.10 & 2.63 & 45 & 1.50 \\
\hline 10 & 10 & 120 & 0.11 & 4 & 50 & 1.67 \\
\hline
\end{tabular}

Table 2. Variants of investigated models of joints of C21 type

\begin{tabular}{|c|c|c|c|c|c|c|c|c|c|c|}
\hline $\begin{array}{l}\text { Number of } \\
\text { variant }\end{array}$ & $\begin{array}{c}\text { Height of } \\
\text { convexity } \\
a, \mathrm{~mm}\end{array}$ & $\begin{array}{c}\text { Width of } \\
\text { convexity } b \text {, } \\
\text { mm }\end{array}$ & $\begin{array}{c}\text { Relative } \\
\text { height } a / b\end{array}$ & $\begin{array}{c}\text { Relative } \\
\text { width } b / s\end{array}$ & $\begin{array}{c}\text { Height of } \\
\text { convexity } \\
a_{1}, \mathrm{~mm}\end{array}$ & $\begin{array}{l}\text { Width of } \\
\text { convexity } \\
b_{1}, \mathrm{~mm}\end{array}$ & $\begin{array}{c}\text { Relative } \\
\text { height } a_{1} / b_{1}\end{array}$ & $\begin{array}{c}\text { Relative } \\
\text { width } \\
b_{1} / s_{1}\end{array}$ & $\begin{array}{l}\text { Full section } \\
\mathrm{s}+a+a_{1}\end{array}$ & $\begin{array}{l}\text { Coefficient } \\
\text { of rein- } \\
\text { forcement } K_{\mathrm{r}} \\
\quad(s+a+ \\
\left.\quad+a_{1}\right) / s\end{array}$ \\
\hline 11 & 2.5 & 23 & 0.11 & 0.77 & 0.83 & 7.6 & 0.11 & 0.25 & 33 & 1.11 \\
\hline 12 & 4.5 & 43 & 0.10 & 1.43 & 1.50 & 14.3 & 0.10 & 0.48 & 36 & 1.20 \\
\hline 13 & 7.5 & 73 & 0.10 & 2.43 & 2.50 & 24.3 & 0.10 & 0.81 & 40 & 1.33 \\
\hline 14 & 2.5 & 25 & 0.10 & 0.83 & 0.83 & 8.3 & 0.10 & 0.28 & 33 & 1.11 \\
\hline 15 & 4.5 & 45 & 0.10 & 1.50 & 1.50 & 15 & 0.10 & 0.50 & 36 & 1.20 \\
\hline 16 & 7.5 & 75 & 0.10 & 2.50 & 2.50 & 25 & 0.10 & 0.83 & 40 & 1.33 \\
\hline 17 & 2.5 & 29 & 0.09 & 0.97 & 0.83 & 9.6 & 0.09 & 0.32 & 33 & 1.11 \\
\hline 18 & 4.5 & 49 & 0.09 & 1.63 & 1.50 & 16.3 & 0.09 & 0.54 & 36 & 1.20 \\
\hline 19 & 7.5 & 79 & 0.10 & 2.63 & 2.50 & 26.3 & 0.10 & 0.88 & 40 & 1.33 \\
\hline
\end{tabular}

of metal, this concentration as well as residual welding stresses do not influence the strength of welded joint as a whole. From this point of view the use of convexity (reinforcement) for increasing the load-carrying capacity of butt joint at static loading is quite possible.

The known recent works are devoted to determination of degree of stress concentration in the site of transition from deposited to base metal [8-10] and effect of concentration on strength of welded joints [11, 12]. Unfortunately, there are no almost data on stressed state of deposited metal (weld metal) as a whole and, as a consequence, the quantitative relations, which allow determining the convexity sizes, are necessary for compensation of decrease in characteristics of weld metal strength. Therefore, the subject of the present work is urgent.

The aim of the present work is the establishment of dependence of level and nature of distribution of stresses on convexity sizes, study of possibility of compensation of weld metal decreased strength by increase in convexity sizes.

The investigations were carried out by the method of computer modeling using licensed pro- gram complex ANSYS (vers. 10). Plane-strain problems were solved using finite elements method (FEM) PLANE 182. The butt joints of C25 type (symmetric, with $\mathrm{X}$-shaped edge groove) and C21 (nonsymmetric, with V-shaped edge groove) of thickness $s=30 \mathrm{~mm}$ were investigated. Height and width of convexity were varied (Table 1). Shape of convexity was taken in the form of arc.

Due to symmetry of joint C25 with respect to horizontal $x$ and vertical $y$ axes, FE-model was plotted for the upper right quarter of physical model at a proper fixation of units on axes $x$ and $y$ (Figure 1). In joint C21, symmetrical only with respect to axis $y$, the model was plotted for the right half at a proper fixation of units on axis $y$.

Size along axis $x$ was selected so that the distribution of stresses near the edges was close to uniform that eliminated the effect of these areas on stressed state in the weld zone.

The elastic problem was solved. Physico-mechanical properties were taken the same as for the steel: elasticity modulus $E=2 \cdot 10^{5} \mathrm{MPa}$, Poisson coefficient $\mu=0.3$. 


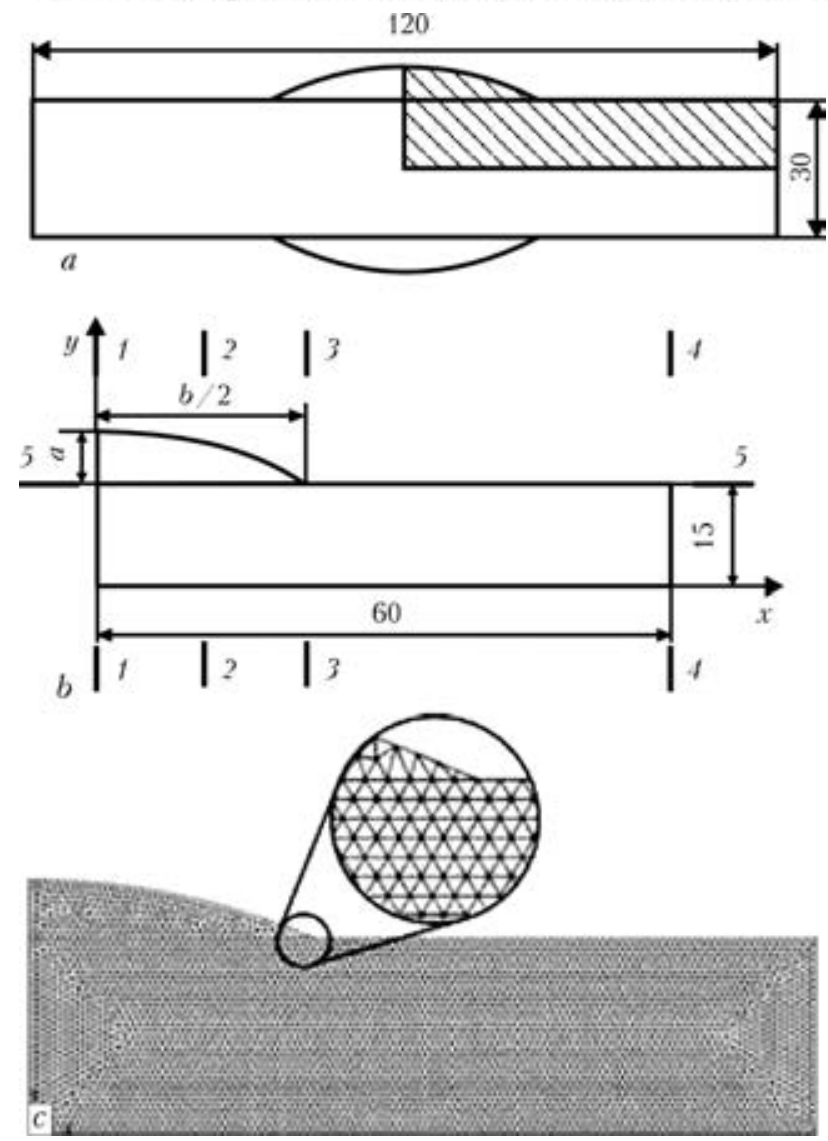

Figure 1. General view of physical $(a)$, calculation $(b)$ and FE (c) models of joint C25 (see description 1-5 in the text)

Models were loaded by uniformly distributed tensile forces on edges, generating the stresses $\sigma_{x}=100 \mathrm{MPa}$ on them.

Fields of longitudinal and transverse, tangent and equivalent (by Mises) stresses as well as their diagrams in sections on weld axis (1), at the distance $b / 4$ or $b_{1} / 2$ from axis $y$ in joints C25 and C21, respectively (2), along convexity edge (3), on node edge (4) and along upper and lower edges of models $(5,6)$ were studied $(\mathrm{Fi}-$ gures $1, b$ and $2, b$ ).

Analysis of fields (Figures 3 and 4) showed that their nature in changing the sizes of convexities is little changed as a whole. Near the sites of concentration (transition from deposited metal to base one), the transverse and tangent stresses are appeared. In addition, small transverse and tangent stresses occur in the inner part of the deposited metal. Metal in convexities is noticeably unloaded.

Nature of distribution of longitudinal and equivalent stresses is little differed. On the weld axis (section 1) of joint C25 these stresses are maximum in the middle part, where they somewhat exceed the average level, and they are gradually decreased with approach to convexities (Figure 5). Due to appearance of transverse and tangent stresses the level of equivalent stresses is somewhat differed from longitudinal ones.

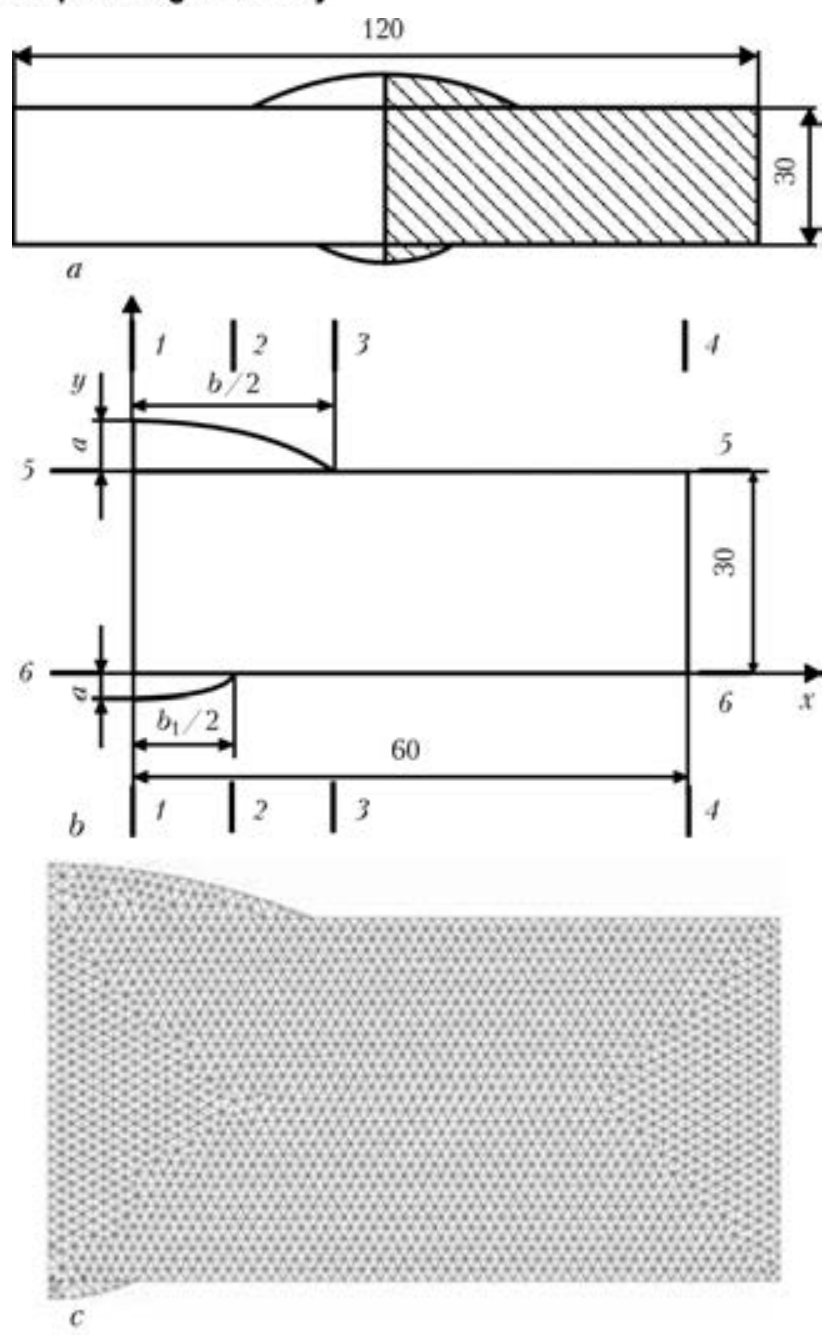

Figure 2. General view of physical $(a)$, calculation $(b)$ and $\mathrm{FE}(c)$ models of joint C21 (see description 1-6 in the text)

At the distance of convexity width quarter (section 2) the nature of distribution and level of stresses is retained. In site of concentration of stresses (section 3) all the stresses are abruptly growing. Sizes of convexity have small effect on nature of diagrams of stresses, somewhat changing their level (see Figure 5).

In joint $\mathrm{C} 21$ the nature of distribution of stresses in the upper half of joint is retained as a whole, but their level is somewhat decreased as a result of model bending due to its asymmetry relative to longitudinal axis (Figure 6). In the lower part in this case the bending decreases the degree of loading in the convexity region (section 1) and increases the degree of concentration in the site of transition from base to deposited metal (section 2).

For convenience of quantitative estimation of level of stresses, Tables 3 and 4 give values of maximum $\left(\sigma_{\max 1}, \quad \sigma_{\max 2}, \sigma_{\max 3}\right)$, minimum $\left(\sigma_{\mathrm{min} 3}\right)$ and average $\left(\sigma_{\mathrm{av} 1}, \sigma_{\mathrm{av} 2}, \sigma_{\mathrm{av} 3}\right)$ equivalent stresses in sections $1-3$. There, the values of coefficients of overloading (degree of exceeding of 


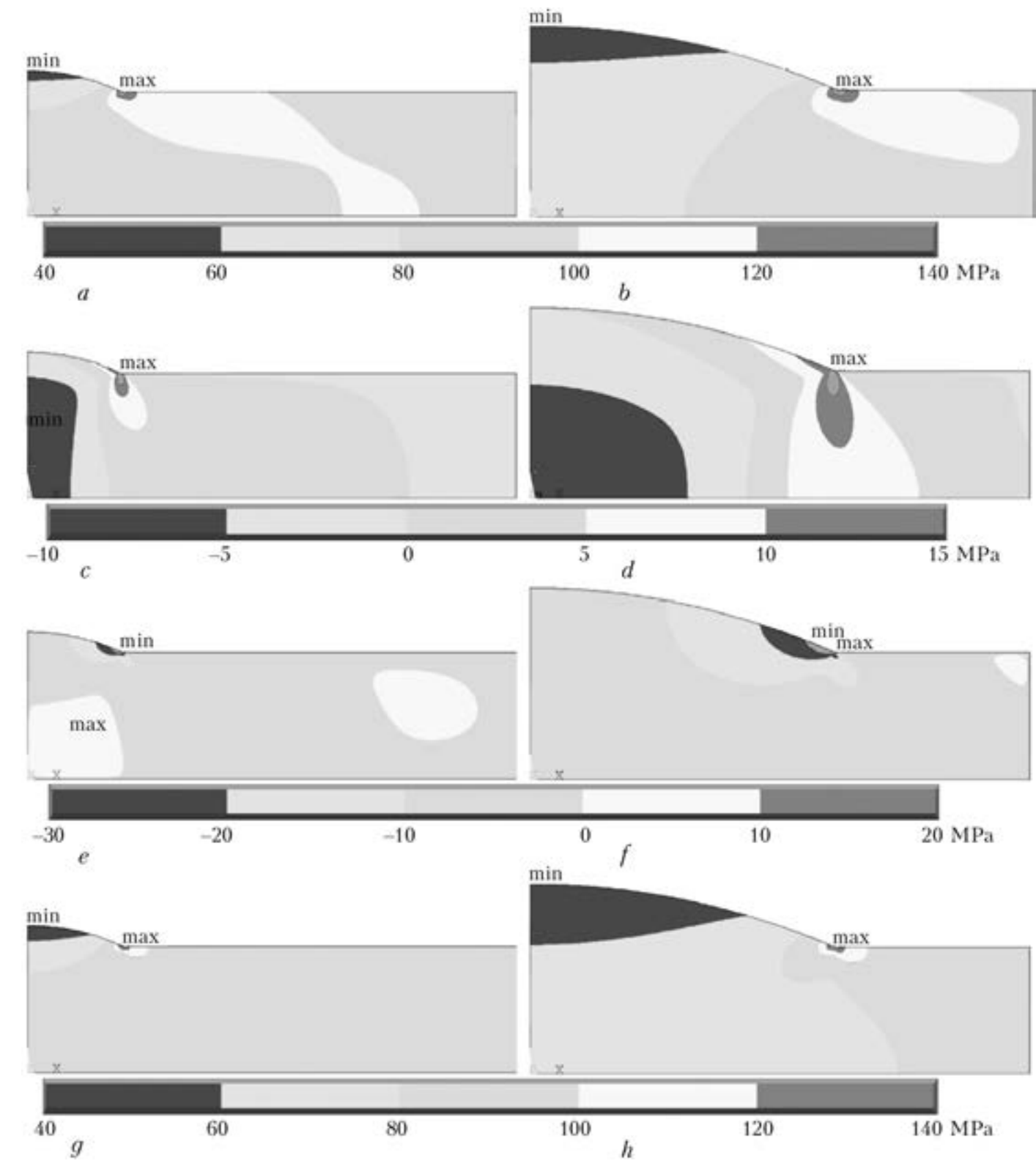

Figure 3. Fields of longitudinal $(a, b)$, transverse $(c, d)$, tangent $(e, f)$ and equivalent $(g, h)$ stresses: $a, c, e, g-$ variant $1 ; b, d, f, h-$ variant 3

maximum stresses over average ones in section) in the first and second sections $\left(\sigma_{\max 1} / \sigma_{\mathrm{av} 1}\right.$ and $\left.\sigma_{\max 2} / \sigma_{\mathrm{av} 2}\right)$ and coefficients of concentration of stresses in sections $3\left(\sigma_{\max 3} / \sigma_{\mathrm{av} 3}\right)$ and 2 in joint C21 $\left(\sigma_{\max 2} / \sigma_{\text {av2 }}\right)$ are also given.

As is seen from Tables, the degree of overloading is little changed with changing the convexity sizes.

In joint C25 in change of reinforcement coefficient $K_{\mathrm{r}}$ (thickness increase in weld zone) from 1.17 to 1.50 (see Table 1 ) the coefficient of overloading by equivalent stresses is remained at the level of 1.13-1.18 in section 1 and 1.07-1.10 in section 2. As is seen, the change does not exceed 3-5\%. Moreover, the comparison of sections 1 and 2 shows that value and nature of distribution of stresses in them are very small differed and here the coefficient of overloading is somewhat higher in section 1 , therefore in further calcula- tions only section 1 will be regarded, and the coefficient of overloading will be taken equal to 1.145 by equivalent stresses.

In section 3 the coefficient of stress concentration $\left(\sigma_{\max 3} / \sigma_{\mathrm{av} 3}\right)$ in change of $K_{\mathrm{r}}=(s+2 a) / s$ from 1.17 up to 1.50 is increased negligibly and remain at the level of about 2 (1.92-2.18).

In joint C21 in $K_{\mathrm{r}}$ change in investigated variants in the ranges of 1.11-1.33 (see Table 2) the coefficient of overloading by equivalent stresses in section 1 is changed proportionally from 1.14 to 1.34 , i.e. it is almost remained equal to coefficient of reinforcement.

In section 2 the coefficient of concentration with $K_{\mathrm{r}}$ growth is increased from 1.43 up to 2.39, and in section 3 it is not almost changed, remaining in the ranges of 1.59-1.70. 

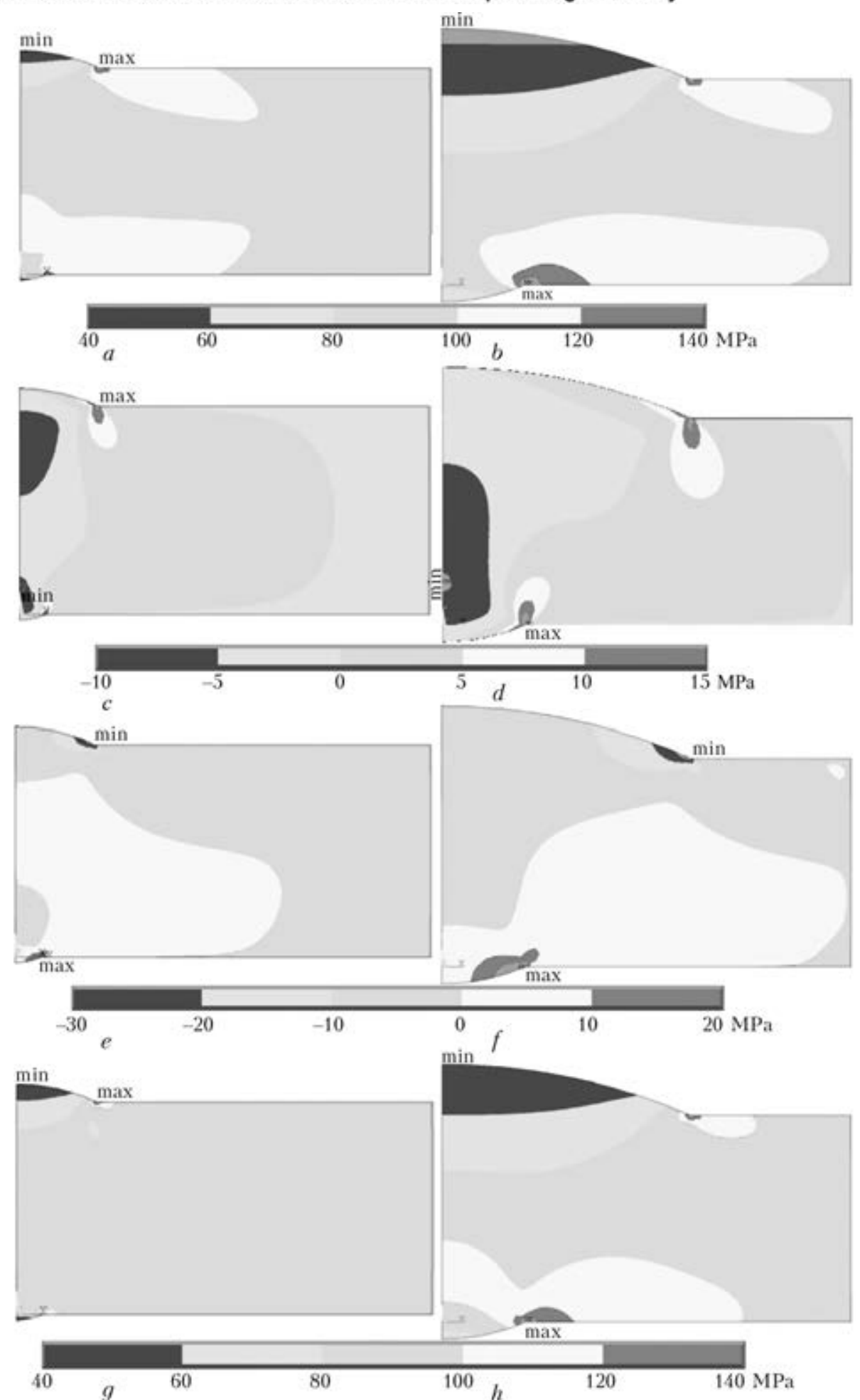

Figure 4. Fields of longitudinal $(a, b)$, transverse $(c, d)$, tangent $(e, f)$ and equivalent $(g, h)$ stresses: $a, c, e, g-$ variant $11 ; b, d, f, h-$ variant 13

In joint $\mathrm{C} 25$ the growth of average and maximum equivalent stresses in section 1 is decreased with increase in height of convexity (Figure 7 , $a$ ), that evidences of principal capability of using convexity to compensate the decrease in strength of weld metal and strength improvement of such a joint during static loads.

In joint C21 the level of maximum stresses in section 1 almost does not depend on the height of convexities, though average stresses are decreased (Figure $7, b$ ), i.e. in the joint of such a type the increase of even static strength due to a growth of convexities is practically impossible. To obtain the dependence of necessary height of convexity in joint C25 on the correlation of strength of weld and base metal, let us introduce the term of relative strength of weld metal (level or coefficient of softening of weld metal, coeffi- 


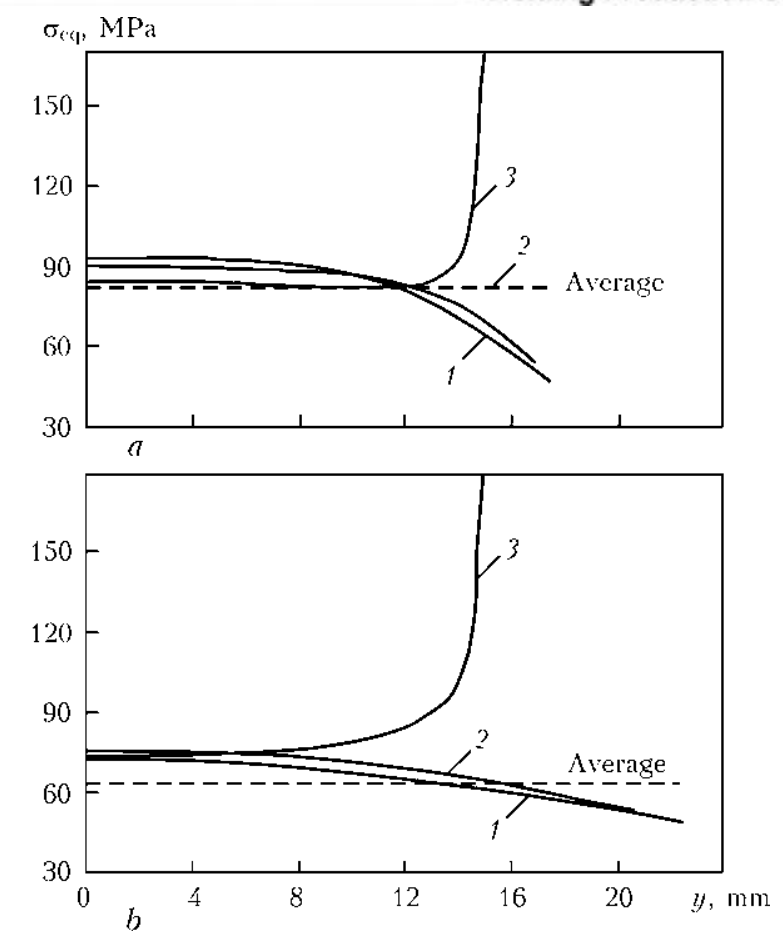

Figure 5. Diagrams of equivalent stresses in sections 1-3 for variants $1(a)$ and $3(b)$

cient of decrease of strength of weld metal) $\kappa_{\mathrm{wm}}=\frac{\left[\sigma_{\mathrm{wm}}\right]}{\left[\sigma_{\mathrm{bm}}\right]}=\frac{\sigma_{\mathrm{ywm}}}{\sigma_{\mathrm{ybm}}}$ and use the condition of equilibrium of the node

$$
\sigma_{\mathrm{av} 1}(s+2 a)=\sigma_{\mathrm{bm}} s
$$

and condition of strength for section 1

$$
\sigma_{\max 1} \leq\left[\sigma_{\mathrm{wm}}\right] \text { or } \kappa_{\mathrm{ovl} 1} \sigma_{\mathrm{av} 1} \leq\left[\sigma_{\mathrm{wm}}\right],
$$

where $\kappa_{\text {ovl1 }}=\sigma_{\max 1} / \sigma_{\text {av }}$ is the coefficient of overloading in section $1 ;\left[\sigma_{\mathrm{wm}}\right]$ and $\sigma_{\mathrm{y} w \mathrm{wm}}$ are the admissible stresses and yield strength of weld metal, respectively; $\left[\sigma_{\mathrm{bm}}\right]$ and $\sigma_{\mathrm{y} \text { bm }}$ are the admissible stresses and yield strength of base metal, respectively.

From the equilibrium equation (1)

$$
\sigma_{\mathrm{av} 1}=\sigma_{\mathrm{bm}} \frac{s}{s+2 a} \text { or } \sigma_{\mathrm{av} 1}=\sigma_{\mathrm{bm}} / K_{\mathrm{r}} \text {, }
$$

where $K_{\mathrm{r}}=\frac{s+2 a}{s} \geq 1$.

It is obvious that in the ultimately loaded state, equation (3) shall be written in the form of $\sigma_{\mathrm{av} 1}=\left[\sigma_{\mathrm{bm}}\right] / K_{\mathrm{r}}$.

Then the condition of strength in section 1 (2) can be written as

$$
K_{\mathrm{ovl1}} \frac{\left[\sigma_{\mathrm{bm}}\right]}{K_{\mathrm{r}}} \leq\left[\sigma_{\mathrm{wm}}\right] \text { or } \frac{\kappa_{\mathrm{ovl} 1} \frac{\left[\sigma_{\mathrm{bm}}\right] \leq\left[\sigma_{\mathrm{wm}}\right]}{s+2 a}}{s},
$$

hence, shall obtain after transformations
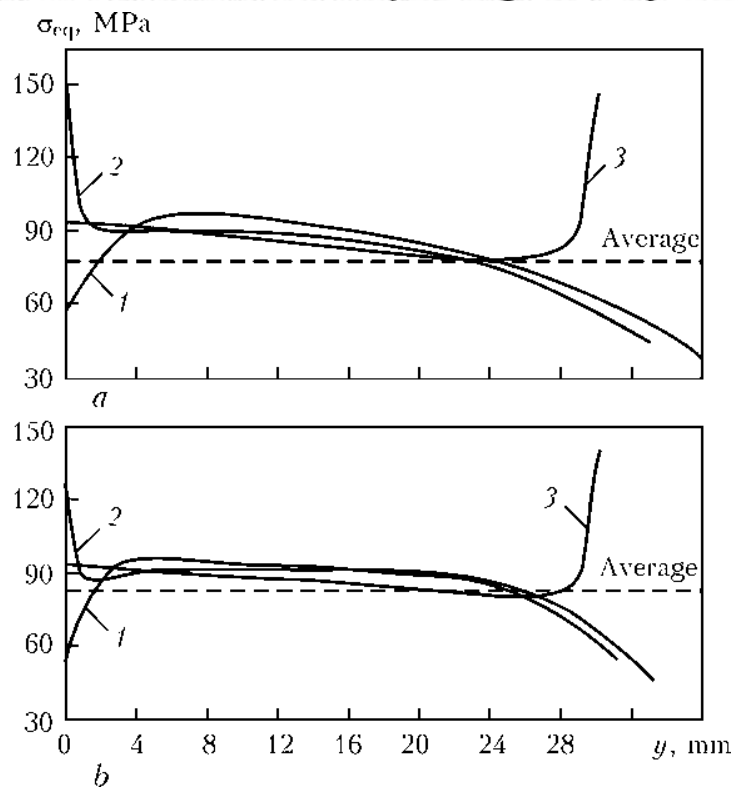

Figure 6. Diagrams of equivalent stresses in sections 1-3 for variants $11(a)$ and $13(b)$

$$
a \geq 0.5 s\left(\frac{\kappa_{\mathrm{ovl}}}{\kappa_{\mathrm{wm}}}-1\right),
$$

or at $K_{\mathrm{ovl}}=1.145 a \geq 0.5 s\left(\frac{1.145}{\kappa_{\mathrm{wm}}}-1\right)$.

Thus, the necessary value of convexity height shall be determined by the degree of uniformity of distribution of stresses in weld metal $\left(\kappa_{\text {ovl }} \geq\right.$ $\geq 1)$ and decrease of strength of weld metal as compared to the base metal $\left(\kappa_{\mathrm{wm}} \leq 1\right)$. Thus, at $\kappa_{\mathrm{ovl}}=1.145$ and decrease in strength of weld metal by $20 \%$, i.e. $\kappa_{\mathrm{wm}}=0.8$ for the thickness of $30 \mathrm{~mm}$, the necessary minimum height of convexity will amount to $6.5 \mathrm{~mm}$, and at decrease of strength of weld metal by $10 \%$ it will be $4 \mathrm{~mm}$.

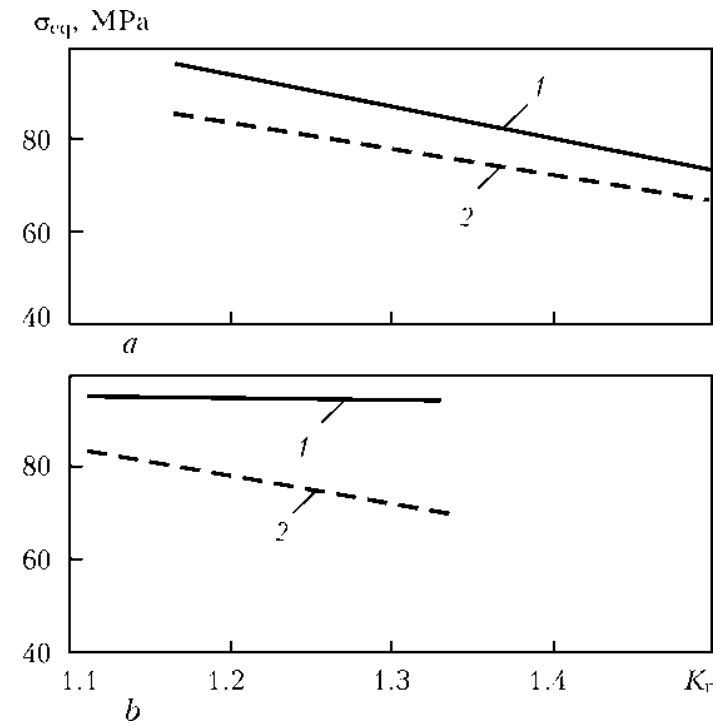

Figure 7. Dependence of maximum (1) and average (2) equivalent stresses in section 1 for joints C25 $(a)$ and C21 (b) on coefficient of weld reinforcement 
Welding Production Chair of Admiral Makarov National Shipbuilding University

Table 3. Equivalent stresses in sections $1-3$ in the investigated variants of joints of C25 type

\begin{tabular}{||c|c|c|c|c|c|c|c|c|c|c||}
\hline \hline Number of variant & $\sigma_{\max 1}$ & $\sigma_{\mathrm{av} 1}$ & $\sigma_{\max 2}$ & $\sigma_{\mathrm{av} 2}$ & $\sigma_{\min 3}$ & $\sigma_{\max 3}$ & $\sigma_{\mathrm{av} 3}$ & $\sigma_{\max 1} / \sigma_{\mathrm{av} 1}$ & $\sigma_{\max 2} / \sigma_{\mathrm{av} 2}$ & $\sigma_{\max 3} / \sigma_{\mathrm{av} 3}$ \\
\hline 1 & 93 & 82 & 89 & 83 & 84 & 170 & 85 & 1.13 & 1.07 & 2.0 \\
\hline 2 & 87 & 74 & 84 & 77 & 77 & 183 & 83 & 1.18 & 1.09 & 2.2 \\
\hline 3 & 72 & 64 & 75 & 68 & 73 & 188 & 81 & 1.13 & 1.10 & 2.3 \\
\hline 4 & 92 & 82 & 89 & 83 & 83 & 167 & 85 & 1.12 & 1.07 & 2.0 \\
\hline 5 & 86 & 74 & 83 & 76 & 77 & 180 & 83 & 1.16 & 1.09 & 2.2 \\
\hline 6 & 72 & 63 & 75 & 68 & 73 & 186 & 81 & 1.14 & 1.10 & 2.3 \\
\hline 7 & 91 & 81 & 88 & 82 & 82 & 160 & 85 & 1.12 & 1.07 & 1.9 \\
\hline 8 & 84 & 73 & 82 & 76 & 77 & 174 & 83 & 1.15 & 1.08 & 2.1 \\
\hline 9 & 70 & 63 & 74 & 68 & 74 & 182 & 81 & 1.11 & 1.09 & 2.2 \\
\hline $\begin{array}{c}\text { Average value for } \\
\text { all the variants }\end{array}$ & - & - & - & - & - & - & - & 1.14 & 1.08 & 2.13 \\
\hline
\end{tabular}

Table 4. Equivalent stresses in sections $1-3$ in the investigated variants of joints of C21 type

\begin{tabular}{||c|c|c|c|c|c|c|c|c|c|c||}
\hline \hline Number of variant & $\sigma_{\max 1}$ & $\sigma_{\mathrm{av} 1}$ & $\sigma_{\max 2}$ & $\sigma_{\mathrm{av} 2}$ & $\sigma_{\min 3}$ & $\sigma_{\max 3}$ & $\sigma_{\mathrm{av} 3}$ & $\sigma_{\max 1} / \sigma_{\mathrm{av} 1}$ & $\sigma_{\max 2} / \sigma_{\mathrm{av} 2}$ & $\sigma_{\max 3} / \sigma_{\mathrm{av} 3}$ \\
\hline 1 & 95 & 83 & 123 & 86 & 80 & 141 & 88 & 1.14 & 1.43 & 1.60 \\
\hline 2 & 97 & 78 & 150 & 81 & 78 & 146 & 87 & 1.24 & 1.85 & 1.68 \\
\hline 3 & 95 & 71 & 177 & 74 & 77 & 148 & 87 & 1.34 & 2.39 & 1.70 \\
\hline 4 & 95 & 83 & 126 & 86 & 80 & 140 & 88 & 1.14 & 1.47 & 1.59 \\
\hline 5 & 97 & 78 & 150 & 81 & 78 & 146 & 87 & 1.24 & 1.85 & 1.68 \\
\hline 6 & 94 & 71 & 176 & 74 & 77 & 147 & 87 & 1.32 & 2.38 & 1.69 \\
\hline 7 & 95 & 83 & 126 & 86 & 81 & 136 & 88 & 1.14 & 1.47 & 1.55 \\
\hline 8 & 96 & 78 & 150 & 81 & 78 & 143 & 87 & 1.23 & 1.85 & 1.64 \\
\hline 9 & 94 & 70 & 175 & 73 & 77 & 145 & 87 & 1.34 & 2.40 & 1.67 \\
\hline $\begin{array}{c}\text { Average value for } \\
\text { all the variants }\end{array}$ & - & - & - & - & - & - & - & - & - & 1.64 \\
\hline
\end{tabular}

\section{Conclusions}

1. At change of sizes of convexity in rather wide range the coefficient of concentration of equivalent stresses in the sites of transition from base to deposited metal is changed in the ranges of 1.9-2.3 in joint $\mathrm{C} 25 ; 1.55-1.7$ from the outer side and 1.45-2.40 from the back side of joint $\mathrm{C} 21$.

2. Presence of convexity in the symmetric joint C25 somewhat decreases the level of tensile and equivalent stresses inside the weld metal, that provides a possibility to compensate the decrease of its strength as compared to the base metal, but this decrease is not proportional to the increase of section area.

3. The expression was obtained, which allows calculating the necessary value of convexity in joint C25 at the known level of decrease of deposited strength metal as compared to the base one.

4. Presence of convexities and their size in non-symmetric joint C21 almost does not influence the level of maximum equivalent stresses in the section along the weld axis, therefore, it is impossible to compensate the decreased strength of weld metal by increase of convexities.
2. GOST 8713-79: Submerged-arc welding. Welded joints. Main types, structural elements and sizes. Publ. 2005. Moscow: Standart.

3. GOST 14771-76: Gas-shielded arc welding. Main types, structural elements and sizes. Publ. 2000. Moscow: Standart.

4. GOST 2601-84: Welding of metals. Terms and definitions of basic concepts. Publ. 1995. Moscow: Standart.

5. DSTU 3761.3-98: Welding and related processes. $\mathrm{Pt}$ 3: Welding of metals: joints and welds, technology, materials and equipment. Terms and definitions. Publ. 1999. Kyiv: GKSMSU.

6. Nikolaev, G.A., Kurkin, S.A., Vinokurov, V.A. (1982) Welded structures. Strength of welded joints and deformation of structures. Moscow: Vysshaya Shkola.

7. Nikolaev, G.A., Kurkin, S.A., Vinokurov, V.A. (1971) Calculation, design and fabrication of welded structures. Moscow: Vysshaya Shkola.

8. Karkhin, V.A. (1985) Influence of weld shape on stress distribution in tensile of large thickness butt joints. Avtomatich. Svarka, 9, 25-28.

9. Stakanov, V.I., Kostylev, V.I., Rybin, Yu.I. (1987) About calculation of stress concentration coefficient for butt welded joints. Ibid., 11, 19-23.

10. Karkhin, V.A., Kostylev, V.I., Stakanov, V.I. (1988) Influence of geometric parameters of butt, $\mathrm{T}$ - and cruciform joints on stress concentration coefficient. Ibid., 3, 6-11.

11. Pustovit, A.I., Voronin, S.A., Yushchenko, K.A. (1987) Influence of stress concentration on strength of martensitic steel welded joints. Ibid., 9, 1-3.

12. Makhnenko, V.I. (2006) Resource of safety service of welded joints and assemblies of modern structures. Kiev: Naukova Dumka.

1. GOST 5264-80: Manual arc welding. Welded joints. Main types, structural elements and sizes. Publ. 1993. Moscow: Standart. 


\title{
TECHNOLOGICAL CHARACTERISTICS OF AUTOMATIC SUBMERGED ARC SURFACING WITH HIGH-FREQUENCY OSCILLATIONS OF ELECTRODE END
}

\author{
V.A. LEBEDEV ${ }^{1}$, S.V. DRAGAN ${ }^{2}$, Zh.G. GOLOBORODKO ${ }^{2}$, I.V. SIMUTENKOV ${ }^{2}$ and Yu.A. YAROS ${ }^{3}$ \\ ${ }^{1}$ E.O. Paton Electric Welding Institute, NASU \\ 11 Bozhenko Str., 03680, Kiev, Ukraine. E-mail: office@paton.kiev.ua \\ ${ }^{2}$ Admiral Makarov National Shipbuilding University \\ 9 Geroev Stalingrada Ave., 54025, Nikolaev, Ukraine. E-mail: simutenkov@inbox.ru \\ ${ }^{3}$ AMITI Ltd. \\ 42 Novozavodskaya Str., 54028, Nikolaev, Ukraine. E-mail: yaros.amity.mk.ua@gmail.com
}

\begin{abstract}
Applying to the electrode of HF pulsed displacements, generated by a specially-developed electromechanical generator, allows increasing the efficiency of electrode melting and providing control of geometric parameters of bead in automatic submerged arc surfacing (ASAS). The present work is aimed at the experimental evaluation of the effect of HF electrode oscillations on technological characteristics of the ASAS process of structural steels. It was found that stability of arc process and quality of deposited layer formation in ASAS with HF pulsed displacements of electrode correspond to similar characteristics for surfacing without controlling action. Analysis of oscillograms of current and arc voltage shows that HF electrode oscillations allow controlling electrode metal transfer parameters. The HF electrode end oscillations under the action of pulsed displacements lead to changes in frequency of fluctuations of arc voltage: from $15-20 \mathrm{~Hz}$ in natural drop metal transfer to the frequencies without distinctly expressed extremums, which is predetermined by refining of drops, detached from electrode. The increase in frequency of controlling action results in growth of deposition coefficient rate from $15 \mathrm{~g} /(\mathrm{A} \cdot \mathrm{h})$ without oscillations up to $22.6 \mathrm{~g} /(\mathrm{A} \cdot \mathrm{h})$ at $320 \mathrm{~Hz}$ frequency. The change in amplitude of oscillations from 0.5 up to $3 \mathrm{~mm}$ in the frequency range under study allows decreasing the share of base metal in deposited metal at 30\% overlapping of beads from 0.25 (surfacing without oscillations) to 0.14. 9 Ref., 5 Figures.
\end{abstract}

$\boldsymbol{K} \boldsymbol{e} \boldsymbol{y} \boldsymbol{w} \boldsymbol{o r d s}:$ automatic surfacing, pulsed displacement, oscillations, electrode, technological characteristics

Despite the long-time period of development, the existing technology of automatic submerged arc surfacing (ASAS) attracts attention of researchers due to its potential of increase in the quality of deposited layer and efficiency [1]. The capabilities of ASAS may be realized in full through various methods of control of the electrode metal transfer and the properties of deposited layer. Electrical, mechanical and magnetic methods, as well as their combinations, are most actively used for this purpose [2, 3]. The combination of several methods allows selecting the most efficient parameters of controlling action, however as a rule, such an approach is expensive [3]. The similar effect, but a less expensive one, may be reached through electromechanical method, realized by using the generator of HF pulsed displacements of electrode $[4,5]$ in combination with a serial welding equipment.
The principle of this method consists of control of electrode metal transfer process by periodical forced removal of the liquid-metal layer from electrode end in the form of drops, which mass is determined by the frequency of vibration action. The latter, generated by the generator of pulsed displacements via a striker, is applied to the electrode at the stickout area in compliance with the schemes, given in [4].

The transverse HF (up to $10 \mathrm{kHz}$ ) mechanical pulsed action on electrode wire allows controlling the sizes of deposited bead and efficiency of process in ASAS. The investigations showed [4] that in this case the depth of penetration and the share of base metal in deposit can be 3 times reduced, and the electrode melting coefficient can be increased by 10-12\%.

The present work is aimed at the experimental evaluation of effect of HF electrode oscillations on technological characteristics of the process of ASAS of assemblies and parts of structural steels (crane wheels, brake drum pulleys, etc.), subjected to intensive wear. 
Welding Production Chair of Admiral Makarov National Shipbuilding University

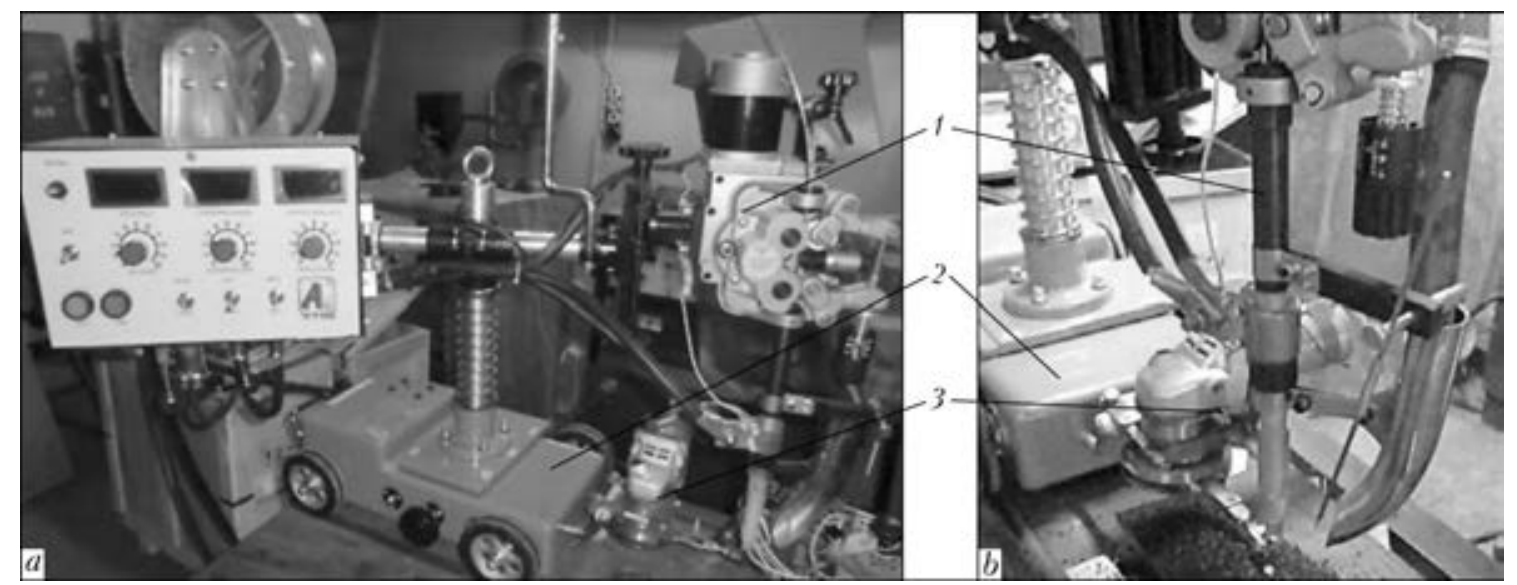

Figure 1. Options of arrangement of generator of pulsed displacements of electrode wire on welding tractor: $a, b-$ transverse to and along the deposited bead, respectively; 1 - welding head; 2 - carriage of tractor; 3 - mechanical generator

The program of experimental investigations and the evaluation of the obtained results were carried out using the facilities of the Admiral Makarov National Shipbuilding University, AMITI Company, and the E.O. Paton Electric Welding Institute of the NAS of Ukraine.

The investigations were carried on the stand, consisting of AST 1000 welding complex (inverter power source which forms a dropping voltampere characteristic, and welding tractor) and generator of $\mathrm{HF}$ pulsed displacements of electrode (Figure 1), which is fixed on the welding head, equipped with the arc voltage adjustment system by the effect on the wire feed rate. The application of the stabilized power source allowed making deposition with electrode oscillations (by secondary disturbing effect) at minimum admissible current, preserving the high stability of process, and the rate, recommended by the standard documents [6].

The stability of the surfacing process and the effect of electrode oscillations on the nature of metal transfer were evaluated by oscillograms of current and arc voltage, registered via electronic USB-oscillograph and statistically processed using the package LabView 2013 applied programs.
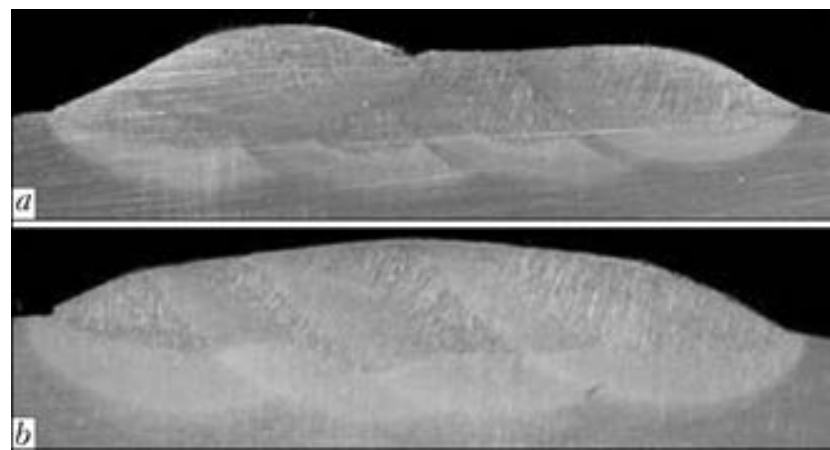

Figure 2. Macrosections of deposited layer made without (a) and with (b) HF oscillations of electrode
The deposition of beads was carried out on the specimens of $500 \times 200 \times 10 \mathrm{~mm}$ size, made of structural steel VSt3sp (killed). In compliance with the recommendations [6], the following combinations were used as welding consumables: wire Sv-08A + flux OSTs-45, and wire Sv08G2S + flux ANK-18. Surfacing condition parameters were also set up in compliance with [6] $d_{\mathrm{e}}=2 \mathrm{~mm} ; I_{\mathrm{s}}=200-250 \mathrm{~A} ; U_{\mathrm{a}}=27-30 \mathrm{~V} ; v_{\mathrm{s}}=$ $=18-22 \mathrm{~m} / \mathrm{h}$. In all the cases, the HF pulsed displacements were applied normal to electrode axis, but along the deposited bead. The parameters of the condition of electrode wire end oscillations were changed within the following limits: frequency $f_{\text {osc }}=250-9000 \mathrm{~Hz}$, amplitude $A_{\text {osc }}=$ $=0.5-3 \mathrm{~mm}$. In all the cases, the selection criteria for efficient parameters of oscillation conditions were the technological stability of process and the quality of deposited layer formation. Stability of arc process was evaluated by oscillograms of current and voltage. The quality of the deposited beads formation was evaluated by visual inspection and measurement. The deposition coefficient was determined by the standard techniques [7]. Geometric parameters of the deposited beads and the share of base metal were determined by macrosections (Figure 2).

The effect of the mechanical HF oscillations of electrode on the stability of deposition process was evaluated continuously by oscillographic testingy of current and voltage, starting the process without electrode oscillations, and continuing it with oscillations.

It should be noted that the peculiarity of the metal transfer control by the electrode transverse oscillations is the absence of change in arc length and related voltage fluctuations, predetermined by the control process itself, in contrast, for example, to process at pulsed wire feed [2]. The mentioned fact makes identification of effect of 

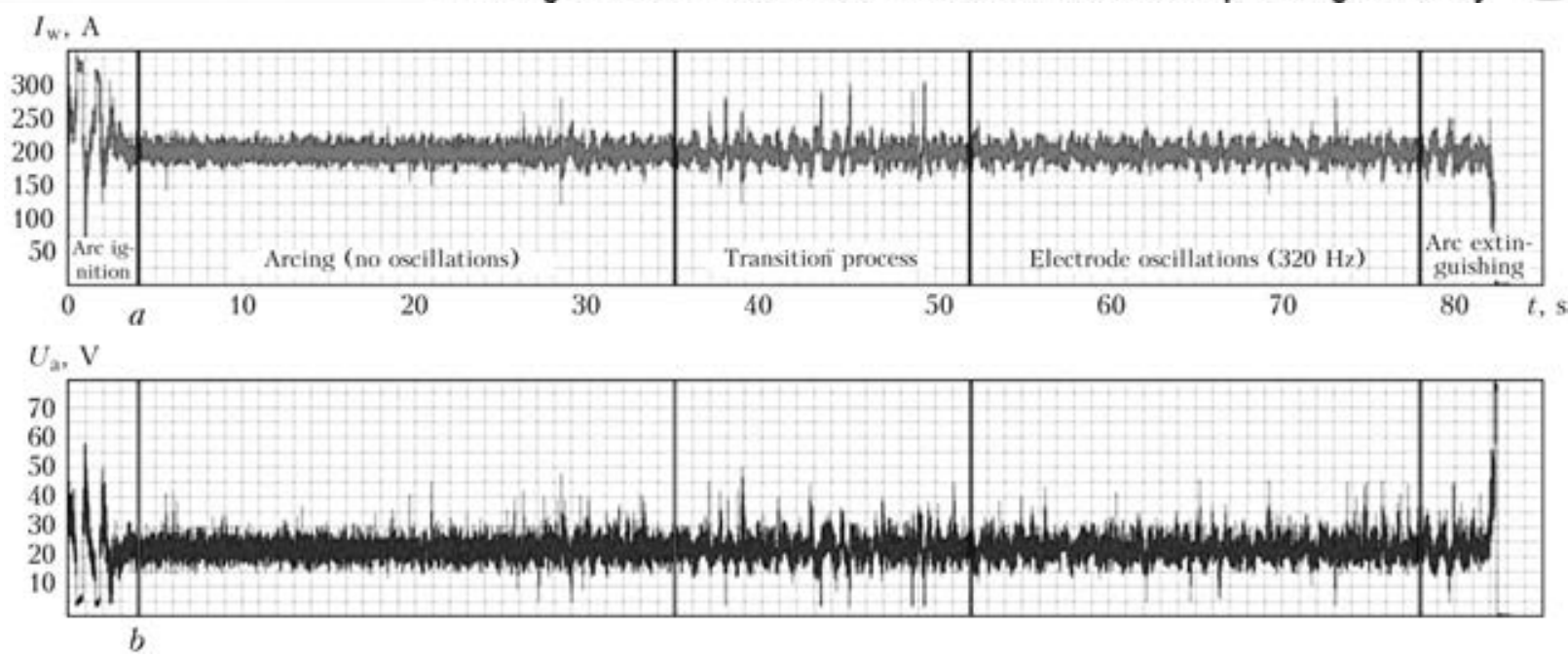

Figure 3. Oscillograms of current $(a)$ and arc voltage $(b)$ in deposition at $d_{\mathrm{e}}=2 \mathrm{~mm}, l_{\mathrm{st}}=50 \mathrm{~mm}, I_{\mathrm{S}}=200 \mathrm{~A}, U_{\mathrm{a}}=$ $=30 \mathrm{~V}, v_{\mathrm{s}}=21 \mathrm{~m} / \mathrm{h}$ and $f_{\text {osc }}=320 \mathrm{~Hz}$

electrode oscillations on metal transfer difficult. In this connection, the surfacing was performed under conditions, characterized by the process of coarse drop metal transfer, distinctly visible on the oscillograms (Figure 3) [8]. The oscillograms show areas of arc ignition, deposition without oscillations, transition process (at starting generator of pulsed displacements), deposition with electrode oscillations and arc extinguishing.

During deposition with electrode oscillations, despite a certain increase in amplitude of current and voltage fluctuations, the stability of process remains high. There are typical periodical changes of the investigated parameters, confirming the occurrence of controlling process of removal of the liquid-metal layer from the electrode end. The confirmation is the results, obtained from the oscillograms, processed by the Fourier transformation (Figure 4).

The analysis of oscillograms shows that oscillations of arc voltage with frequency $15-20 \mathrm{~Hz}$ (see Figure 4, $a$ ), typical for the natural drop metal transfer, are transformed into the spectrum of frequencies without distinctly expressed peaks (see Figure 4, $b$ ), which is related to the reducing

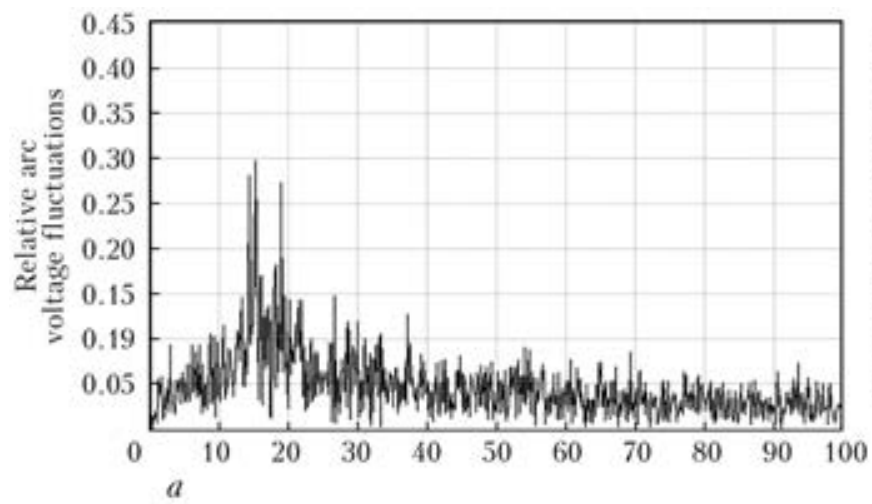

effect of the drops, refined by HF oscillations, on voltage and current in the arc. The appearance of voltage peaks of $1-2 \mathrm{~Hz}$ is related to high-amplitude oscillations $\left(A_{\mathrm{osc}}>3 \mathrm{~mm}\right)$, generated by the generator of pulsed displacements.

During deposition without and with electrode oscillations at frequency from $0,250,305$ up to $350 \mathrm{~Hz}$, the deposition coefficient grows as follows, $\mathrm{g} /(\mathrm{A} \cdot \mathrm{h}): 15.0-15.2 ; 17.9-18.2 ; 19.6-20.0$; $22.4-22.6$, that is confirmed by the calculation results obtained earlier [9].

Such a change in deposition coefficient is related to the fact that with growth of frequency of electrode oscillations, the thickness of liquidmetal layer on the electrode wire end and the average temperature of the detached drops are decreased. Due to this, the effective efficiency factor of electrode melting by the arc, rate of electrode melting, and efficiency of surfacing process are increased. Furthermore, the geometry of deposition changes (Figure 5): depth of base metal penetration $h$ and width of bead $e$ decrease, while the height of bead $g$ increases.

The main factor, which determines the sizes of deposited bead at HF oscillations of electrode,

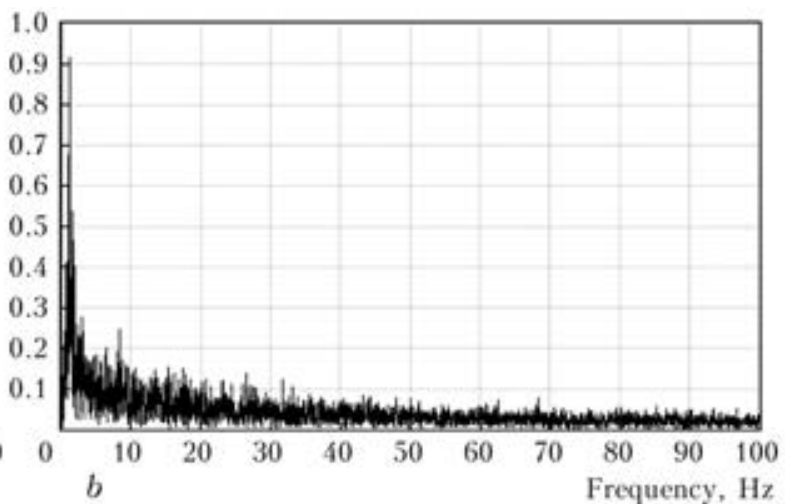

Figure 4. Frequency spectra of arc voltage in deposition without $(a)$ and with $(b)$ oscillations of electrode 


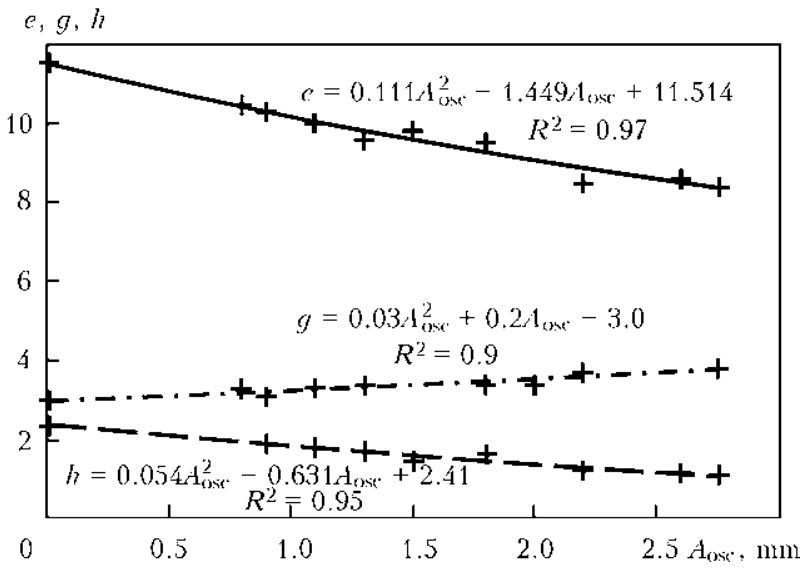

Figure 5. Effect of amplitude of $\mathrm{HF}\left(f_{\mathrm{osc}}=250-9000 \mathrm{~Hz}\right)$ pulsed displacements of electrode on geometrical parameters of deposited bead

is the amplitude of oscillations of its end. The amplitude of oscillations of the electrode wire end, when using the designed generator of pulsed displacements, is rather easy to control by the selection of point of applying of pulsed action at the electrode stickout and the change in frequency of pulsed displacements. In addition, the amplitude of electrode end oscillations can be regulated by the change in stickout length, however this is possible only in those cases, when the stickout length can be quite easily changed (deposition by wires of larger diameters of $4^{-}$ $6 \mathrm{~mm}$ of steel with a low specific resistance).

With increase in frequency the amplitude of oscillations is proportionally growing, thermal and force effect of arc and drops of electrode metal on weld pool is decreased, hence, depth of penetration $h$ and share of base metal in the deposited layer are decreased. Thus, the share of base metal during deposition with $30 \%$ overlapping of beads without electrode oscillations amounts to 0.25 , while with electrode oscillations it amounts to 0.14 , being the positive factor of saving welding consumables in surfacing.

To obtain the quantitative evaluation of effect of oscillations amplitude on the sizes of bead in deposition with HF oscillations of electrode, the experimental data (see Figure 5) were approximated by quadratic polynomials with sufficient accuracy for practice (mean-square deviation $\left.R^{2} \geq 0.9\right)$.

The obtained results give grounds to consider that the technology of the ASAS of structural steels with HF oscillations of electrode is reasonable for repair of propeller drive shafts and crane wheel flanges in accordance with the requirements of RD 212.0080-87 (covering ship mechanisms and devices, parts of mechanisms of handling machinery of ports and hydraulic and engineering structures) [6].

\section{Conclusions}

1. The pulsed displacement, applied to electrode wire, which in its turn causes HF electrode end oscillations, allows controlling technological characteristics of process and geometrical characteristics of bead in ASAS of structural steels.

2 . With increase in frequency of pulsed displacements the amplitude of electrode oscillations is growing proportionally, reaching $3 \mathrm{~mm}$ at $320 \mathrm{~Hz}$. Furthermore, the deposition coefficient is growing from 15.0 up to $22.6 \mathrm{~g} /$ (A.h) without decrease in stability of arc process, depth of penetration is 3 times increased, height of deposited bead increases by $30 \%$.

1. Lashchenko, G.I. (1998) Energy characteristics of processes of consumable electrode arc welding. Avtomatich. Svarka, 9, 18-23.

2. Lebedev, V.A. (2008) Aspects of selection of equipment for electric arc and automatic welding with pulse feed of electrode wire. Svarochn. Proizvodstvo, 5, 45-49.

3. Paton, B.E., Lebedev, V.A., Mikitin, Ya.I. (2006) Method of combined control of electrode metal transfer process in mechanized arc welding. Ibid., 8, 27-32.

4. Goloborodko, Zh.G., Dragan, S.V., Simutenkov, I.V. (2013) Automatic submerged arc surfacing of structural steels with transverse high-frequency movements of electrode. The Paton Welding J., 6, 34-37.

5. Simutenkov, I.V., Dragan, S.V., Gal, A.F. Device for electrode wire feed. Pat. 104894 Ukraine. Fil. 21.12.2011. Publ. 25.03.2014.

6. $R D$ 212.0080-87: Guiding document on standardization. Rules. Automatic submerged arc surfacing of steel cylindrical parts with carbon and corrosionresistant steel. Fundamentals. Introd. 01.03.88.

7. Leskov, G.I. (1970) Electric welding arc. Moscow: Mashinostroenie.

8. Paton, B.E., Lebedev, V.K. (1966) Electric equipment for arc and electroslag welding. Moscow: Mashinostroenie.

9. Dragan, S.V., Simutenkov, I.V., Ignatenkov, O.V. (2012) Procedure for determination of parameters of electrode high-frequency mechanical oscillations in automatic submerged arc surfacing. Visnyk DDMA, 3, 124-129.

Received 30.50.2014 


\title{
INCREASE OF SERVICE PROPERTIES OF ELECTRIC-ARC AND PLASMA COATINGS BY USE OF ELECTRIC-PULSE EFFECT ON DOUBLE-PHASE HIGH-TEMPERATURE FLOW
}

\author{
A.N. DUBOVOJ, A.A. KARPECHENKO and M.N. BOBROV \\ Admiral Makarov National Shipbuilding University \\ 9 Geroev Stalingrada Ave., 54025, Nikolaev. E-mail: welding@nuos.edu.ua
}

\begin{abstract}
There are publications on increase of physical-mechanical properties of coatings by means of modulation of plasma arc and using of additional sources of electric field intensity. The work studies an influence of electric and pulse effect on double-phase high-temperature flow (DHTF), and, as a result, on structure and service properties of electric-arc and plasma coatings. Relationship of amplitude-frequency characteristics of high-voltage electric pulses with microstructure and properties of obtained coatings was investigated. It is shown that electric-pulse effect promotes for reduction of metal drops in DHTF and provides denser structure of plasma powder of PG-19M-01 grade and electric-arc coating from wire Sv-08G2S. 18-30\% rise of adhesion strength, 20-35\% of hardness and 1.7 times increase of wear resistance are observed. 8 Ref., 3 Tables, 5 Figures.
\end{abstract}

Keywords: thermal coatings, electric pulse, hardness, wear resistance, adhesion strength

Development of technologies for strengthening and reconditioning of machine parts and their assemblies is still relevant problem, which is manly solved at current stage of development of science and technology by deposition of functional coatings using the methods of thermal spraying (TS). In recent time, plasma and electric-arc methods receive more and more attention among TS methods. The plasma method is characterized by ability of deposition of coatings from refractory materials as well as versatile. Interest to electric-arc spraying is explained by high method efficiency, manufacturability and low cost. However, both methods have disadvantages, namely high porosity level (from 6 to $12 \%$ ) and low adhesion strength (to $30 \mathrm{MPa}$ for electric-arc coatings and to $50 \mathrm{MPa}$ for plasma ones). Additional technological operations, i.e. surface melting, electromechanical treatment, soaking etc. are used for increase of physical-mechanical properties of thermal coatings. This results in rise of coating cost due to increase of energy-consumption, usage of additional materials and development of new devices.

It is known fact that rise of physical-mechanical properties of plasma coatings can be provided by pile-up of short pulses on direct current of plasma arc. Thus, works [1,2] show that plasmatron during arc modulation is transformed in a source of shock waves, which interact with spray particles on spraying distance. This interaction results in refining and acceleration of particles, that provides for increase of physical-mechanical properties of obtained coatings. Wellknown works [3, 4] are dedicated to plasma spraying using additional source of electric field intensity. According to performed investigations, the conclusions were made on positive influence of given effect on particle rate and coating adhesion strength.

Aim of the present work lies in investigation of effect of electric-pulse effect on double-phase high-temperature flow (DHTF) and, as a result, on structure and service properties of electric-arc and plasma coatings.

Electric-arc coatings from Sv-08G2S grade wire and plasma coatings from PG-19M-01 grade powder were selected as object for investigation. Electric-arc coatings were deposited on KMD-2 machine by EM-14M spraying element using the following mode: arc voltage $25 \mathrm{~V}$, amperage $110 \mathrm{~A}$, pressure of compressed air $0.6 \mathrm{MPa}$, spraying distance $100 \mathrm{~mm}$. Plasma coatings were made on «Kiev-7» machine, equipped by PUN-1 plasmatron at following mode: arc voltage $180 \mathrm{~V}$, amperage $150 \mathrm{~A}$, spraying distance $180 \mathrm{~mm}$, consumption of plasma gas $6.5 \mathrm{~m}^{3} / \mathrm{h}$, pressure of transporting gas $0.01 \mathrm{MPa}$. Compressed air was used as plasma and transporting gases. Coating hardness was measured using Vickers type device at $5 \mathrm{~kg}$ loading on indenter. Metallographic examinations were carried out on optic microscope 
Table 1. Interval of variations and levels of factors at experiment planning for electric-arc and plasma spraying with electric-pulse effect

\begin{tabular}{||l|c|c|}
\hline \multicolumn{1}{|c|}{ Factor } & Frequency, kHz & Voltage, $\mathrm{kV}$ \\
\hline Coded designation & $X_{1}$ & $X_{2}$ \\
\hline Zero level $X_{i 0}$ & 6 & 7.5 \\
\hline Variation interval $\Delta X$ & 2 & 2.5 \\
\hline Low $X_{i}$ level & 4 & 5 \\
\hline Upper $X_{i}$ level & 8 & 10 \\
\hline
\end{tabular}

MMU-3. Coating wear resistance was determined using friction machine SMTs-2, coatingto-base adhesion strength was evaluated by tensile machine UMM-5.

Source of high-voltage electric pulses, directly connected to spraying element, was used for providing of electric-pulse effect on DHTF. Preliminary experiments showed that application of frequencies up to $4 \mathrm{kHz}$ and voltages to $5 \mathrm{kV}$ have no significant effect on strength properties of the coatings and porosity, therefore corresponding ranges of frequency and intensity of electric pulses (Table 1) were selected for experiment planning.

A method of full factorial experiment of $2^{\mathrm{k}}$ type was used for determination of optimum parameters of electric-arc effect on DHTF. Coating hardness was taken as optimizing parameter. Frequency and voltage was selected as variable factors. Such factors as current, voltage, spraying distance etc. were registered at indicated modes. Each mode was used for spraying of five speci- mens, then they were polished to $1 \mathrm{~mm}$ coating thickness and their hardness $H V 5$ was measured.

Tables 2 and 3 give a plan of full factorial experiment and its results.

Regression coefficients were calculated based on statistically processed experimental data, the checks were performed on their importance and adequacy of received models to real process of spraying of electric-arc and plasma coatings on known procedures [5]. The following regression equations were received as a result of mentioned above:

- for electric-arc spraying: $Y=2352+171 X_{1}+$ $+45 X_{2}-65 X_{1} X_{2}$

- for plasma spraying: $Y=1342+62 X_{1}+$ $+24 X_{2}-16 X_{1} X_{2}$.

Built models were used for optimizing of parameters of electric-pulse effect on DHTF by steepest ascent method. The maximum value of hardness for electric-arc spraying was obtained at $6.5 \mathrm{kHz}$, and at $5 \mathrm{kHz}$ for plasma one. Voltage value made $5 \mathrm{kV}$. Analysis of microstructures (Figure 1) indicate that application of electricpulse effect on DHTF results in refinement of coating structural elements as well as reduction of porosity from 6 to $3 \%$ for electric-arc coatings and from 6 to $2 \%$ for plasma ones, at that coating hardness increased per 35 and $20 \%$, respectively.

Size range of spray particles was determined by metallographic method using samples, collected during spraying in water. Images of microstructures were received using digital camera Delta Optic HDCE-20C, equipped with Scope

Table 2. Plan and results of experiments for electric-arc coatings from wire Sv-08G2S

\begin{tabular}{||c|c|c|c|c|c|c|c|c|c|c|}
\hline \hline \multicolumn{3}{|c|}{ Coded value of factors } & \multicolumn{5}{c|}{ Response function, MPa } & \multicolumn{2}{c|}{ Root-mean- } \\
square \\
deviation, \\
MPa
\end{tabular}

Table 3. Plan and results of experiments for electric-arc coatings from powder PG-19M-01

\begin{tabular}{|c|c|c|c|c|c|c|c|c|c|c|}
\hline \multicolumn{4}{|c|}{ Coded value of factors } & \multicolumn{5}{|c|}{ Response function, $\mathrm{MPa}$} & \multirow{2}{*}{$Y_{i}, \mathrm{MPa}$} & \multirow{2}{*}{$\begin{array}{c}\text { Root-mean- } \\
\text { square } \\
\text { deviation, } \\
\mathrm{MPa}\end{array}$} \\
\hline$X_{0}$ & $X_{1}$ & $X_{2}$ & $X_{12}$ & $Y_{1}$ & $Y_{2}$ & $Y_{3}$ & $Y_{4}$ & $Y_{5}$ & & \\
\hline+ & - & - & + & 1330 & 1372 & 1390 & 1400 & 1330 & 1364 & 29.5 \\
\hline+ & - & + & - & 1470 & 1430 & 1450 & 1450 & 1415 & 1443 & 18.9 \\
\hline+ & + & - & - & 1230 & 1270 & 1270 & 1320 & 1270 & 1272 & 28.6 \\
\hline+ & + & + & + & 1290 & 1280 & 1320 & 1294 & 1254 & 1288 & 21.4 \\
\hline
\end{tabular}



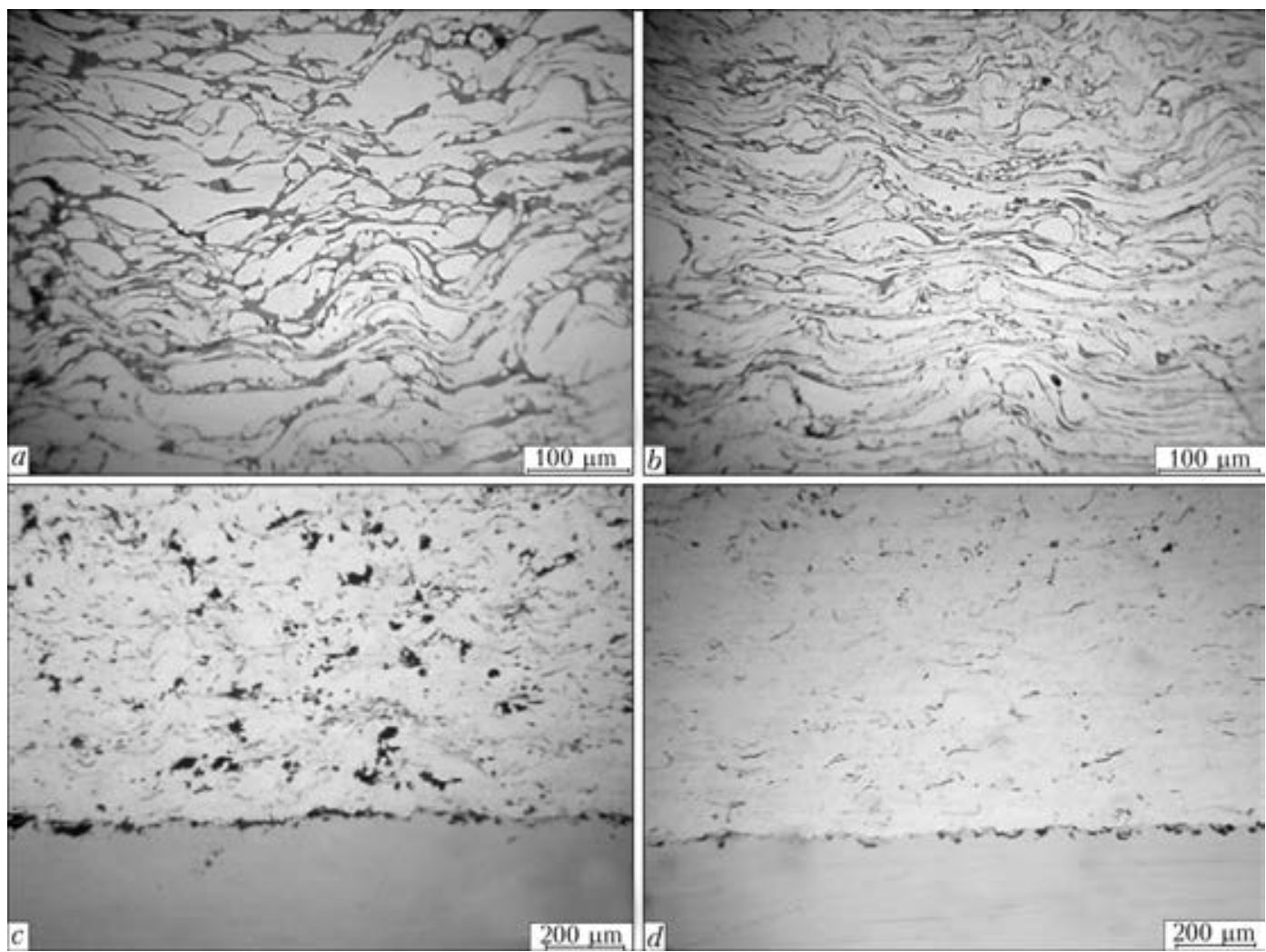

Figure 1. Microstructure of coatings: $a$ - electric-arc coating produced by traditional technology; $b-$ electric-arc coating deposited using electric-pulse effect $(6.5 \mathrm{kHz}, 5 \mathrm{kV}) ; c-$ plasma coating produced by traditional technology; $d$ - plasma coating deposited using electric-pulse effect $(6.5 \mathrm{kHz}, 5 \mathrm{kV})$

Image 9.0 software. Obtained images were analyzed in software metallographic complex MEGRAN. Five samples each, including around 1000 particles, were analyzed in general. Examination results, given in Figure 2, showed that application of electric-pulse effect of optimum mode provides for additional fragmentation of particles in double-phase flow.

Molten metal drops disperse as a result of aerodynamic effect of gas jet in plasma as well as electric-arc spraying. At that, dispersion of

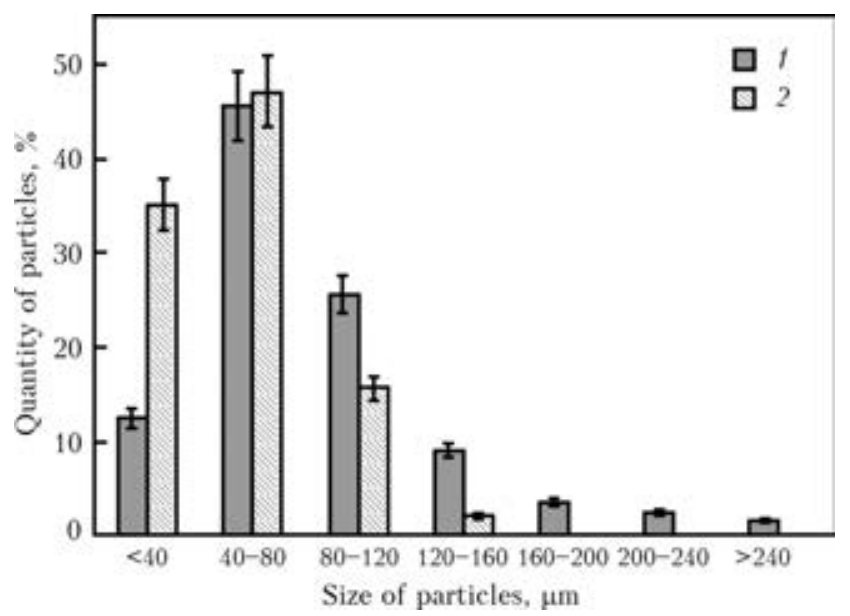

Figure 2. Fractional composition of particles in electricarc spraying: 1 - spraying was carried out using traditional technology; 2 - using electric-pulse effect at optimum mode liquid drop takes place only at reaching of critical droplet diameter, and drop decomposition is impossible at lower size. Further fragmentation of molten drop is possible in two ways in use of additional pile-up of electric pulses on DHTF. The first one is explained by appearance of nonself-maintaining gas discharge in piling-up of pulse potential difference over the spraying distance. The gas discharge is accompanied by ap-

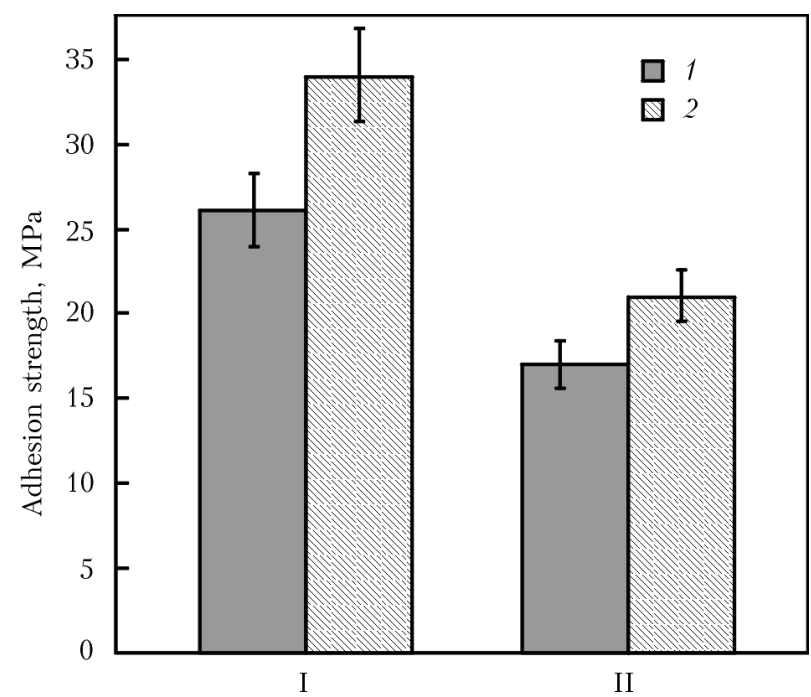

Figure 3. Results of determination of adhesion strength of electric-arc (I) and plasma coatings (II): 1 - spraying was carried out using traditional technology; 2 - using electric-pulse effect at optimum mode 

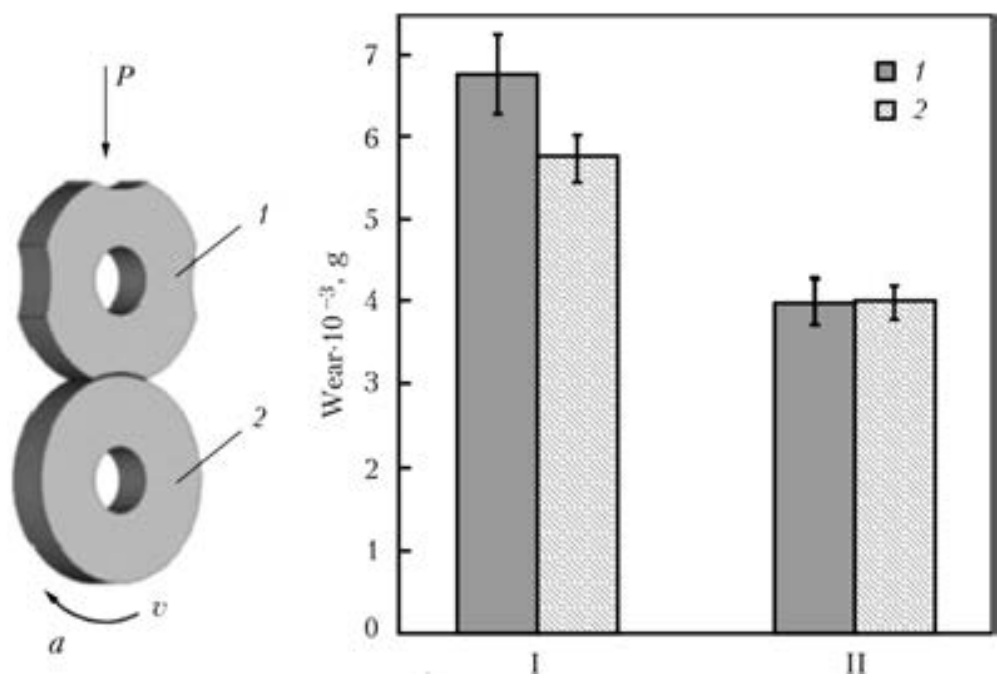

Figure 4. Wear resistance of electric-arc coatings: $a-$ scheme of wear resistance testing $(1-$ shoe; $2-$ roller $)$; $b-$ results of wear resistance testing: I - without pile-up of electric pulses; II - with pile-up of high-voltage electric pulses of $6.5 \mathrm{kHz}$ and $5 \mathrm{kV}(1-$ coating; 2 - shoe $)$

pearance of shock waves, which provide additional dispersion of liquid drops in high-temperature flow. The second one is related with acquiring of additional charge by liquid particles, which results in reduction of their surface tension and particle decomposition due to appearance of Coulomb repulsive forces in alternating electric

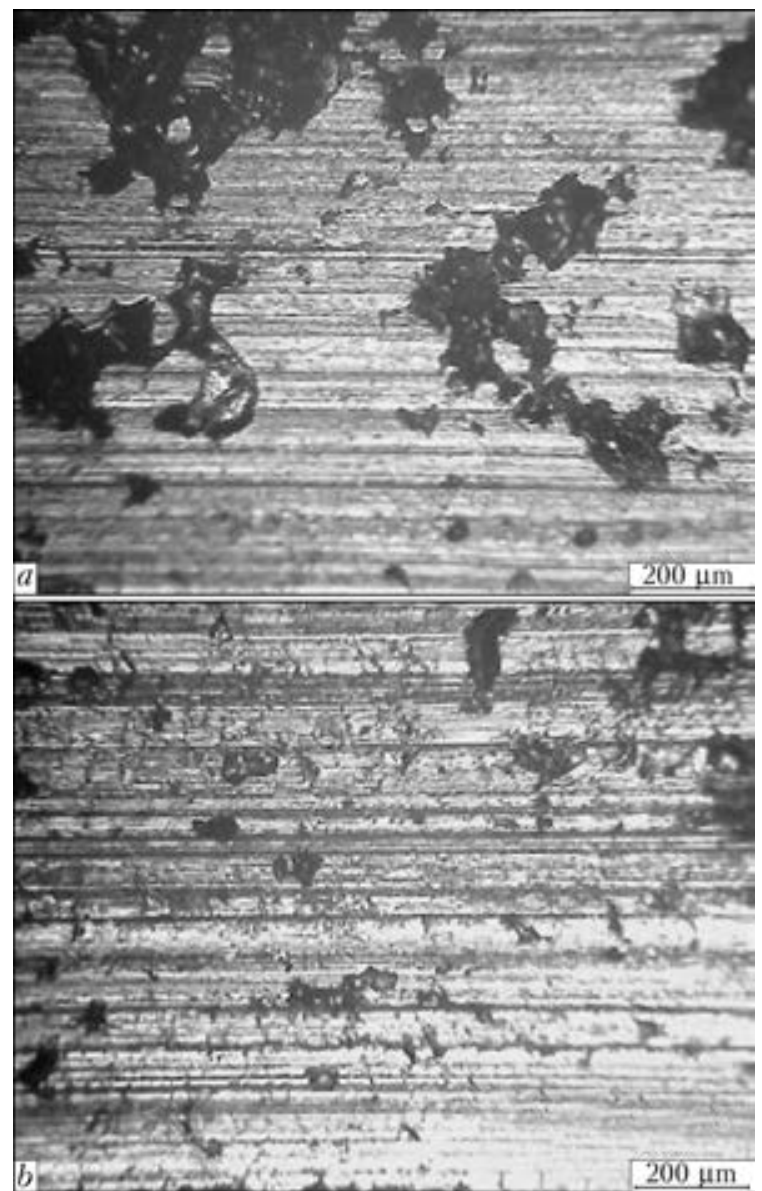

Figure 5. Microstructure of friction surface of sprayed roller: $a$ - spraying by traditional technology; $b$ - using electric-pulse effect at optimum mode field [6-8]. Effect of shock waves provides for rise of particle rate, and reduction of deviation from average diameter related with fragmentation results in decrease of velocity spread. All this provides denser and more uniform package of particles in the coating, its strength increases and porosity reduces.

Tests on coating-to-base adhesion strength and wear resistance were carried out for determination of service properties of the coatings.

Coating-to-base adhesion strength was determined using the method of «pulling of tapered pin». Specimens for determination of adhesion strength were manufactured from quality structural carbon steel 45. The coatings before deposition were degreased by technical ethanol and subjected to jet-abrasive machining. Thickness of the deposited coatings made $0.6 \mathrm{~mm}$. Spraying was carried out using the modes mentioned above. Five specimens were used for one pass spraying at one mode in order to receive the results of coating-to-base adhesion strength. Five parallel tests each were performed for each mode. Figure 3 shows the results of determination of coating-to-base adhesion strength.

Thus, piling-up of high-voltage electric pulses of $5 \mathrm{kV}$ amplitude and $6.5 \mathrm{kHz}$ frequency on DHTF provides for $30 \%$ rise of adhesion strength of electric-arc steel coating and $20 \%$ of bronze plasma one. Increase of adhesion strength of received coatings can be explained through rise of their rate due to fragmentation as well as effect of the shock waves, that provides for larger real area of particle-to-base contact.

Wear resistance of electric-arc coatings was determined on roller-shoe scheme (Figure $4, a$ ) in limited supply of lubrication at 30 drops per minute rate. Engine oil of M10G2K GOST 8581- 
75 grade was used as lubrication. Circumferential speed of rotation of the roller made $0.8 \mathrm{~m} / \mathrm{s}$, pressure $4 \mathrm{MPa}$. Measurements of weight loss were carried out after breaking-in on TBE- 0.21 scales after each $10 \mathrm{~km}$ of pass. In total there were ten measurements each.

Shoe and roller were also manufactured from steel 45. Electric-arc coating was deposited on the roller after degreasing and jet-abrasive machining. The shoe was subjected to heat improvement, i.e. quenching was carried out from $840{ }^{\circ} \mathrm{C}$ for $50 \mathrm{~min}$ and cooling in water. Hardness after quenching made $H R C$ 54-55. Further, tempering was carried out at $550{ }^{\circ} \mathrm{C}$ for $1 \mathrm{~h}$ and cooling in air. Hardness after tempering made HRC 30-32.

Analysis of the results on evaluation of wear resistance (Figure 4, $b$ ) showed that electric-arc coating, deposited using high-voltage electric pulses, has 1.7 times lower wear than coating sprayed using traditional technology.

Analysis of friction surface of the coatings showed that mechanochemical wear-out is typical for studied specimens under set conditions. It is accompanied by formation on the surface of mating pair of films, enriched by oxygen (Figure 5).

Friction surface of the roller, sprayed with pile-up of electric pulses (Figure $5, b$ ) is denser and has porosity 2 times lower than the coating sprayed on traditional technology (Figure $5, a$ ). Figure $5, b$ shows friction traces of small depth which have more uniform arrangement over friction surface, that results in lower wear-out.

It should be noted that price of source for generation of high-voltage electric pulses makes approximately $5 \%$ of cost, for example, of equipment for electric-arc spraying. At that, effect of its application can provide producing of the coat- ings with service properties increased on average by $30 \%$.

\section{Conclusions}

Using of electric-pulse effect on DHTF in electric-arc and plasma spraying of coatings allows reducing size of metal drops in double-phase flow and receiving denser structure of plasma coating from powder PG-19M-01 and electric-arc coating from wire $\mathrm{Sv}-08 \mathrm{G} 2 \mathrm{~S}$. Determined are the optimum parameters of electric-arc effect in plasma and electric-arc spraying of the coating, which provide rise of adhesion strength by $18-30 \%$, hardness by $20-35 \%$, respectively, and wear resistance of electric-arc coating in 1.7 times.

1. Gutman, B.E. (1988) Drop refinement in plasma spraying with current modulation. Avtomatich. Svarka, 9, 37-39.

2. Kadyrmetov, A.M. (2012) Study of processes of plasma spraying and strengthening of coatings and ways of their quality control. Nauchny Zhurnal Kub$G A U, 81,1-18$.

3. Korotkikh, V.M. (2011) Controlled energy-saving technologies of plasma spraying of protective coatings for agricultural purpose. Vestnik AltajGAU, 82(8), 83-87.

4. Galyshkin, N.V., Korotkikh, V.M. Unit for plasma spraying. Pat. 2335347 Russia. Int. Cl. B05B7/22. Fil. 09.01.2007.

5. Adler, Yu.P., Markova, E.V., Granovsky, Yu.V. (1976) Planning of experiment in search of optimal conditions. Moscow: Nauka.

6. Grigoriev, A.I. (2000) Electrodispersion of liquid in realization of oscillating instability of its free surface. Zhurnal Tekhn. Fiziki, Vol. 70, Issue 5, 22-27.

7. Grigoriev, A.I. (2000) Capillary electrostatic instabilities. Sorovsky Obraz. Zhurnal, Vol. 6, Issue 6, 37-43.

8. Grigoriev, A.I. (2009) Electrostatic instability of highly-charged spray of conducting liquid. Zhurnal Tekhn. Fiziki, Vol. 79, Issue 4, 36-45.

Received 24.10.2014 


\title{
INSTABILITY OF MODE IN CIRCUIT WITH CAPACITY AND ELECTRIC ARC SUPPLIED BY DIRECT CURRENT SOURCE
}

\author{
E.N. VERESHCHAGO and V.I. KOSTYUCHENKO \\ Admiral Makarov National Shipbuilding University \\ 9 Geroev Stalingrada Ave., 54025, Nikolaev, Ukraine. E-mail: vikmkua@mail.ru
}

\begin{abstract}
Stability and appearance of oscillations in electric arc current were investigated for specific conditions of DC electric circuit. It is indicated that circuit with arc has always parallel to it capacity, formed by unit own capacities. The electric arc as element of electric circuit is described using generalized model, which considers thermal delay of electric arc and does not limit its static volt-ampere characteristic. Considered is an effect of parameters of electric arc on transfer process, conditions of appearance of continuous and divergent oscillations are obtained. Principle and equivalent schemes of investigated circuit are presented. Dissipative properties of oscillation system are characterized with the help of coefficient of circuit attenuation, specific damping as well as coefficient of energy loss in the system. Suppression frequency, pass band, frequency of own oscillations and dynamic resistance of the circuit are determined. Resistive damping of oscillations is studied, desirable value of damping resistor is determined and results of calculations and modelling are illustrated. Received results can be used in designing and adjustment of new power sources for welding and related technologies as well as estimation of damping and stabilizing of operating power sources. 8 Ref., 4 Figures.
\end{abstract}

Keywords: arc welding, electric and plasma arc, stability of process, transfer processes, oscillation damping, calculation and modelling

Stability of electric arc under specific conditions in electric circuit was multiply investigated [18]. It is important to note that circuit with the arc has always parallel to it capacity, formed by unit own capacities. At that output capacity, for example, in welding inverters, is used as a fixing (damping) circuit or for noise reduction [7]. These capacities achieve $0.01 \mu \mathrm{F}$ and even make several microfarads $[1,4,7]$ considering capacity of trigger elements of arc and mains. Now let's study stable and unstable state of electric arc with capacity and its effect on electric circuit in more details.

Electric arc as element of the electric circuit is described in present study using generalized model, which considers thermal delay of the electric arc and does not limit its static volt-ampere characteristic (VAC). As a result, differential resistance $R_{\text {difo }}$ and series to it small stray inductance $L$, shunted by active resistance $R 1$, were simulated in the scheme for investigation of stability of uncontrolled nonlinear resistance electric arc. In this case investigated electric circuit (Figure 1) is formed by parallel connection of ideal current source, element with input arc resistance $Z_{\text {а }}(p)$, resistance $R_{i}$ and capacity $C$.

(c) E.N. VERESHCHAGO and V.I. KOSTYUCHENKO, 2014
Presence of resistor $R_{i}$ takes into account all types of losses in the system, i.e. final (even if sufficiently high), internal (output) resistance of current source as well as effect of external circuits.

Characteristic of impedor is its input (or internal) resistance:

$$
Z_{\text {in }}(p)=Z(p)=\frac{k_{1}+k_{2} p}{1+T_{1} p+T_{2}^{2} p^{2}},
$$

where $k_{1}=R_{\mathrm{dif} 0} ; \quad k_{2}=\theta R_{\mathrm{st} 0} ; \quad T_{1}=\theta+R_{\mathrm{dif} 0} C$; $T_{2}^{2}=\theta R_{\text {st } 0} C ; \theta$ is the constant of arc time

If $p=j \omega$ is included in equation (1), then it describes frequency transfer function of the circuit at $0 \leq \omega \leq \infty$ :

$$
Z(j \omega)=\frac{k_{1}+k_{2} j \omega}{1+T_{1} j \omega+T_{2}^{2}(j \omega)^{2}},
$$

modulus of which and phase are, respectively, the following

$$
\mid Z(j \omega)\}=\frac{\sqrt{k_{1}^{2}+k_{2}^{2} \omega^{2}}}{\sqrt{\left(1-T_{2}^{2} \omega^{2}\right)+T_{1}^{2} \omega^{2}}},
$$

$$
\psi(\omega)+\arg Z(j \omega)+\operatorname{arctg} \frac{k_{2} \omega}{k_{1}}-\operatorname{arctg} \frac{T_{1} \omega}{1-T_{2}^{2} \omega^{2}} .
$$

Formula (1) is good to be represented as follows: 


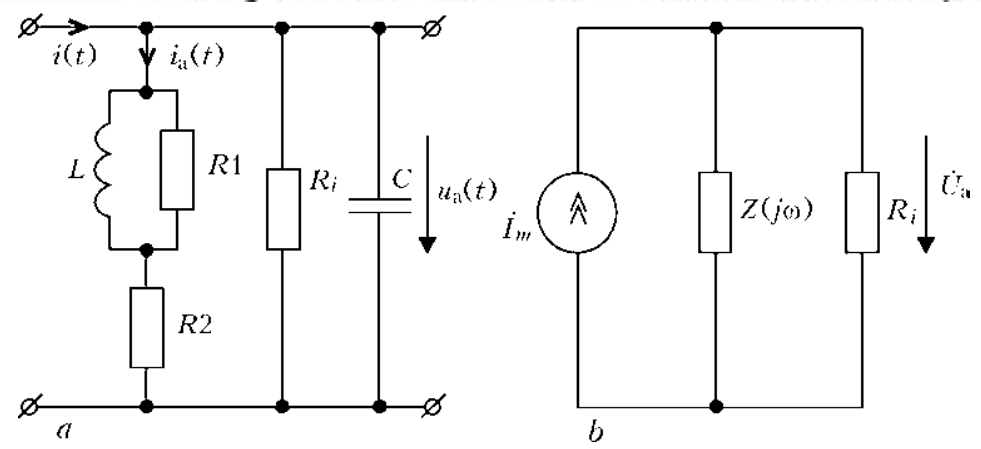

Figure 1. Principle $(a)$ and equivalent scheme of studied circuit $(b): L=\theta\left(R_{\mathrm{st} 0}-R_{\mathrm{dif} 0}\right) ; R_{1}=R_{\mathrm{st} 0}-R_{\mathrm{dif} 0} ; R_{\mathrm{st} 0}, R_{2}=$ $R_{\text {dif } 0}-$ static and differential resistance of arc in selected working point $I_{0}$

$$
Z(p)=\frac{k_{1}+k_{2} p}{1+2 \xi T p+T^{2} p^{2}}=\frac{k_{1}+k_{2} p}{1+\frac{2 \xi p}{\omega_{0}}+\frac{p^{2}}{\omega_{0}^{2}}},
$$

where

$$
T=T_{2}+\sqrt{\theta R_{\text {st } 0} C}
$$

$\xi=T_{1} / 2 T=\frac{1}{2}\left(\frac{\sqrt{\theta}}{R_{\mathrm{st} 0} C}+\sqrt{\frac{C}{\theta R_{\mathrm{st} 0}}} R_{\mathrm{dif} 0}\right)$ is the damping parameter; $\omega_{0}=1 / \sqrt{\theta R_{\mathrm{st} 0} C}$ is the frequency of own oscillations of the system;

$\alpha=\xi \omega_{0}$.

The next representation is used for description of impedor:

$$
Z(j \omega)=r(\omega)+j x(\omega)
$$

where

$$
\begin{aligned}
& r(\omega)=\operatorname{Re} Z(j \omega)=\frac{k_{1}\left(1-T_{2}^{2} \omega^{2}\right)+k_{2} T_{1} \omega^{2}}{\left(1-T_{2}^{2}\right) \omega^{2}+T_{1}^{2} \omega^{2}} ; \\
& x(\omega)=\operatorname{Im} Z(j \omega)=\frac{k_{2} \omega\left(1-T_{2}^{2} \omega^{2}\right)-k_{1} T_{1} \omega}{\left(1-T_{2}^{2} \omega^{2}\right)=T_{1}^{2} \omega^{2}} .
\end{aligned}
$$

Given operator resistance has the only zero at $p=-R_{\mathrm{dif} 0} / R_{\mathrm{st} 0} \theta$ and two poles in points with coordinates

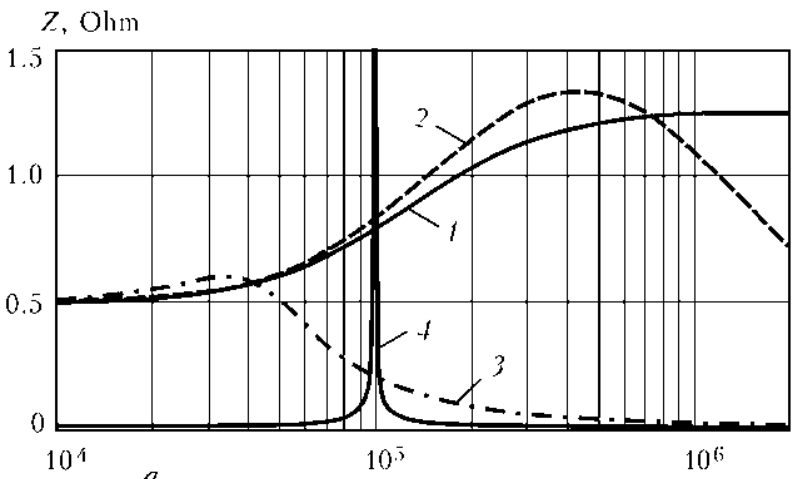

$$
\begin{aligned}
P_{1,2}= & -\alpha \pm j \sqrt{\omega_{0}^{2}-\alpha^{2}}=-\frac{1}{2}\left(\frac{1}{R_{\mathrm{st} 0} C}+\frac{R_{\mathrm{dif} 0}}{R_{\mathrm{st} 0} \theta}\right) \pm \\
& \pm j \sqrt{\frac{1}{\theta R_{\mathrm{st} 0} C}-\frac{1}{4}\left(\frac{1}{R_{\mathrm{st} 0} C}+\frac{R_{\mathrm{dif} 0}}{R_{\mathrm{st} 0} \theta}\right)^{2}},
\end{aligned}
$$

which can be complexly-associated as well as real ones depending on relationship between $\omega_{0}$ and $\alpha$.

Figure 2 shows the family of amplitude- and phase-frequency characteristics of the circuit with following parameters: $\theta=1 \mu \mathrm{s} ; R_{\mathrm{st} 0}=$ $=1.25 \mathrm{Ohm}, R_{i}=\infty, R_{\mathrm{dif} 0}=-0.49 \mathrm{Ohm}$.

Generation of divergent own oscillations in the electric circuit with losses (see Figure 1, $a$ ) is possible only, if the circuit, in addition to passive elements $R, L, C$, includes also active ones, transmitting part of energy from external sources into the circuit. A widespread model of such active element is a resistor with negative resistance. Studied circuit becomes unstable (will be self-excited), if present in it negative resistance $R_{\text {difo }}>R_{\text {dif0 cr }}$ (condition of self-excitation lies in complete compensation of circuit loss).

Capacity $C$ can be selected in such a way that the impedor would be damped in desired pass band, that eliminates effect of resonance peak. Cutoff frequency of the impedor can be made respectively large in selection of capacity $C$, providing value of damping parameter around 0.7 .

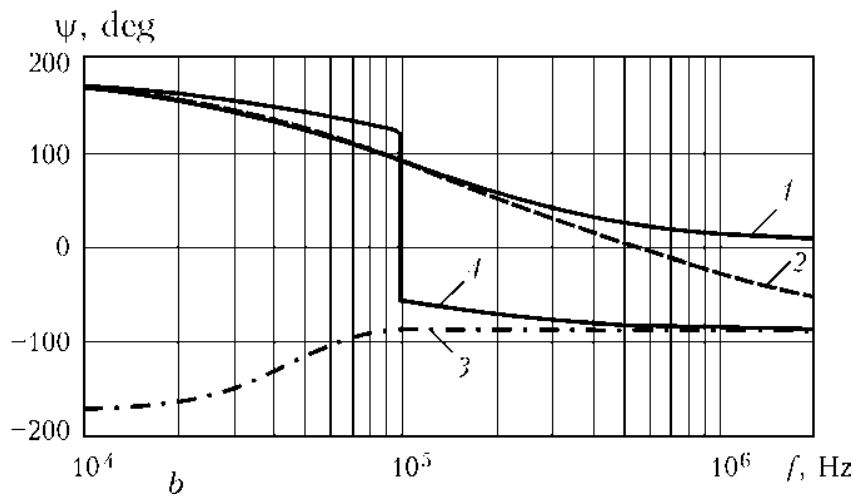

Figure 2. Amplitude- $(a)$ and phase-frequency $(b)$ characteristic of impedor: $1-C=0 ; 2-0.1 ; 3-10 ; 4-2.041 \mu \mathrm{F}$ 
In this case, the impedor is a low-frequency system, pass band of which represents itself frequency range from zero to cutoff frequency $\omega_{C}$. It should be noted that the impedor frequency band is, roughly speaking, frequency range in which $Z(j \omega)$ value is close to 1 . Accurate value of the cutoff frequency, certainly to significant extent, depends on figure $\xi$.

Differential equation of given circuit, made in relation to voltage $u(t)$ based on input circuit resistance, has the following appearance:

$$
\begin{gathered}
\theta R_{\mathrm{st} 0} C \frac{d^{2} u}{d t^{2}}+\left(R_{\mathrm{dif} 0} C+\theta\right) \frac{d u}{d t}+u= \\
=\theta R_{\mathrm{st} 0} \frac{d i}{d t}+R_{\mathrm{dif} 0} i .
\end{gathered}
$$

Varying of $C$ value allows changing the coefficient at $d u / d t$ derivative. It is well known fact that sign and value of this coefficient determine nature of free oscillations in such dynamic system.

If $R_{\mathrm{dif} 0}<0$ in equation (2), then regeneration, i.e. partial compensation of circuit loss, is possible due to feedback.

Let's determine the conditions of self-excitation scheme (see Figure 1, $a$ ) through study of characteristic equation of this system with internal feedback. It should be indicated that, if, for example $Y_{\text {neg }}=S_{\text {dif }}<0$ ( $S_{\text {dif }}$ is the differential slope of VAC curve) is the negative active conductivity, introduced by the electric arc, then the condition of system self-excitation lies in compensation of the circuit loss.

It means that energy, dissipated in the circuit during period of own oscillations, in stationary mode, is exactly equal the energy, coming into the circuit from external sources per given period of time. Such a mechanism of self-excitation was termed as internal feedback [3, 5 . 7]. RLC-circuit is an oscillating system in this case, and $Y_{\text {neg }}$ (active element) being feedback element.

Roots $\gamma_{1}$ and $\gamma_{2}$ of characteristic equation (2) have real parts

$$
\operatorname{Re} \gamma_{1,2}=-\frac{R_{\mathrm{dif} 0} C+\theta}{2 \theta R_{\mathrm{st} 0} C} .
$$

The system develops into unstable mode, when $\operatorname{Re} \gamma_{1,2}$ value becomes zero. At that since $\left(1-R_{\text {dif } 0} / R_{\text {st } 0}>0\right)$, then own continuous harmonic oscillations of the following form are received:

$$
u_{\text {own }}(t)=A \sin \left(\omega_{0} t+\varphi\right),
$$

where $A, \varphi$ are determined by initial values of $u\left(t_{0}\right)$ and $\dot{u}\left(t_{0}\right)$.
If condenser capacity $C$ achieves the critical value $C_{\mathrm{cr}}=-\theta S_{\mathrm{dif}}$, then the characteristic equation is transformed into

$$
d^{2} u / d t^{2}+\omega_{0}^{2} u=0,
$$

where $\omega_{0}=\omega_{C} \sqrt{1-\frac{R_{\mathrm{dif} 0}}{R_{\mathrm{st} 0}}}=\frac{1}{\sqrt{L C}} \sqrt{1-\frac{R_{\mathrm{dif} 0}}{R_{\mathrm{st} 0}}}$ is the frequency of own oscillations.

Critical value of negative resistance is found based on

$$
R_{\text {difo cr }}=-\theta / C .
$$

It can be seen from the latter expression that the lower the condenser capacity $C$, the more the negative resistance, necessary for circuit self-excitation, is.

Figure 1, $a$ shows the circuit with parameters $C=1 \mu \mathrm{F}, \theta=10 \mu \mathrm{s}, R_{\text {dif } 0 \mathrm{cr}}=-10$ Ohm. If $R_{\text {dif } 0}=$ $=-2 \mathrm{Ohm}$, then $C_{\mathrm{cr}}=5 \mu \mathrm{F}$.

It is obvious that electric arc with parallel capacity has stable arcing, until fulfillment of condition $\theta>-C R_{\text {difo }}$.

Dissipative properties of the oscillating system can be characterized using coefficient of circuit attenuation $\alpha$, relative damping $\xi=\alpha / \omega 0$ (dimensionless parameter) as well as coefficient of energy loss $\eta=2 \alpha / \omega_{0}$ in the system. Energy dissipation can be also estimated with the help of absorption coefficient $\psi$, related by simple approximated dependence with other characteristic of the process of energy dissipation in the system, namely logarithmic oscillation decrement $\delta: \psi=$ $=2 \delta=4 \pi \alpha / \omega_{0}=4 \pi \ln A_{1} / A_{2}$, where $A_{1}, A_{2}$ are the amplitudes of two neighbor oscillations relatively to set value. Approximated formula from work [7] $\eta=2 \delta / \sqrt{4 \pi^{2}+\delta^{2}} \approx \delta\left(1-0.0127 \delta^{2}\right) / \pi$, error of which does not exceed $1 \%$ at $\delta \leq 3$, can be used at large $\delta$ values and at low damping $\left(\delta^{2}<<6\right) \eta=\delta / \pi=\psi / 2 \pi$.

Circuit becomes unstable at $C>C_{\mathrm{cr}}$. Introducing parameter

$$
\alpha=\frac{1}{2}\left[-\theta / L C-R_{\mathrm{dif} 0} / L\right]\left(1-\frac{R_{\mathrm{dif} 0}}{R_{\mathrm{st} 0}}\right)>0,
$$

differential equation is received:

$$
\frac{d^{2} u}{d t^{2}}-2 \alpha \frac{d u}{d t}+\omega_{0}^{2} u=0,
$$

solution of which describes harmonic oscillations with amplitude exponentially increasing in time

$$
u(t)=A e^{\alpha t} \cos \sqrt{\omega_{0}^{2}-\alpha^{2}} t+B e^{\alpha t} \sin \sqrt{\omega_{0}^{2}-\alpha^{2}} t,
$$

where $A$ and $B$ are the constants, depending on initial conditions. 

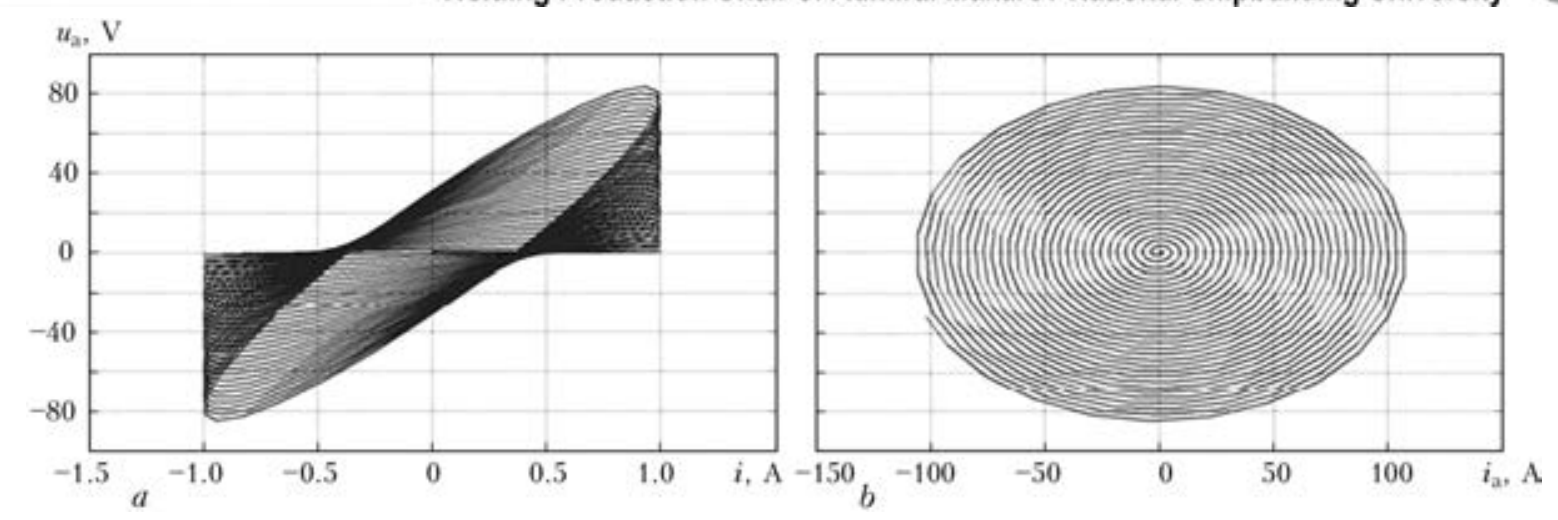

Figure 3. $u$-i-diagrams: $a-u_{\mathrm{a}}=f(i) ; b-u_{\mathrm{a}}=f\left(i_{\mathrm{a}}\right)$

If $\alpha<<\omega_{0}$, then in accordance with (3) the basic frequency of auto-oscillations, appearing in linear mode, is close to the frequency of circuit own oscillations.

Referring to equivalent circuit (see Figure 1, $b)$, it can be seen that current with complex amplitude $I_{\mathrm{m}}$, coming from the current source, flow through resistance

$$
\begin{gathered}
Z_{\mathrm{eq}}(j \omega)=Z(j \omega) R_{i} /\left[Z(j \omega)+R_{i}\right]= \\
=\frac{p \theta R_{\mathrm{st} 0}+R_{\mathrm{dif} 0}}{p^{2} \theta R_{\mathrm{st} 0} C+p\left[R_{\mathrm{dif} 0} C+\theta\left(1+R_{\mathrm{st} 0} / R_{i}\right)\right]+R_{\mathrm{dif} 0} / R_{i}+1} .
\end{gathered}
$$

Simple transformations show that

$$
Z_{\text {eq }}(j \xi)=\frac{R_{\text {res.eq }}}{1+j \xi_{\text {eq }}},
$$

where $R_{\text {res.eq }}=R_{\text {res }} /\left(1+R_{\text {res }}\right) / R_{i}$ is the equivalent resistance of circuit at resonance considering discharge resistance $R_{i}$; $\xi_{\text {eq }}=\xi_{0} /\left(1+R_{\text {res }}\right) / R_{i}$ is the equivalent generalized detuning; $\xi_{0}$ is the dimensionless generalized detuning at $R_{i}=\infty$.

It can be assumed that effect of $R_{i}$ lies in the fact that quality factor of the oscillating system reduces and becomes equal the equivalent quality factor

$$
Q_{\text {eq }}=\frac{Q}{1+R_{\text {res }} / R_{i}} .
$$

According to the latter formula, reduction of effect of $-R_{\text {res }}$ on the oscillating system requires decreasing of resonance resistance $R_{\text {res }}$ by means of $R_{i}$ parallel connection.

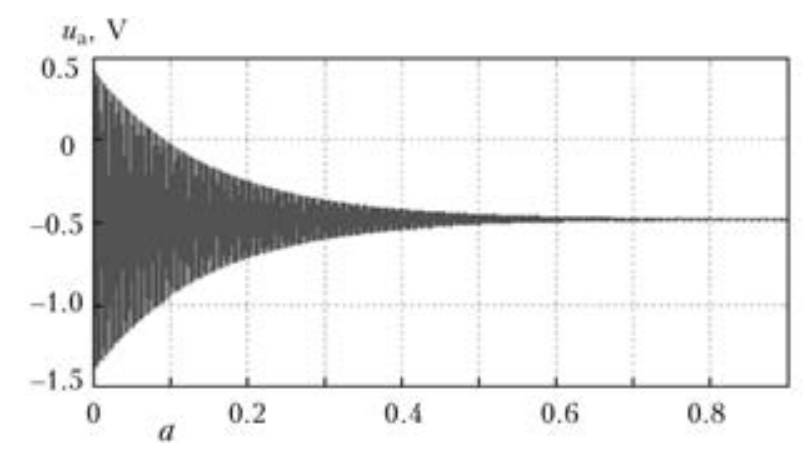

Let's study parallel oscillating circuit of the following parameters: $\theta=1 \mu \mathrm{s}, R_{\mathrm{st} 0}=1.25 \mathrm{Ohm}$, $R_{\text {dif } 0}=-0.49 \mathrm{Ohm}, C=C_{\mathrm{cr}}=2.041 \mu \mathrm{F}$, tuned for $f_{\text {res }}$ frequency. Frequency of own oscillations in the circuit

$$
\begin{aligned}
& \omega_{0}=\frac{1}{\sqrt{\theta R_{\mathrm{st} 0} C}} \sqrt{1-R_{\mathrm{dif} 0} / R_{\mathrm{st} 0}-\frac{C}{\theta} R_{\mathrm{dif} 0}^{2} / R_{\mathrm{st} 0}}= \\
& =0.626 \cdot 10^{6}\left(\mathrm{~s}^{-1}\right) ; \quad f_{0}=99.7 \cdot 10^{3} \mathrm{~Hz} \approx 100 \mathrm{kHz} .
\end{aligned}
$$

Resonance frequency of oscillating system

$$
R_{\mathrm{res}}=\frac{R_{\mathrm{dif} 0}\left[\left(\theta \omega_{0}\right)^{2} R_{\mathrm{st} 0} / R_{\mathrm{dif} 0}+1\right]}{\left(\theta \omega_{0}\right)^{2} R_{\mathrm{st} 0} / R_{\mathrm{dif} 0}+1}=-10.66(\mathrm{kOhm}) .
$$

Equivalent resistance of the circuit with resonance considering shunting effect $R_{i}\left(R_{i}=\right.$ $=10 \mathrm{kOhm}$ ) is

$$
R_{\text {res.eq }}=161.52 \mathrm{kOhm} .
$$

$\xi_{\text {eq }}=0$ in circuit resonating, therefore it follows from (4) that resonance coefficient of circuit transfer is

$$
K_{\text {res }}=R_{\text {res.eq }}
$$

It is obvious that active resonance resistance of circuit $R_{\text {res }}$ plays for this circuit a role of shunting resistor $R$ without consideration of internal source and damping resistor (introduced by resistance $R_{i}$ ).

If $R_{\text {res }}<0$ is the active constituent of input circuit resistance at resonance, and $1 / R_{i}>0$ is

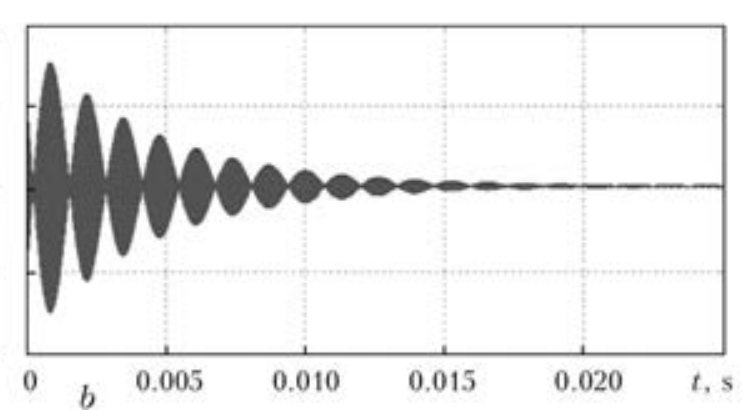

Figure 4. Circuit response on $R_{i}=10(a)$ and $1(b) \mathrm{kOhm}$ switching function 
the parallel conduction, introduced by current source and damping resistor, then the condition for providing of stability and absence of self-oscillation (stabilizing and damping) will take the form

$$
-R_{i} / R_{\text {res }}<1 \text {. }
$$

If this condition is fulfilled, then damping, reflected by member with positive coefficient in the main equation of small oscillation, results in attenuation of oscillations. Studied system will be self excited, if negative resistance present in it is lower than introduced resistance $-R_{\text {res }} / R_{i \text { in }}$. It should be indicated that instability-promoted overvoltages influence the unit in whole.

Figure 3 shows an example of calculation results. At that the main conditions with $\theta=1 \mu \mathrm{s}$, $R_{\text {dif } 0}=-0.49 \mathrm{Ohm}, C=2.041 \mu \mathrm{F}$ were selected in such a way as to provide instabilities. It should be noted that appearing instability results in oscillations of voltage as well as arc current.

Spiral form of characteristic on $u$-i-diagram (see Figure 3, b) shows that voltage and arc current are phase-shifted relatively to each other.

It is useful to compare circuit transfer characteristics, obtained at different $R_{i} / R_{\text {res }}$ values (Figure 4). If $R_{i}=10 \mathrm{Ohm}$, then the self-oscillations with negative attenuation are received (Figure 4, $a$ ).

At last, in general case, the system transfer characteristic (Figure 4,b) represents itself a quasi-harmonic attenuating oscillation with pulsations.

Effect of $R_{i}$ depending on $R_{i} /\left|R_{\text {res }}\right|$ is demonstrated in rate of reduction of current and arc voltage in time. If values of $R_{i} /\left|R_{\text {res }}\right|$ relationship lie approximately between 0.95 to 0.5 , it promotes significant attenuation of voltage (current) oscillations in comparison with $R_{i}=\infty$ case. If in contrast this relationship is more reduced, then the oscillations will continue attenuation, but relative change is already not so large. Moreover, $R_{i} /\left|R_{\text {res }}\right|$ reduction promotes pulsation appearance.

Thus, resistance $R_{i}$ for resistive damping should make approximately $R_{i} \approx \mid R_{\text {res }}$ in practical application.

\section{Conclusions}

1. Appearance of oscillation is possible in electric circuit with the electric arc. Set oscillation amplitude is determined by type of non-linear characteristic of the electric arc, included in the circuit.

2. Found frequency characteristics of input resistance of the circuit allow determining areas of system instability with complex or non-linear loading.

3. The oscillations attenuate with sufficiently low rate in the circuit, having only resistance damping at $-R_{i} / R_{\text {res }} \approx 1$.

4. Capacity of condenser $C$ can be such selected that the impedor would be damped in desired pass band.

1. Vereshchago, E.N., Kostyuchenko, V.I. (2013) Physical-mathematical model of plasmatron supply circuit. Svarochn. Proizvodstvo, 2, 19-25.

2. Gladkov, E.A. (2006) Control of processes and equipment in welding. Moscow: Akademia.

3. Demirchyan, K.S., Nejman, L.R. (2003) Theoretical principles of electrical engineering. Vol. 2: Theory of electric circuits. St.-Petersburg: Piter.

4. Dyurgerov, N.G., Sagirov, Kh.N. (2009) Stability of system of arc self-adjustment in mechanized and automatic welding. Svarochn. Proizvodstvo, 2, 13-14.

5. Loos, A.V., Lukutin, A.V., Saraev, Yu.N. (1998) Power sources for pulse technological processes. Tomsk: TPI.

6. Sidorets, V.N., Pentegov, I.V. (2013) Deterministic chaos in nonlinear circuits with electric arc. Kiev: IA «Svarka».

7. Vereshchago, E.N., Kvasnitsky, V.F., Miroshnichenko, L.N. et al. (2000) Circuitry of inverter power sources for arc charge: Manual. Nikolaev: NUS.

8. Tsybulkin, G.A. (2002) To the question of GMAW stability. The Paton Welding J., 5, 14-16.

Received 30.05.2014 


\title{
EFFECTIVENESS OF NATURAL GAS TRANSPORTATION BY SEA AT APPLICATION OF HIGH PRESSURE WELDED CYLINDERS
}

\author{
B.E. PATON, M.M. SAVITSKY, A.M. SAVITSKY and A.A. MAZUR \\ E.O. Paton Electric Welding Institute, NASU \\ 11 Bozhenko Str., 03680, Kiev, Ukraine. E-mail: office@paton.kiev.ua
}

\begin{abstract}
The paper gives an assessment of technical and economic capabilities of natural gas transportation by sea, allowing for modern gas carrier design, conditions of their loading and unloading and itinerary. Prospects for application of container version of gas transportation into Ukraine are shown. Preparation period before start of gas supply is shortened to 6 months, as manufacture of light-weight car cylinders and gas pipes has already been mastered in Ukraine. Furtheron, it is recommended to envisage construction and application of specialized gas carriers fitted with long metal-plastic cylinders, which are comparable with short pipelines, that allows reducing the strength margin to 1.75. As a result, cylinder metal content is reduced, and volume of transported gas is increased. Application of high-strength steels of 30KhGSA type to develop such cylinders is promising. 22 Ref., 5 Tables, 7 Figures.
\end{abstract}

Keywords: sea transportation of natural gas, metal-plastic cylinders, long cylinders, high-strength steels, welding with higher heating rate, activating fluxes, economic indices

Welding is an energy-dependent process. Its development is inseparably linked to solving the problems of energy carrier supply, particularly natural gas, which by its energy and ecological characteristics, as well as strategic reserves, surpasses all the currently available energy carriers $[1,2]$.

Ukraine, having the most developed gas-transportation system in Europe, experiences a high shortage of gas. Ukraine's traditional local sources can now cover only one third of its needs [2]. Searching for new traditional deposits on the land and on the shelf involves deep-hole drilling and requires development of engineering facilities. Nontraditional sources - gas-bearing shale, coal beds and other dense collectors have not been well enough studied, either in terms of gas content or risks and, therefore, also require considerable financial and time expenses [2]. Technology of using renewable gas sources has local application so far, the evidence of which is rapid expansion of disposal dumps.

Gas-hydrates have a special place among nontraditional methane sources. They contain up to $70 \%$ of its total world deposits, and in Black Sea economic zone of Ukraine - up to $10^{14}$ $10^{15} \mathrm{~m}^{3}$ [3]. However, commercial production of gas-hydrates has not been mastered yet, and its development is conducted with extreme care be- cause of the risk of violation of ecological equilibrium at the sea floor and methane outburst in hear-earth atmosphere.

Investment proposed by PRC in the amount of 3.4 bln USD for construction of synthetic gas plants of the total capacity of about $10 \mathrm{bln}^{3} /$ year in Donetsk, Lugansk and Odessa regions, as well as 3 bln USD for construction of a superport with oil and gas terminals, will not speed up solution of gas problems, either. The latter coincides with the intentions of Ukrainian gas companies to diversify gas supply through external purchases of liquefied natural gas (LNG). However, construction of receiving terminal for LNG requires not only high financial and time expenses, but also long-term contracts to ensure uninterrupted gas supply. Ukraine does not have any of that, just as it does not have the normative-legal basis for construction of a terminal for LNG receiving and processing.

Technology of supply of compressed natural gas $(\mathrm{CNG})$ is more mobile and less costly.

Current researchers of gas supply problems demonstrate [4-7] that at average distances (up to 3000 nautical miles) and sufficient capacity $\left(\geq 12 \mathrm{mln} \mathrm{m}^{3}\right.$ ) of high-pressure cargo system of gas carriers, CNG technology can be more readily mastered and cost-effective. Compressed gas does not require such deep purification, or expenses for its liquefying, storage and re-gasification (Table 1, Figure 1) [7]. And its receipt does not require high-tech and expensive coastal facilities. Gas loading can be performed directly from GTS 


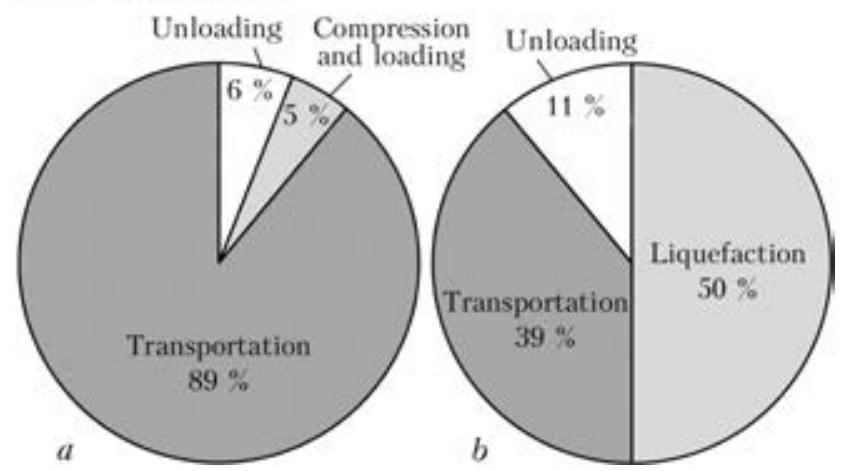

Figure 1. Price components for CNG $(a)$ and LNG (b) projects

or wells on the shelf, and unloading - through GTS into gas storages. As a result, a tradeoff variant is possible, when application of a floating tanker-regasifier and underwater buoy of submerged turret loading type taken out into the sea beyond the port water area, will allow receiving both liquefied and compressed gas. This solution allows application of both LNG and CNG technologies, with the only difference that LNG first passes through re-gasifier to GTS and CNG is supplied directly. Such a solution of gas supply problem will allow using price fluctuation

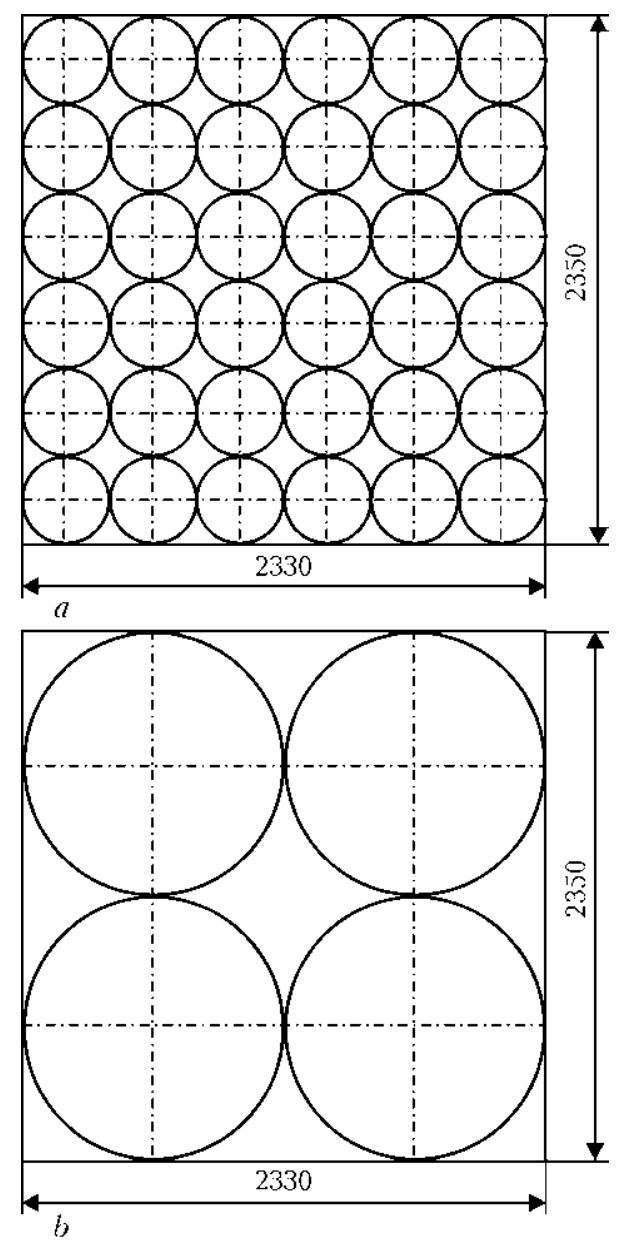

Figure 2. Schematic of container fitting with high pressure cylinders (horizontal location): $a-390 \mathrm{~mm}$ diameter; $b-$ $1020 \mathrm{~mm}$
Table 1. Comparison of gas prices depending on distance (data of University of Houston) [7]

\begin{tabular}{||c|c|c|c|}
\hline \multirow{2}{*}{ Distance, miles } & \multicolumn{3}{|c|}{ Kind of gas, USD $/ 1000 \mathrm{~m}^{3}$} \\
\cline { 2 - 4 } & Liquefied & Compressed I & Compressed II \\
\hline 500 & 355 & 272 & 272 \\
\hline 1000 & 365 & $274-284$ & $282-290$ \\
\hline 1500 & 375 & $306-310$ & $315-326$ \\
\hline 2000 & 385 & $330-337$ & $311-362$ \\
\hline 2500 & 395 & $344-390$ & $350-398$ \\
\hline 3500 & 425 & $408-443$ & $398-434$ \\
\hline 5000 & 465 & $484-549$ & $470-543$ \\
\hline
\end{tabular}

Note. I - gas volume of $0.91 \cdot 10^{6} \mathrm{~m}^{3}$; II $-0.15 \cdot 10^{6} ; 1000 \mathrm{~m}^{3}$ gas cost, USD: 75 , liquefaction -40 , gasification -40 .

in the spot market and accelerate diversification of supply.

More over, development of CNG technology will allow faster mastering of Black and Azov Sea shelf in production of traditional natural gas from small and medium-sized deposits, from which it is not cost-effective to lay pipelines of about $9 \mathrm{mln} \mathrm{UAH} / \mathrm{km}$ cost to the coast. Application of CNG-carriers (vessels or barges) provides a cardinal solution of the problem of gas supply to the shore. Trying this technology out in the USA in 1960s at large distances, however, turned out to be less effective, compared to LNG. However, the situation is changing cardinally, in connection with shelf mastering and closer located users entering the market.

The objective of this work was evaluation of technical and economic capabilities of natural gas transportation by sea, allowing for design features of cargo system of modern gas carriers, conditions of their loading-unloading and itineraries.

Investigations of technical capabilities and cost-effectiveness of application of CNG technology in Ukraine point to two variants of its realization. The first is based on application of currently available container carriers, which can be converted into gas carriers, fitting their containers with welded cylindrical metal-plastic cylinders (Figure 2) [8, 9]. Technical characteristics of 20 and 40 feet sea containers and weight and dimensional characteristics of the cylinder components are given in Table 2 .

Container variant of gas transportation in Ukraine allows reducing to 6 months the preparatory period for the start of gas supply, as manufacture of light-weight car cylinders and gas pipes has already been mastered in Ukraine. For the future, however, construction and use of 
Table 2. Technical characteristics of 20 and 40 feet sea containers and weight-and-dimensional characteristics of cylinder components (liner material is unidirectional glass-reinforced plastic)

\begin{tabular}{|c|c|c|c|c|c|c|c|c|}
\hline \multirow{4}{*}{ Shell material } & \multirow{4}{*}{$\begin{array}{c}\text { Cylinder } \\
\text { diameter, } \\
\mathrm{mm}\end{array}$} & \multirow{4}{*}{ Characteristics } & \multicolumn{6}{|c|}{ Working pressure, MPa } \\
\hline & & & \multicolumn{2}{|c|}{20} & \multicolumn{2}{|c|}{25} & \multicolumn{2}{|c|}{30} \\
\hline & & & \multicolumn{6}{|c|}{ Container size, feet } \\
\hline & & & 20 & 40 & 20 & 40 & 20 & 40 \\
\hline \multirow{7}{*}{$\begin{array}{c}\text { Heat-treated } \\
\text { steel 30KhGSA } \\
\left(\sigma_{\mathrm{t}}=960 \mathrm{MPa}\right)\end{array}$} & \multirow[t]{3}{*}{390} & Cylinder $m / V, \mathrm{~kg} / 1$ & 0.65 & 0.64 & 0.73 & 0.71 & 0.82 & 0.80 \\
\hline & & Weight of container with cylinders, kg & 15772 & 32232 & 17464 & 35328 & 19336 & 39324 \\
\hline & & Gas volume in container at $20^{\circ} \mathrm{C}, \mathrm{n} \cdot \mathrm{m}^{3}$ & 4176 & 8814 & 5220 & 11018 & 6264 & 13222 \\
\hline & \multirow[t]{4}{*}{1020} & Cylinder $m / V, \mathrm{~kg} / 1$ & 0.64 & 0.64 & 0.71 & 0.70 & 0.81 & 0.80 \\
\hline & & Cylinder weight, $\mathrm{kg}$ & 8856 & 19788 & 9824 & 21644 & 11208 & 24736 \\
\hline & & Weight of container with cylinders, $\mathrm{kg}$ & 11056 & 23688 & 12024 & 25544 & 13408 & 28636 \\
\hline & & Gas volume in container at $20^{\circ} \mathrm{C}, \mathrm{n} . \mathrm{m}^{3}$ & 2770 & 6184 & 3460 & 7730 & 4152 & 9276 \\
\hline \multirow{5}{*}{$\begin{array}{c}\text { X80 steel pipe } \\
\text { GOST } 1078 \\
\left(\sigma_{t}=640 \mathrm{MPa}\right)\end{array}$} & \multirow[t]{5}{*}{1020} & Cylinder volume, 1 & 3460 & 7730 & 3460 & 7730 & 3460 & 7730 \\
\hline & & Cylinder $m / V, \mathrm{~kg} / 1$ & 0.81 & 0.80 & 0.92 & 0.90 & 1 & 0.99 \\
\hline & & Cylinder weight, $\mathrm{kg}$ & 11160 & 24600 & 12732 & 27828 & 13840 & 30612 \\
\hline & & Weight of container with cylinders, kg & 13360 & 28500 & 14932 & 31728 & 16040 & 34512 \\
\hline & & Gas volume in container at $20{ }^{\circ} \mathrm{C}, \mathrm{n} . \mathrm{m}^{3}$ & 2770 & 6184 & 3460 & 7730 & 4152 & 9276 \\
\hline
\end{tabular}

modern specialized gas carriers should be envisaged, which have the capability for further improvement of cargo system. A combination of the two projects should be used as an analog here [5], complementing it by our own developments on metal-plastic cylinders [8]. Coselle project envisages winding 156-162 $\mathrm{mm}$ diameter up to 10 miles long pipe into a bundle, that, by the decision of US coast service, can be regarded as a section of floating pipeline with strength margin of 1.75 instead of 2.5. This allows lowering the module weight (one tank), increase by $30 \%$ the number of modules on a vessel, and the total volume of cargo system, respectively.

The project disadvantage is the complexity of bundle manufacturing, which only three to four plants in the world can cope with. Therefore, it is believed to be more rational to use the idea, underlying the «Vortrans» project. The latter envisages laying long cylinders into a sealed cooled hold along the entire ship hull. The project authors propose increasing the capacity of gas carrier cargo system due to cooling the cylinders with gas to $-30{ }^{\circ} \mathrm{C}$. Here, either the cylinder metal content can be lowered, or their capacity can be increased as a result of gas pressure lowering.

However, lowering working temperatures, in addition to energy losses, is known to involve increase of brittleness of high-strength steels, which can provide maximum improvement of weight and dimensional characteristics of cylin- ders. Therefore, it is more rational to apply reinforcement of cylinder bodies by glass-reinforced plastic. This will allow eliminating expenses for cooling at loading and for heating at unloading, reducing their metal content and eliminating the possibility of embrittlement and fragmentation in case of formation of a fatigue or brittle crack. In addition, long cylinders (200$300 \mathrm{~m}$ ) can be regarded as looping (pipeline branches), which, similar to the main pipelines, are allowed to operate with a lower strength margin. Experience of their operation in densely populated regions of many countries has been confirmed many times. Now, having applied successive binding of cylinders, they can be connected into one floating pipeline [9, 10].

Thus, the cargo system of CNG carriers can be improved due to either reducing the wall thickness and, therefore, metal content without changing the working pressure, or increasing the working pressure at unchanged wall thickness and metal content [9].

It is common knowledge that at loading by inner pressure of a cylindrical cylinder with semispherical covers, axial stresses

$$
\sigma_{\mathrm{a}}=\frac{r_{\text {in }}}{2 \delta} \frac{P_{\text {work }}}{\varphi_{\mathrm{w}}} K_{\mathrm{m}}
$$

are 2 times lower than radial stresses

$$
\sigma_{\mathrm{r}} \frac{r_{\text {in }}}{\delta} \frac{P_{\text {work }}}{\varphi_{\mathrm{w}}} K_{\mathrm{m}},
$$




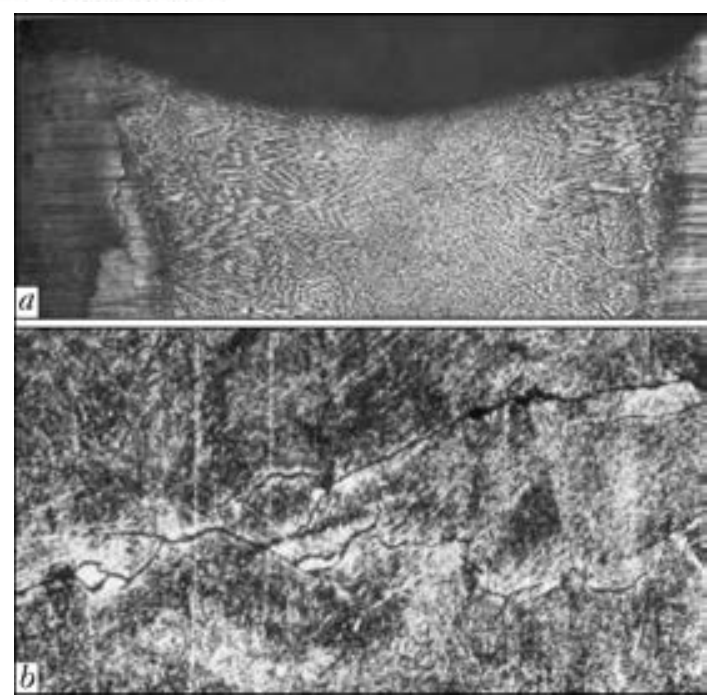

Figure 3. Fatigue cracks in welded joints of 30KhGSA steel: $a$ - welded joint macrosection; $b$ - secondary microstructure of welded joint $(\times 300)$

where $\sigma_{\mathrm{a}}$ and $\sigma_{\mathrm{r}}$ are the axial and radial stresses in cylinder walls, respectively, MPa; $r_{\text {in }}$ is the cylinder inner radius, $\mathrm{mm} ; \delta$ is the wall thickness of cylinder metal body, $\mathrm{mm} ; P_{\text {work }}$ is the working gas pressure in the cylinder, MPa; $\varphi_{\mathrm{w}}$ is the weld strength factor; $K_{\mathrm{m}}$ is the coefficient of strength margin.

Therefore, additional strengthening is required only for the cylindrical part of the body.

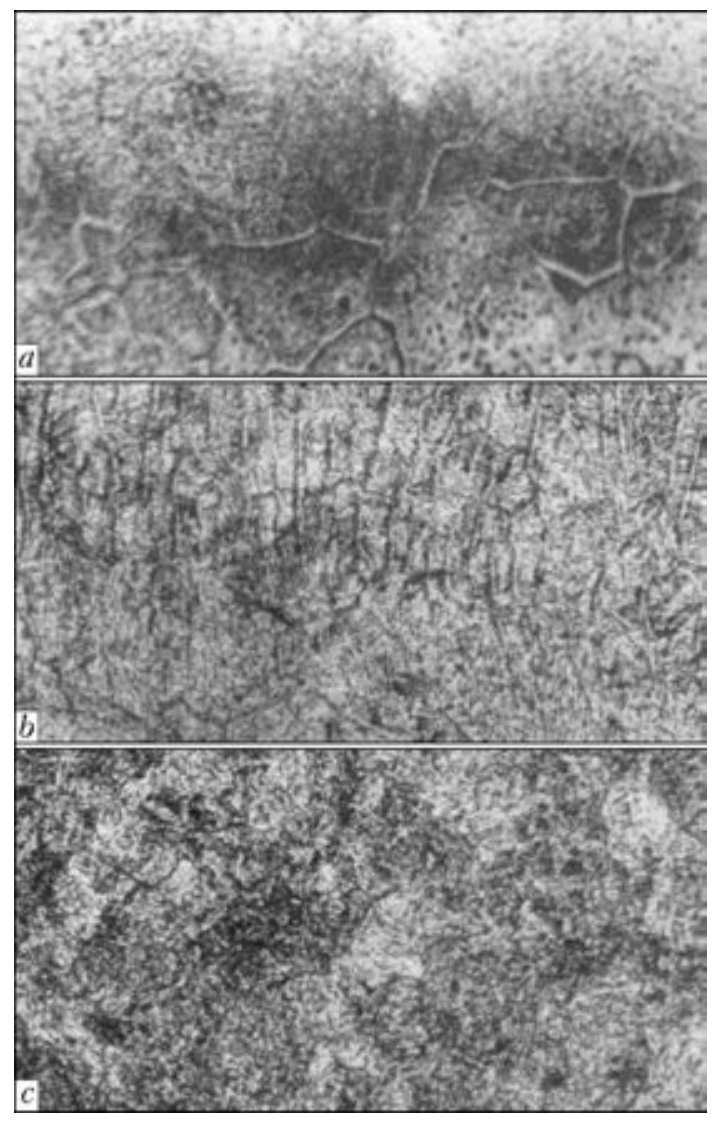

Figure 4. Microstructure $(\times 260)$ of welded joint: $a$ - before quenching; $b$ - after quenching; $c$ - after thermomechanical treatment
Using for this purpose lighter $\left(1.8-2.2 \mathrm{~g} / \mathrm{cm}^{3}\right)$ glass-reinforced plastic, the strength of which is equal to that of steel, it is possible to reduce cylinder weight by $30-40 \%$, doubling its static strength and increasing its cyclic fatigue life 3 to 5 times [8]. The latter is due to lowering of the influence of surface concentrators as a result of their filling by binder.

Modern high-strength steels allow, depending on heat treatment modes, changing strength characteristics from 600 to $2000 \mathrm{MPa}$ [11]. Here, welded joints with welds of identical composition under static loading can have equal strength to that of base metal [12]. The situation changes, however, at low-cycle loading. Fatigue life (number of loading-unloading cycles) of welded joints depends essentially on local stress concentrations and microplastic deformations, as a result of higher, compared to base metal, physical and chemical inhomogeneity, particularly at fusion boundary [13]. Figure 3 gives typical fatigue cracks in overheated region of boundary zone. It is seen that they are related to crystalline structure of metal exposed to thermal cycle of welding. Elimination of unfavourable consequences of this impact required a package of structure improvement techniques, including thermal cycles of welding and subsequent treatment of cylinders, particularly longitudinal welds oriented normal to radial stresses.

It is experimentally established that to ensure the required fatigue life of metal-plastic cylinders with steel bodies [14], it is necessary to achieve metal ductility and toughness values not lower than $\delta_{5} \geq 12-15 \%, \alpha_{\mathrm{n}} \geq 80 \mathrm{~J} / \mathrm{cm}^{2}$. Comprehensive thermomechanical treatment of longitudinal welds, as welded body sections the most vulnerable and sensitive to local stress concentrations, improves their structure (Figure 4), and provides the required combinations of ductility and toughness of welded joint metal, extending the fatigue life of combined cylinders (Figure 5).

At glass roving strength of $940-1180 \mathrm{MPa}$ steel (30KhGSA) and composite shells have quasiequal strength, and at equal thickness after 15,000 loading-unloading cycles they preserve their strength margin $\geq 2.6 \sigma_{\mathrm{t}}$. In case of application of $09 \mathrm{G} 2 \mathrm{~S}$ steel, the strength of which is equal to about $490 \mathrm{MPa}$ [15], to achieve the required strength margin of the cylinder, it is required to increase steel body thickness by almost 2 times, if the reinforcing shell is formed only on the cylindrical part. Reduction of cylinder body wall thickness, as shown by joint investigations of PWI and Institute of Mechanics 


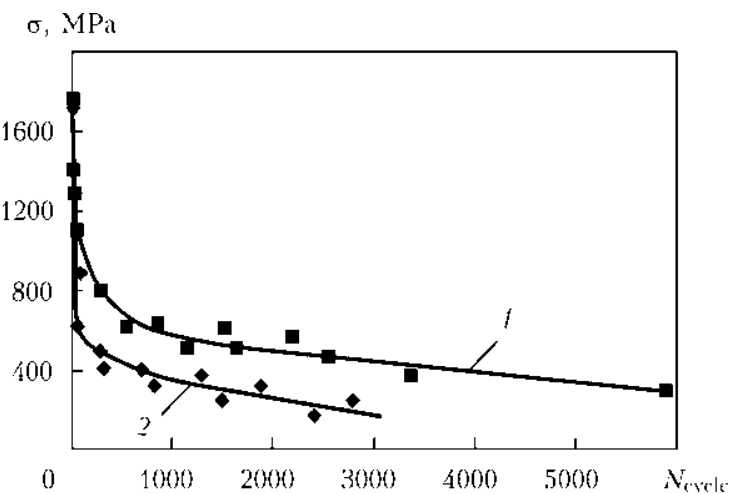

Figure 5. Curves of cylinder performance under cyclic loads: 1 - after thermomechanical treatment; 2 - after heat treatment

of NASU, is achieved by forming a «cocoon» type shell.

It is difficult to realize winding of long cylinders into a «cocoon». Therefore, an optimum solution here can be increase of either pipe wall thickness, or steel strength point in proportion to cylinder diameter (expressions (1) and (2), Figure 6).

High-strength steels of 30KhGSA type, having high $\sigma_{t}$ and $\sigma_{y}$ values, are prone to quenching in air with formation of low-ductile structures that, under certain conditions, can lead to crack initiation in welded joints. It also is important to note that 30KhGSA steel, alloyed by silicon, has almost 2.4 times lower heat conductivity than that of iron [15, 16]. This lowers the intensity of heat removal from the welding zone, and extends the duration of metal staying in high temperature range, that intensifies development of chemical microinhomogeneity of weld metal, lowering metal mechanical properties and its resistance to crack initiation and propagation [12, 17]. Therefore, the rationality of preheating and concurrent heating of $30 \mathrm{KhGSA}$ steel in welding is questionable. More useful, as shown by investigations, is increase of cooling rate above point $A_{(r)}$, and certain slowing of joint cooling at temperatures of completion of austenite decomposition with the purpose of decomposition products self-tempering and increase of their ductility.

Experience of welding and heat treatment of steels of the above group [18-20] confirms that elimination of heating allows forming in the joints fine-grained structures of tempered martensite or bainite-martensite mixture just due to parameters of thermal cycle of welding. One of the methods to solve this problem is application of welding modes with increased $\left(\geq 500{ }^{\circ} \mathrm{C} / \mathrm{s}\right.$ ) rates of metal heating, that is achieved either by increase of energy concentration in the arc, or reduction of heating duration at application of an arc with lower concentration.
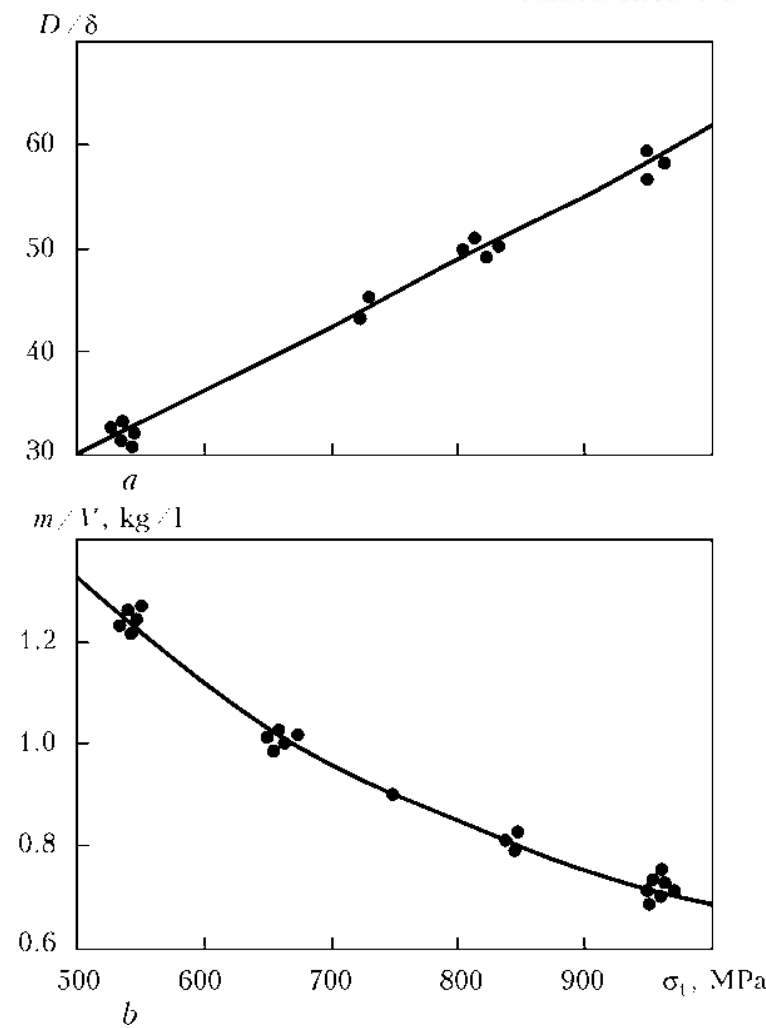

Figure 6. Influence of steel strength on the ratio of pipe diameter to wall thickness $(a)$ and cylinder weight to its volume $(b)$

Activating fluxes are an effective means of increasing heating concentration [21, 22]. Heat power of the arc in consumable-electrode welding usually is $2-3$ times higher than with nonconsumable electrode at the same welding currents. Therefore, in order to obtain an equivalent effect, nonconsumable-electrode welding with activating flux is performed at rates approximately $2-3$ times lower than in gas-shielded consumableelectrode welding with activating flux. Maximum influence on kinetics of structure formation in the first case is achieved at up to $6 \mathrm{~mm}$ metal thickness, when metal heating rates are equal to $\geq 600-700{ }^{\circ} \mathrm{C} / \mathrm{s}$. With increase of metal thickness the rates of heating in nonconsumable-electrode welding with activating flux decrease abruptly, therefore, it is rational to apply gas-shielded consumable-electrode welding with activating flux. It allows welding $10-20 \mathrm{~mm}$ thick metal in one pass with heating rates of $\geq 3000{ }^{\circ} \mathrm{C} / \mathrm{s}$, that essentially reduces the time of metal staying in the region of high temperatures during heating, and also reduces the volumes of overheated metal.

It is known that increase of rates of highstrength metal heating is accompanied by its accelerated cooling and, therefore, quenching with formation of higher hardness zones (Figure 7, curve 1). Metal hardness in the zone here is 1.52 times higher than that of thermally improved base metal. Therefore, for high pressure vessels, 
$I I^{\prime} 0.2$

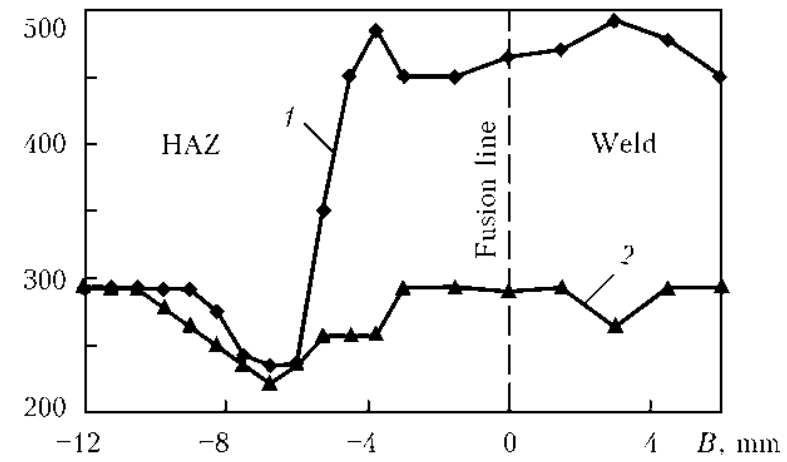

Figure 7. Influence of local tempering on microhardness in weld metal and HAZ: 1 - after welding; 2 - after local tempering

local tempering of welded joints is envisaged, in keeping with the requirements of [14]. Its aim is to achieve maximum leveling of the difference between hardness of metal strengthened to $900-$ $1000 \mathrm{MPa}$ and hardness of weld metal and HAZ (Figure 7, curve 2). Here, as follows from the above Figure, the softening zone practically does not change its characteristics, yet does not go beyond the limits of admissible hardness and strength, i.e. its performance is commensurate with that of base metal. By absolute value metal strength in the softening zone is below base metal strength by just $\leq 10 \%$, and impact toughness here is almost 2 times higher. Studies of stamped covers showed that local lowering of strength margin within the above limits does not influence item performance. Moreover, $15 \%$ increase of work loads at cylinder testing does not reduce their strength margin. This can be the prerequisite for increase of working pressure in the cylinders, at which the design strength margin can be allowed to be lowered to 1.75 . This will permit better use of reserves incorporated in cylinder design due to the fact that minimum values of mechanical properties, obtained at uniaxial tension, are usually assumed in calculations. These values are higher under the conditions of biaxial loading. Characteristics of cylinders with strength margins of 2.5 and 1.75 are shown in Table 3.

Table 3. Cylinder variants for cargo system of specialized CNG-carriers (planned mass of pipelines on the ship is 85.5 thou t)

\begin{tabular}{|c|c|c|c|c|}
\hline \multirow{4}{*}{ Parameter } & \multicolumn{4}{|c|}{$K_{\mathrm{m}}$} \\
\hline & \multicolumn{2}{|c|}{2.5} & \multicolumn{2}{|c|}{1.75} \\
\hline & \multicolumn{4}{|c|}{$\sigma_{\mathrm{t}}, \mathrm{MPa}$} \\
\hline & 640 & 960 & 640 & 960 \\
\hline Pipe typesize & MP1220 × 27.06 & MP1220 × 18.04 & MP1220 × 18.3 & MP1220 $\times 12.2$ \\
\hline Length of pipelines on the ship, $\mathrm{km}$ & 77.2203 & 07.9273 & 106.4463 & 145.0136 \\
\hline
\end{tabular}

Table 4. Technico-economic indices of sea transportation of $10 \mathrm{bln} \mathrm{m}^{3}$ of gas per year to 1 thou $\mathrm{km}$ distance

\begin{tabular}{|c|c|c|c|c|c|c|c|c|}
\hline \multirow{3}{*}{$\begin{array}{c}\text { Aggregate state of gas } \\
1\end{array}$} & \multirow{2}{*}{\multicolumn{2}{|c|}{$\begin{array}{l}\text { Investments, mln USD } \\
\text { (place) }\end{array}$}} & \multicolumn{4}{|c|}{ Operating costs, mln USD } & \multirow{2}{*}{\multicolumn{2}{|c|}{$\begin{array}{l}\text { Sum of expenses in } \\
20 \text { years }[2]+[6] \text {, } \\
\text { mln USD (place) }\end{array}$}} \\
\hline & & & \multicolumn{2}{|c|}{ In 1 year (place) } & \multicolumn{2}{|c|}{ In 20 years (place) } & & \\
\hline & 2 & 3 & 4 & 5 & 6 & 7 & 8 & 9 \\
\hline NGH (crystalline hydrates) & \multicolumn{2}{|c|}{$2644(\mathrm{~V})$} & \multicolumn{2}{|c|}{$606(\mathrm{~V})$} & \multicolumn{2}{|c|}{$12120(\mathrm{~V})$} & \multicolumn{2}{|c|}{$14764(\mathrm{~V})$} \\
\hline LNG & \multicolumn{2}{|c|}{$2030(\mathrm{IV})$} & \multicolumn{2}{|c|}{243 (II) } & \multicolumn{2}{|c|}{4860 (II) } & \multicolumn{2}{|c|}{$6890(\mathrm{III})$} \\
\hline $\mathrm{CNG}\left(K_{\mathrm{m}}=1.75\right)$ & \multicolumn{2}{|c|}{1348 (II) } & \multicolumn{2}{|c|}{$210(\mathrm{I})$} & \multicolumn{2}{|c|}{$4200(\mathrm{I})$} & \multicolumn{2}{|c|}{$5548(\mathrm{I})$} \\
\hline $\mathrm{CNG}\left(K_{\mathrm{m}}=2.5\right)$ & \multicolumn{2}{|c|}{1771 (III) } & \multicolumn{2}{|c|}{$282(\mathrm{IV})$} & \multicolumn{2}{|c|}{$5720(\mathrm{IV})$} & \multicolumn{2}{|c|}{$7491(\mathrm{IV})$} \\
\hline CNG (container carrier renting) & \multicolumn{2}{|c|}{$1251(\mathrm{I})$} & \multicolumn{2}{|c|}{270 (III) } & \multicolumn{2}{|c|}{5400 (III) } & \multicolumn{2}{|c|}{6651 (II) } \\
\hline
\end{tabular}

Table 5. Rating of methods of sea transportation of $10 \mathrm{bln}^{3}$ of natural gas per year depending on shipment distance

\begin{tabular}{||l|c|c|c|c|c||}
\hline \multirow{2}{*}{\multicolumn{1}{c|}{ Aggregate state of gas }} & \multicolumn{5}{c||}{ Shipment distance, km } \\
\cline { 2 - 6 } & 620 & 1000 & 2000 & 3000 & 5000 \\
\hline NGH (crystalline hydrates) & V & V & V & V & V \\
\hline LNG & IV & III & II-I & II & II \\
\hline CNG $\left(K_{\mathrm{m}}=1.75\right)$ & I & I & I-II & IV & IV \\
\hline CNG $\left(K_{\mathrm{m}}=2.5\right)$ & III & IV & IV & III & III \\
\hline CNG $($ container carrier renting) & II & II & III & & \\
\hline
\end{tabular}


PWI developed an algorithm and required software, allowing performance of multifactorial technico-economic evaluation of the proposed variants of gas transportation, determination of required capital and operating costs, depending on volume and distance of gas transportation, its aggregate state, vessel size and type of cargo system of gas carriers, navigation water areas, terms of passing straits and channels, port and other charges.

Capital investments included construction of receiving terminal (its coastal and offshore part), and construction of the required number of tankers. Alongside new ship construction, also renting variants were considered, including those with ship refitting and mounting gas transportation system.

The following variants of gas delivery itineraries of different length were considered, including those from off-shore wells in the Azov-Black Sea shelf $(220 \mathrm{~km}))$, within the Black Sea area (Supsa-Feodosia, $620 \mathrm{~km}$ ), variant with going beyond the Black Sea limits: Egypt-Ilyichevsk (1971 km); Skikda-Ilyichevsk (2843 km), Shardzhi-Ilyichevsk $(7384 \mathrm{~km})$.

Variants of transportation of crystalline hydrates (NGH), LNG, CNG with coefficients of strength margin of ship gas transportation system $K_{\mathrm{m}}=2.5$ and 1.75 , and of renting ships for container shipments of compressed gas were considered. Results of calculations given in Tables 4 and 5, led to the following conclusions.

CNG transportation can unambiguously be recommended for servicing the Azov-Black Sea shelf. Capital investments and annual current costs are 1.5-2 times lower than with LNG.

At increase of shipment leg to $620 \mathrm{~km}$ (that includes all possible itineraries within Black Sea water area), the advantage of compressed gas over liquefied gas in terms of capital costs is 1.2 times, and current expenses become practically equal.

For cases related to going beyond the Black Sea limits through Bosporus, Dardanelles, and the more so beyond Mediterranean Sea limits through the Suez Channel, the variant of gas transportation in the liquefied state can be unambiguously recommended. With $200 \mathrm{~km}$ leg the capital investments still remain to be equal, but current costs drop by $10 \%$. With $3000 \mathrm{~km} \mathrm{leg}$ the capital investments and current costs decrease by $15 \%$, with more than $7000 \mathrm{~km}$ leg capital investments decrease by $40 \%$, and current costs - by $30 \%$.

1. (2012) Methane is the fuel of 21st Century! wzw. neoplan.ru / nevs / Metan. 16.05.2012.

2. (2013) How future gas-extraction in Ukraine is evaluated. Ukrainian power engineering 23.05.2013. http: / / ua-energy.org / post/32050

3. Karp, I.M., Eger, D.O., Zarubin, Yu.O. et al. (2006) State-of-the-art and prospects of development of oil-and-gas complex of Ukraine. Kyiv: Naukova Dumka.

4. Votintsev, A.V. (2007) Transportation of natural compressed gas. Gaz. Promyshlennost, 3, 62-63.

5. Ren, Ch.G., Zelenovskaya, E.V. (2011) Review of existing methods for transportation of natural gas for long distances and assessment of their applicability. Neft, Gas i Biznes, 3, 3-9.

6. (2006) Offshore transportation of natural compressed gas. Morskaya Birzha, 16(2), 65-69.

7. wrww.uh.edu/news-events/media-publications

8. Paton, B.E., Savitsky, M.M., Savichenko, A.A. (1995) Structure and technology of fabrication of high-pressure vessels. Avtomatich. Svarka, 9, 5-8.

9. Savitsky, M.M., Savitsky, A.M., Suprunenko, V.A. et al. (2013) Determination of parameters of lightweight steel vessels for cargo system of CNG-transportation. Visnyk NUK, 1, 4-14.

10. Paton, B.E., Kryzhanivsky, E.I., Savytsky, M.M. et al. Method of transportation of natural compressed gas by mobile pipeline: Declarat. Pat. on utility model 67664 Ukraine. Int. Cl. F17C 5/00. Fil. 08.12.11. Publ. 27.02.12.

11. Potak, Ya.M. (1972) High-strength steels. Moscow: Metallurgiya.

12. Makara, A.M. (1964) On uniform strength of highstrength steel welded joints. In: New problems of welding engineering. Kyiv: Tekhnika, 247-268.

13. Trufyakov, V.I. (1973) Fatigue of welded joints. Kiev: Naukova Dumka.

14. (2007) Rules for construction and safe service of vessels operating under pressure. Kyiv: Osnova.

15. (1989) Handbook on steel and alloy grades. Ed. by V.G. Sorokin. Moscow: Mashinostroenie.

16. Zinoviev, B.E. (1989) Thermophysical properties of metals at high temperatures: Refer. Book. Moscow: Metallurgiya.

17. Sterenbogen, Yu.A., Petrov, P.F. (1979) Effect of solidification temperature interval on susceptibility of steels to formation of solidification cracks during welding. Avtomatich. Svarka, 7, 10-13.

18. Savitsky, A.M., Vasiliev, V.G., Savitsky, M.M. et al. (2005) Influence of the heating stage on structure formation of welded joints on hardening steels. The Paton Welding J., 1, 15-17.

19. Savitsky, O.M. (2005) Influence of rapid heating on structure of carbon steels at local thermal action. Metaloznavstvo ta Obrobka Metaliv, 4, 33-35.

20. Gridnev, V.N., Meshkov, Yu.Ya., Oshkaderov, S.P. et al. (1973) Physical principles of electrothermal strengthening of steel. Kiev: Naukova Dumka.

21. Dudko, D.A., Savitsky, A.M., Savitsky, M.M. (1996) Gas metal arc welding with activating flux. Avtomatich. Svarka, 10, 54-55.

22. Paton, B.E., Savitsky, M.M., Gvozdetsky, V.S. et al. (2003) Application of active fluxes and active gases to increase efficiency of arc and plasma welding. The Paton Welding J., 5, 2-5.

Received 09.04.2014 


\title{
WEAR-RESISTANT ARC SURFACING OVER THE LAYER OF ALLOYING CHARGE
}

\author{
V.V. PEREMITKO \\ Dneprodzerzhinsk State Technical University \\ 2 Dneprostroevskaya Str., 51918, Dneprodzerzhinsk, Ukraine. E-mail: welding@dstu.dp.ua
}

\begin{abstract}
Given are the results of study of structure, hardness and relative wear resistance of surface layers of parts, restored by submerged arc surfacing with addition of powdered materials and superposition of external magnetic axial field. Using powders of silicon carbide $\mathrm{SiC}$ and aerosil $\mathrm{SiO}_{2}$ the paste-like mixture on the base of GF-021 primer was prepared and deposited by beads along the surfacing direction. During experiments the composition of mixture, number of layers being deposited, eccentricity in arrangement of layers relative to electrode wire axis, as well as induction of external magnetic field were varied. Coming from the obtained results, the highest values of hardness of the deposited metal were observed at $B=20-50 \mathrm{mT}$. Optimum pitch in deposition of layers is 4-6 mm. Hardness is growing with increase of number of layers being deposited. Regression equations of mentioned relationships are presented. Due to external magnetic field it became possible to decrease the heat effect on added powdered materials without melting of their particles. Analysis of microstructures proves the effect of magnetic field on crystallization. The uniform distribution of particles of powdered material was occurred, grain number reached 10-12 over 6-8 initial one. Wear tests revealed the least losses in mass of specimens, deposited with addition of $\mathrm{SiO}_{2}$ particles. In this case the allowable plastic deformation and maximum increase in hardness of surface layers are occurred. 8 Ref., 4 Tables, 4 Figures.
\end{abstract}

$\boldsymbol{K} \boldsymbol{e} \boldsymbol{y} \boldsymbol{w} \boldsymbol{o} \boldsymbol{r} \boldsymbol{s}:$ submerged arc surfacing, external mag netic field, powders $\mathrm{SiC}$ and $\mathrm{SiO}_{2}$, mixtures on the base of primer, analysis of microstructure, hardness, regression relationships, wear resistance

The practice of restoration surfacing of parts in different branches of industry predetermined a great number of directions in development and improvement of methods of traditional arc consumable electrode surfacing. In different times the technology and equipment were offered, which allowed increasing the efficiency of surfacing, providing the deposition of layers in multi-layer coatings in various spatial positions and of different chemical composition, including composite ones [1].

At general tendency of applying non-deficit and inexpensive surfacing materials for restoration and hardening of parts, the main difficulty is encountered in attaining the high wear resistance of contact surfaces being restored. The increase in service characteristics of the deposited working layer is attained usually by the selection and optimizing the chemical composition of electrode or filler surfacing materials and, when necessary, by subsequent heat treatment [1-5].

To increase the term of service of parts, operating under conditions of abrasive wear, the updating of installation for automatic submerged arc surfacing was made, technology of surfacing over the layer of alloying charge was developed,

surfacing of specimens was performed by the developed technology, microstructure and wear resistance of deposited specimens were examined.

The principle of offered changes consists in superposition of controlling axial magnetic field on welding arc during surfacing, which has a retarding effect on rate of molten metal flows in a pool and decreases the depth of base metal penetration [6-8]. The superposition of external magnetic field provides also the increase of transverse sizes of weld pool, thus giving possibility to deposit the powdered filler charge with shifting of its disposition from the arc axis in that weld pool area, where the temperature of molten metal is not relatively high. The latter is important from the point of view of prevention of complete melting of dispersed material, added for refining the structure of metal being deposited and increasing of its wear resistance. Silicon carbide $\mathrm{SiO}$ and aerosil $\mathrm{SiO}_{2}$ with particles size of not more than $200 \mu \mathrm{m}$ were used as dispersed materials. Aerosil is a colloid dioxide of silicon, easily crushed into powder, its technical name is pyrogenic dioxide of silicon.

To improve the conditions of adding and increase in efficiency of effect, the powders of silicon carbide and aerosil were mixed with iron powder $\left(\mathrm{Fe}+\mathrm{SiC}, \mathrm{Fe}+\mathrm{SiO}_{2}\right)$. This allowed improving the assimilation of powders by deposited metal and providing their more uniform concentration in the deposited bead length. For bet- 
ter uniformity of powdered material falling into the bead being deposited, a paste-like mixture on the base of primer GF-021 was prepared, which was then deposited along the line of next deposition at 4-10 $\mathrm{mm}$ pitch in transverse direction (Figure 1).

As the powdered materials are differed by parameters (shape, bulk mass), optimum proportions and consumption of powders per unity of weld length were determined experimentally. The obtained data are summarized in Table 1.

Surfacing of specimens of steel 45 was carried out under flux AN-348A with wire Sv-08A of $3 \mathrm{~mm}$ diameter in the installation of UD-209 type. Surfacing mode: 400 A current, 32-36 V voltage, $160 \mathrm{~m} / \mathrm{h}$ wire feed rate, $12-16 \mathrm{~m} / \mathrm{h}$ surfacing speed, 6-8 $\mathrm{mm}$ surfacing pitch, direct current of reverse polarity. For examination of structure and measurement of hardness the flat specimens of $15 \mathrm{~mm}$ thickness were cut out from deposited plates, and the cylindrical specimens of external diameter from 30 up to $50 \mathrm{~mm}$ and $10 \mathrm{~mm}$ thickness were prepared for wear tests.

By changing the distance $N$, modes of surfacing and characteristics of magnetic field, it is possible to attain that the relatively refractory particles of alloying charge would not be melted completely in the weld pool and after crystallization of the deposited metal would be retained in it in a free state.

During experiments the central non-composition planning of the second order for four factors was made: mixture composition, number of mixture layers being deposited (one to one after drying the latter), eccentricity in arrangement of layer with respect to the torch axis, induction of external magnetic field. Processing of experimental data was carried out by using the package STATISTICA 6.0. Hardness was determined in meter TK-2. Coming from the obtained results, the highest values of hardness of the deposited metal were observed at magnetic induction $\mathrm{B}=$ $=20-50 \mathrm{mT}$ (Table 2$)$.

Table 1. Proportions of mixtures and their consumption per unity of weld length

\begin{tabular}{|c|c|c|c|}
\hline $\begin{array}{l}\text { Number of } \\
\text { mixture }\end{array}$ & $\begin{array}{l}\text { Composition of } \\
\text { mixture }\end{array}$ & $\begin{array}{l}\text { Ratio of } \\
\text { components in } \\
\text { mixture }\end{array}$ & $\begin{array}{l}\text { Consumption of } \\
\text { powder per bead } \\
\text { of } 15 \mathrm{~cm} \text { length, } \mathrm{g}\end{array}$ \\
\hline 1 & \multirow[t]{3}{*}{$\mathrm{SiC}+\mathrm{Fe}$} & $0.04: 1$ & \multirow[t]{3}{*}{0.06} \\
\hline 2 & & $0.08: 1$ & \\
\hline 3 & & $0.12: 1$ & \\
\hline 4 & \multirow[t]{3}{*}{$\mathrm{SiO}_{2}+\mathrm{Fe}$} & $0.15: 1$ & \multirow[t]{3}{*}{0.50} \\
\hline 5 & & $0.30: 1$ & \\
\hline 6 & & $0.45: 1$ & \\
\hline
\end{tabular}

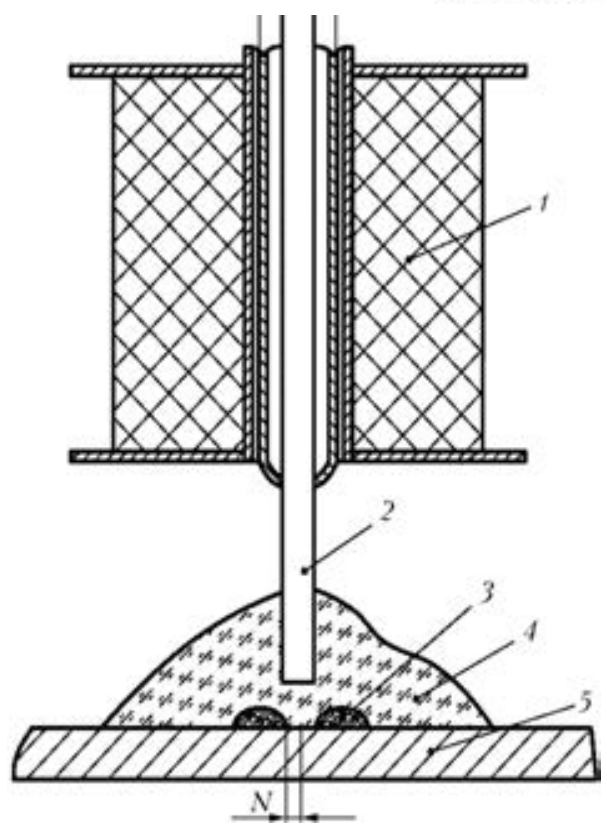

Figure 1. Schematic diagram of automatic submerged arc surfacing over the alloying charge, located out of zone of arc action with magnetic field superposition on arc: 1 coil generating the magnetic field; 2 - wire; 3 - layer of alloying charge; 4 - flux; 5 - specimen being deposited; $N$ - distance from arc center to alloying charge layer

Regression equations of relationships of hardness for two types of mixtures have a form:

$$
\begin{gathered}
H B=156.974+29.190[c]+22.605 n- \\
-2.638[c]^{2}-4.721[c] n-1.829 n^{2},
\end{gathered}
$$

Table 2. Results of determination of hardness of deposited metal

\begin{tabular}{|c|c|c|c|c|c|}
\hline $\begin{array}{l}\text { Number } \\
\text { of } \\
\text { specimen }\end{array}$ & $\begin{array}{l}\text { Number of } \\
\text { mixture }\end{array}$ & $N, \mathrm{~mm}$ & $\begin{array}{c}\text { Number of } \\
\text { mixture } \\
\text { layers } \\
\text { being } \\
\text { deposited }\end{array}$ & $B, \mathrm{mT}$ & $H B$ \\
\hline 1 & $\begin{array}{l}\text { Without } \\
\text { powders } \\
\text { addition }\end{array}$ & 7 & - & 20 & 213.5 \\
\hline 2 & Same & 4 & - & 20 & 217.6 \\
\hline 3 & 6 & 10 & 2 & 50 & 223.0 \\
\hline 4 & 5 & 4 & 2 & 50 & 230.2 \\
\hline 5 & 1 & 10 & 2 & 50 & 215.0 \\
\hline 6 & 2 & 4 & 2 & 50 & 219.7 \\
\hline 7 & 4 & 7 & 2 & 80 & 214.5 \\
\hline 8 & 5 & 7 & 2 & 20 & 220.0 \\
\hline 9 & 3 & 7 & 2 & 80 & 219.7 \\
\hline 10 & 3 & 7 & 2 & 20 & 235.6 \\
\hline 11 & 2 & 7 & 3 & 50 & 220.9 \\
\hline 12 & 4 & 7 & 1 & 50 & 219.1 \\
\hline 13 & 3 & 7 & 3 & 50 & 229.0 \\
\hline 14 & 3 & 7 & 1 & 50 & 227.6 \\
\hline
\end{tabular}
of specimens 

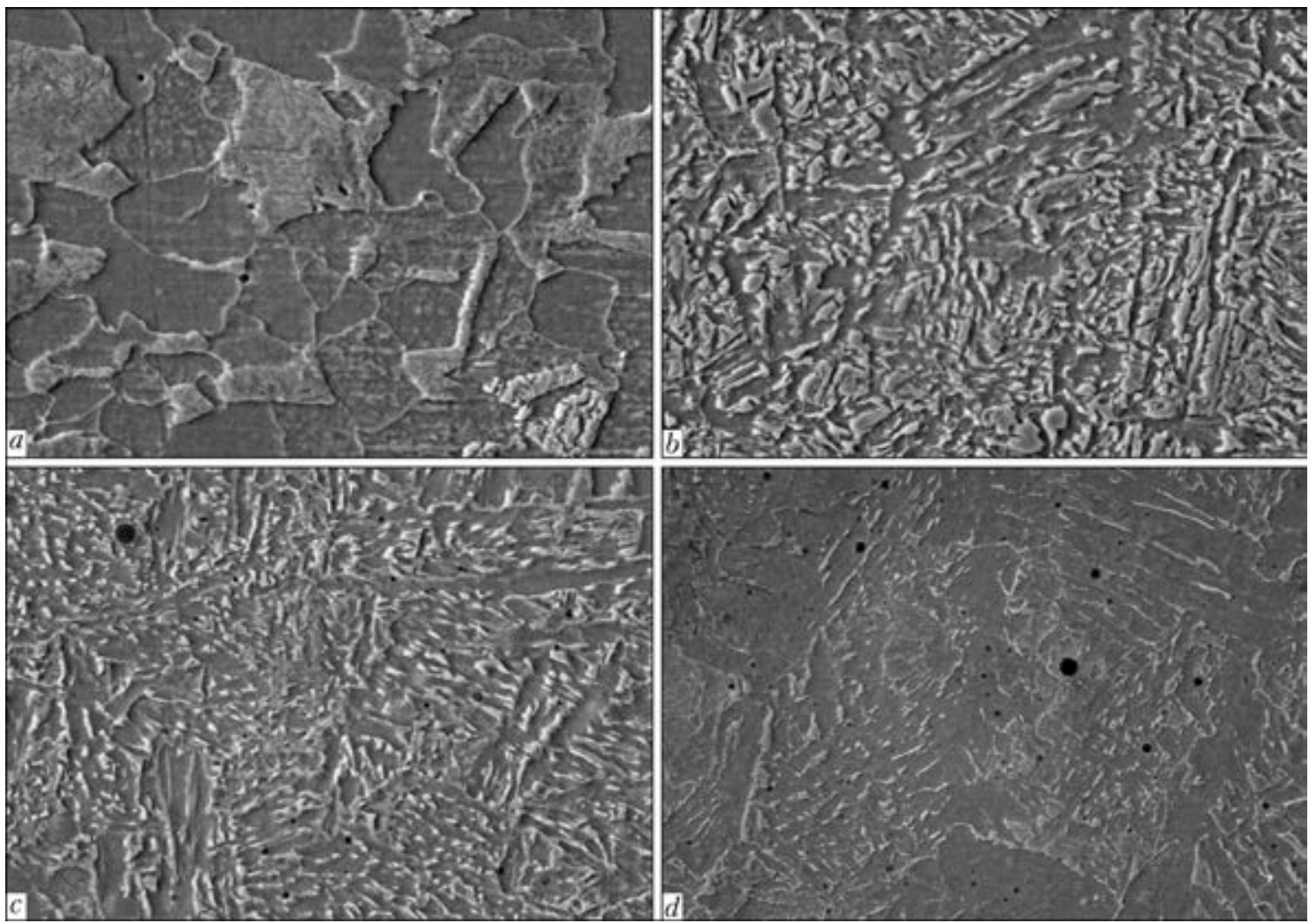

Figure 2. Structure $(\times 1000)$ of deposited metal of specimens: $a-$ base metal (steel 45); $b-$ HAZ; $c, d-$ deposited metal with mixture of powders $\mathrm{SiC}+\mathrm{Fe}$ and $\mathrm{SiO}_{2}+\mathrm{Fe}$ (black spots $-\mathrm{SiC}$ and $\mathrm{SiO}_{2}$ particles, respectively)

$$
\begin{gathered}
H B=177.856+15.427 N-0.176 B- \\
-0.962 N^{2}-0.039 N B+0.002 B^{2} .
\end{gathered}
$$

Equation (1) allows calculating hardness of deposited metal in use of mixture $\mathrm{SiC}+\mathrm{Fe}$. This mixture gives the highest growth of hardness $([c]$ is the concentration of $\mathrm{SiC}$ in mixture, expressed in fact by its number). Equation (2), respectively, allows calculating hardness of deposited metal in use of mixture $\mathrm{SiO}_{2}+\mathrm{Fe}$.

Hardness is growing in change of mixtures composition in the following sequence: (without powder $)<\left(\mathrm{Fe}+\mathrm{SiO}_{2}\right)<(\mathrm{Fe}+\mathrm{SiC})$ and increase in number $n$ of deposited layers of powdered materials up to three $(1<2<3)$. Double applying

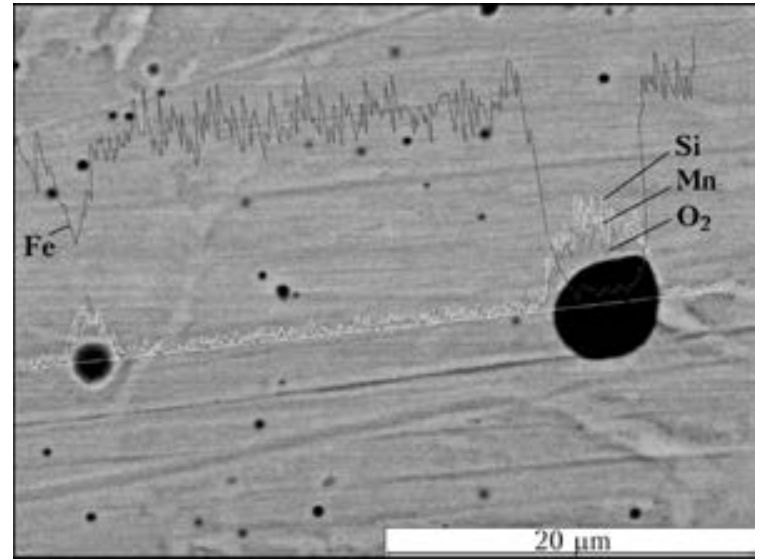

Figure 3. Scheme of scanning of deposited metal of specimens of powder increases the hardness of deposited metal by 1.5 times, and three-time one increases by 1.05 times as compared with double one. Optimum shifting of layers of alloying charge $N$ from weld centre is within the ranges of $4-6 \mathrm{~mm}$.

Specimens were manufactured from deposited plates for examination of microstructure and wear resistance of the deposited metal.

Analysis of microstructures proves the positive effect of magnetic field on the deposited metal crystallization (Figure 2, $a, b$ ). Due to intensive stirring in magnetic field superposition the fer-

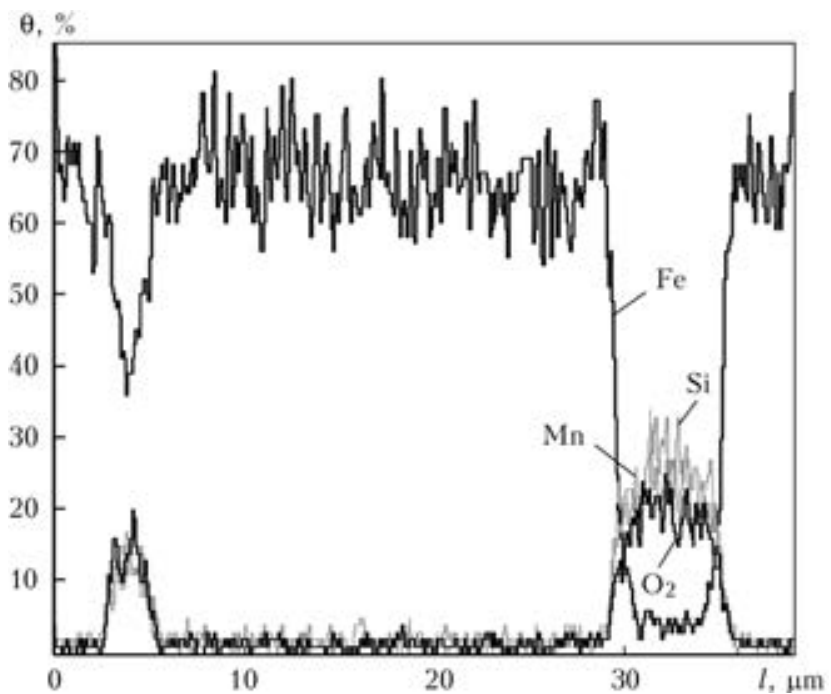

Figure 4. Distribution of elements along the scanning line 
Table 3. Chemical composition of dispersed inclusions, wt.\%

\begin{tabular}{|c|c|c|c|c|c|c|c|c||}
\hline $\begin{array}{c}\text { Number of } \\
\text { mixture }\end{array}$ & $\mathrm{C}$ & $\mathrm{O}$ & $\mathrm{Al}$ & $\mathrm{Si}$ & $\mathrm{S}$ & $\mathrm{Ti}$ & $\mathrm{Fe}$ \\
\hline 3 & 14.74 & 35.72 & 4.61 & 15.14 & 1.18 & 0.30 & 26.81 \\
\hline 6 & 7.15 & 33.08 & 2.56 & 17.76 & 0.97 & 0.28 & 31.59 \\
\hline
\end{tabular}

Table 4. Results of investigation of wear resistance of deposited metal of specimens

\begin{tabular}{|c|c|c|c||}
\hline \multirow{2}{*}{\begin{tabular}{c} 
Number of mixture \\
\cline { 2 - 4 }
\end{tabular}} & Hefore test & After test & For roller, driving/driven \\
\hline $\begin{array}{c}\text { Without adding } \\
\text { of powders }\end{array}$ & 213.5 & 220 & $0.12170 / 0.08485$ \\
\hline 3 & 235.6 & 269 & $0.06929 / 0.05520$ \\
\hline 6 & 223 & 285 & $0.05345 / 0.02925$ \\
\hline
\end{tabular}

rite-pearlite grains have a disoriented directivity. Moreover, the deposited metal has a very fine structure: the deposited metal grain number is 10-12. This is explained by effect of magnetic induction and presence of non-melted particles of silicon dioxide and carbide, which are rather uniformly distributed in the deposited metal.

Identification of inclusions was made by using the energy-dispersed analyzer in scanning electron microscope Zeiss EVO50 (Figures 3 and 4). Detailed examination of structural constituents was made at depth of 2, 4 and $6 \mathrm{~mm}$ from the bead surface at areas of $5 \mathrm{~mm}$ width symmetrically to its axis. The nature of distribution of dispersed inclusions, as well as their number remained approximately similar in all the cases. Size of particles was decreased by an order. The coarsest particles had the linear sizes in the limits of $10 \mu \mathrm{m}$. The obtained data (Table 3 ) prove that the particles retained partially their chemical composition.

Investigations of wear resistance of the deposited metal were carried out in unit MI-1M by roller-roller scheme (time of wear was $2 \mathrm{~h}$, force of rollers pressing was $1 \mathrm{kN}$ ) (Table 4).

As is seen, the maximum loss of mass and minimum wear resistance were observed in a contact pair, deposited without adding of powders. The deposited metal had a minimum hardness, wear was occurred with plastic deformation and delamination of surface layers. Friction pair of specimens, deposited over the charge mixture with $\mathrm{SiC}$ particles, had the highest wear resistance.

Though the hardness of specimens of this type before and after tests was higher than that of non-hardened specimens, their wear occurred without noticeable plastic hardening. The best result was in specimens deposited over charge with aerosil particles. They were hardened to a larger degree in the wear process and had the highest hardness after tests.

\section{Conclusions}

1. The scheme of arc surfacing over the layer of alloying charge is offered with superposition of magnetic field on arc, allowing great (by 1.8-2.2 times) increase of wear resistance of deposited metal in use of non-alloyed wire and widely applied fluxes, as well as powders of silicon dioxide and carbide.

2. Optimum parameters of alloying charge supply relative to arc center (magnetic induction of 20-50 mT, shifting of charge layers relative to arc axis is $4-6 \mathrm{~mm}$ ) are determined, at which the maximum reduction in losses of mass of specimens in wear (from 0.2065 to $0.0827 \mathrm{~g}$ ) and grain refining of deposited metal are attained.

3. Local analysis of dispersed inclusions confirmed that non-melted particles retained mainly their composition (up to $17.76 \% \mathrm{Si}$, up to $14.74 \% \mathrm{C}$, up to $37.72 \% \mathrm{O}_{2}$ ) at significant (by one order) decrease of linear sizes.

1. Ryabtsev, I.A., Senchenkov, I.K. (2013) Theory and practice of surfacing operations. Kiev: Ekotekhnologiya.

2. Chigarev, V.V., Malinov, V.L. (2000) Selection of sparcely-alloyed surfacing materials for different impactabrasive conditions. The Paton Welding J., 5, 55-57.

3. (2000) Repair and increase in wear resistance and service life of machine parts. Ed. by V.S. Popov. Zaporozhie: Motor Sich.

4. Lifshits, L.S., Grinberg, N.A., Kurkumelli, E.G. (1969) Principles of deposited metal alloying. Moscow: Mashinostroenie.

5. Frumin, I.I. (1961) Automatic electric arc surfacing. Kharkov: Metallurgizdat.

6. Razmyshlyaev, A.D., Mironova, M.V. (2009) Magnetic control of formation of beads and welds in arc surfacing and welding. Mariupol: Priazov. STU.

7. Ryzhov, R.M., Kuznetsov, V.D. (2010) Magnetic control of welded joint quality. Kiev: Ekotekhnologiya.

8. Peremitko, V.V. (2013) Development and investigation of repair surfacing technology of undercarriage rollers of caterpillar machines. In: Proc. of 15th Int. Sci.-Pract. Conf. on Technology of Strengthening, Coating Deposition and Repair. Theory and Practice, Pt 1, 168-172. St.-Petersburg: SPU. 


\section{International Conference «Welding Consumables»}

On June 16-18, 2014 in Kiev, the 8th International Scientific and Technical Conference «Welding Consumables» took place at the E.O. Paton Electric Welding Institute (PWI). It was organized by PWI, International Associations «Electrode» and «Welding», as well as Society of Welders of Ukraine (SWU) and Russian Scientific and Technical Welding Society (RSTWS). By the beginning of the Conference the Proceedings were published in the form of a special issue of the journal «Avtomaticheskaya Svarka» («The Paton Welding Journal»), Nos. $6-7,2014$, where the materials of 40 papers related to four subject sections were published:

- arc welding processes: metallurgy, markets (9 papers);

- consumables for mechanized welding processes (19 papers);

- consumables for manual arc welding (7 papers);

- technologies, equipment and control in the consumables manufacturing (5 papers).

The Conference was attended by scientists and engineering and technical specialists of research institutes, higher education institutions, industrial and commercial enterprises, representatives of associations from a number of the cities of Ukraine (Kiev, Zaporozhie, Nikolaev, Kharkov, Mariupol, Sumy, Vinnitsa, Kramatorsk), and also from Russia (Moscow), Poland (Gliwice), Germany (Altlayningen). In total, there were over 80 participants.

The list of organizations and companies whose experts attended the conference included: PWI, PlazmaTek, TM.Veltek, Frunze-elektrod, SWU, RSTWS, Admiral Makarov National Shipbuilding University, NTU «Kharkov Polytechnic Institute», NTUU «Kiev Polytechnic Institute», Priazovsky State Technical University, Ekotekhnologiya, DrahtZug Stein (Germany), Zaporozhstekloflyus, Welding Institute in Gliwice (Poland), Energomashspetsstal.

The Conference was opened by a welcoming speech of Prof. K.A. Yushchenko, PWI Deputy Director. He expressed greetings to participants of the Conference on behalf of Academician Boris E. Paton, who wished the successful and fruitful conference. K.A. Yushchenko outlined the importance and relevance of the Conference topics, the necessity to organize regular meetings of scientists and experts in a number of subject directions to increase the efficiency in the welding production progress.

In total, 32 papers were presented at a plenary session within two days.
The present information was not aimed at publicizing the content of speeches in detail as it is possible to find out more about materials of $\mathrm{pa}^{-}$ pers in Nos. 6-7 of the «Avtomaticheskaya Svarka» journal («The Paton Welding Journal»). As a whole, the presentations reflected a modern range of research areas, which are carried out in the field of metallurgy and technology of arc processes of welding, surfacing and coating, an assessment of the market of Ukraine and the world market of welding consumables, development and application of welding consumables (electrodes, flux-cored and metal wires, fluxes, discrete fillers and powders) in the mechanized processes and manual arc welding, surfacing and thermal coating deposition.

The papers of Prof. O.I. Steklov (the President of RSTWS) «Assurance of integrity of welded structures and constructions at their longterm service by using the renovative technologies», Prof. V.V. Dmitrik (Head of Welding Chair of Kharkov PI) «Features of degradation of welded joint metal in steam pipelines of $H P P$ », Dr. A.A. Mazur (Head the PWI Department) «The market of welding consumables in Ukraine and world market», Prof. Y. Nagaj (Welding Institute in Gliwice) «The role of tests and certification in development of welding consumables market in Poland and the EU countries», R. Rosert (leading specialist of DrahtZug Stein, Germany), «Application of flux-cored wires for welding under industrial conditions», and also papers of A.E. Marchenko, V.N. Shlepakov, V.V. Golovko et al. (the PWI scientists) were of a particular interest.

Great impression on the participants of the Conference was made by a videofilm, presented by V.P. Slobodyanyuk (General Director of PlazmaTek) on subject «Alternative raw materials for production of welding consumables at the present stage». He demonstrated the new integrated approaches in the development of production of covered electrodes and copper-plated wires in Ukraine, which allowed obtaining the challenging results, as every second electrode in Ukraine and the third electrode in Belarus today is produced by PlazmaTek.

During the Conference numerous bilateral talks aimed at cooperation and strengthening of cooperation with interested partners were held and continued during the final evening voyage in the Dnieper river.

A.T. Zelnichenko, B.N. Lipodaev, PWI 